\title{
Impacts of COVID on University's Finances
}

\section{A Vector Autoregressive Analysis in Quebec, Canada}

\author{
Pier-André Bouchard St-Amant ${ }^{1}$, Yanick Wilfred Tadjiogue ${ }^{1}$, Lucie Raymond-Brousseau ${ }^{1}$, Camille \\ Fortier-Martineau ${ }^{1}$, Franck-Aurelien Tchokouagueu ${ }^{1} \&$ Guillaume Dumais $^{1} \&$ Laurence Vallée $^{1}$ \\ ${ }^{1}$ École nationale d'administration publique, Canada \\ Correspondence: Pier-André Bouchard St-Amant, École nationale d'administration publique, Canada.
}

Received: October 5, 2020

Accepted: November 5, 2020

Online Published: November 10, 2020

doi:10.5430/irhe.v5n3p37

URL: https://doi.org/10.5430/irhe.v5n3p37

\begin{abstract}
Did universities benefit from the pandemic? Some did receive more funding than usual. We use vector autoregressive models to forecast both enrollment and public subsidies in a jurisdiction where public funding depends mostly on enrollment. Using unemployment as an established proxy for the impact of recessions on enrollment, we show that the recent COVID pandemic increases pressure on public subsidies. Further, we use our forecasts to decompose the current subsidies between long-term subsidies, recession induced subsidies, and additional funding. We find that the subsidies given during the pandemic were higher than what a typical recession would command for 8 universities out of 18 .
\end{abstract}

Keywords: universities, enrollment, subsidies, forecasts, recession, pandemic

\section{Introduction}

The COVID-19 pandemic has had its toll on universities. They had to massively migrate classes online and adapt their practice to a new reality triggered by social distancing (Dennen, 2020). In parallel, the pandemic also brought about important changes in student enrollment. On the one hand, the pandemic caused massive changes in unemployment, leading several persons to consider higher education studies in the interim. On the other hand, students seeking a campus experience or preferring in-class curriculums deferred their studies to get an education closer to their expectations. These two effects, amongst many others, determine implicitly the final student demand in the context of a pandemic.

Enrollment can bear significant importance to determine university finances. Most jurisdictions that use an input-based funding formula rely on a measure of enrollment to transfer public funds to universities (Frølich, 2010). As such, changes in enrollment can have cumulative effects beyond tuition.

This paper uses empirical techniques to explore how university enrollment and revenues evolve with the forecasting horizon. Comparing a period of one to four years (henceforth mid-term) with a period of twenty years (henceforth long-term) allows us to assess the impact of mid-term factors on enrollment and finance. Aside from the range in years, the difference between forecasts relies on the use of unemployment and other variables as a proxy of mid-term effects on demand. Thus, by comparing the difference between these forecasted values for the next year (henceforth the short-term), one can infer the impact of unemployment on both funding and enrollment. Further, by comparing realized values for the current year, we can further refine the decomposition of effects and find the impact of other factors. In the case of public appropriations, we can deduce the likely change in funding induced by the current pandemic (compared to what would have been otherwise allocated).

Globally, we find that unemployment has a significant mid-term effect on enrollment on most universities, including aggregate systems of universities. By extension, when a funding formula is tied to enrollment, this surge in enrollment implies additional pressure for public appropriations. We also find significant differences between forecasted and realized appropriations in the short-term for several universities. Finally, we also find a great heterogeneity in the magnitude of responses: some universities show a far greater response to changes in the underlying explanatory variables than others. In particular, unemployment has more impact on larger universities. Combined, these three results provide novel insights on the behaviour of university systems in times of a pandemic, or any other disruptive economic event that translates into high unemployment. These results are detailed in more depth in the body of the 
article and can be helpful for both funding planners and university managers alike.

Aside from behavioural insights, this article also develops a robust forecasting methodology based on historical trends in both funding and enrollment. It uses Vector autoregressive models (henceforth VARs) to simultaneously estimate the evolution of enrollment and public appropriations for mid-term forecasts. To our knowledge, this has never been done before. For long-term forecasts, the paper employs instrumental variable regressions (henceforth IV). Both techniques carry a similar statistical advantage. That is, it accounts for the potential endogeneity (interdependence) between public appropriations and enrollment. In jurisdictions where public funding is driven by enrollment, this is quite important: an unanticipated positive shock on enrollment should translate into an increase in public funding. In statistical terms, this means that the estimation error for public subsidies is dependent on the estimation error of enrollment. Using a statistical technique that accounts for such interdependence is useful both for a pure forecasting perspective, and to guarantee an absence of bias in the estimated relationship between enrollment and funding. By using these techniques, we thus present an approach reflecting the typical impact of the true relationship, in the sense of unbiased, between enrollment and funding. These approaches can be useful for practitioners having to forecast both their subsidies and their enrollment patterns.

Because of its availability and of our existing knowledge of the funding formula, we chose the province of Quebec, Canada as the underlying jurisdiction for our analysis (Ministère de l'Éducation et de l'Enseignement supérieur, 2020). The province has 18 independent degree granting universities, all having public funds as their main stream of revenues (see Table 1). Six universities have more than 20000 full-time equivalent students (henceforth FTEs) in a wide variety of programs and tiers; two universities are engineering schools; six universities are regional flagships; two universities are small graduate schools with less than 800 FTEs; one is an online university; and one is a business school. Ten of those universities are members of the Quebec University system, which was one large public university at its inception in the 60's, in the spirit of many public university systems existing in other jurisdictions (CUNY, UC, UT, etc).

Table 1. Synthetic representation of the Québec university system

\begin{tabular}{|c|c|c|}
\hline & Québec University System & Independent universities \\
\hline $\begin{array}{l}\text { Universities with } \\
\text { more than } 20,000 \\
\text { FTEs and a wide } \\
\text { variety } \\
\text { programs. }\end{array}$ & Université du Québec à Montréal (UQAM) & $\begin{array}{l}\quad \text { Concordia University* } \\
\text { McGill University* } \\
\text { Université Laval } \\
\text { Université de Montréal } \\
\text { Université de Sherbrooke }\end{array}$ \\
\hline $\begin{array}{l}\text { Engineering } \\
\text { schools }\end{array}$ & École des technologies supérieures (ETS) + & École polytechnique de Montréal. \\
\hline $\begin{array}{l}\text { Regional } \\
\text { universities }\end{array}$ & $\begin{array}{l}\text { Université du Québec en Abitibi-Témiscamingue } \\
\quad \text { (UQAT) } \\
\text { Université du Québec en Outaouais (UQO) } \\
\text { Université du Québec à Rimouski (UQAR) } \\
\text { Université du Québec à Trois-Rivières (UQTR) } \\
\text { Université du Québec à Chicoutimi (UQAC) }\end{array}$ & Bishop's University $*+$ \\
\hline $\begin{array}{l}\text { Small vocational } \\
\text { graduate schools }\end{array}$ & $\begin{array}{l}\text { École nationale d'administration publique (ENAP) } \\
\text { Institut national de recherche scientifique (INRS) }\end{array}$ & \\
\hline Other & Télé-université du Québec (TÉLUQ) + & Hautes études commerciales (HEC) \\
\hline
\end{tabular}

Legend: Predominantly English Speaking Universities are marked with an asterisk (*) and undergraduate only universities are marked with a plus (+). Universities without an asterisk are predominantly french speaking and universities without a plus sign award graduate degrees. Source: Author's classification and Ministère de l’Enseignement supérieur (Éditeur officiel du Québec, 2020). 


\section{Literature Review}

To our knowledge, there exist no research papers forecasting higher education institution's subsidies, nor papers combining forecasts on enrollment and finances, through the use of time series techniques. Below, we rely on two strands of the literature to situate the scope of our work. First, we look at papers forecasting enrollment through univariate time series methods. Second, we consider papers investigating the relationship between enrollment and unemployment, or recessions. We thus share an estimation paradigm with the first strand and the second strand explores how economic conditions may affect enrollment patterns. Although not within the scope of this review, it should be known that the use of the time series estimation paradigm for other types of financial forecasts is well established. One can look at Andersen, David, KreiB and Mikosch (2009) for a handbook on the matter.

A time series estimation paradigm is focused on predicting future values of one or multiple variables on the basis of its time trends and a few other variables (Hamilton, 1994). Conversely, it is not a paradigm seeking for multiple variables or causes. Although far from representing the complete model ecosystem, two workhorse models have a long tradition: the univariate autoregressive, integrated moving average framework (ARIMA) and the vector-autoregressive framework (VAR) (Box, Jenkins, Reinsel \& Ljung, 2015). The ARIMA model and its variants focus on forecasting a single variable, while VARs seek to forecast more than one variable, and their chronologic interdependence, at the same time. Forecasting techniques applied to enrollment with pre-existing approaches to the time-series paradigm are also discussed in Guérin (1972), Shaw (1984), and Kwak, Brown and Schiederjans (1986).

To our knowledge, Marshall and Oliver (1979) are the first to study enrollment patterns through the use of autoregressive (AR) models. Their study decomposes enrollment at a given time by the semester of enrollment, each cohort being modeled as an AR process. They then forecast total enrollment in a given year as the sum of each forecast. Chen, Li and Hagerdorn (2019) also use seasonal ARIMA models to study enrollment patterns of international students in the midwest, American university. They characterize enrollment patterns through seasonal changes, and institutional variables such as the stringency to obtain American student visas and unemployment. Their final model shows that past enrollment predicts enrollment, as well as persistence in deviations of real values from the forecast. They also find a positive relationship between enrollment and unemployment. Chen (2008) and O'Bryant (1991) have also performed a similar analysis on different institutions. Qin, Shanks, Phillips and Bernard (2019) study how the structure of ARIMA models best fit real patterns and simulated ones. Through simulations, they find that a time-series model estimated on 20 observations outperforms models estimated on larger samples. They then find similar results on true patterns of enrollment. Their findings seem to be much related to the concept of overfitting (Hawkins, 2004). Closer to our work, Boes and Pflaumer (2006) use an ARIMA framework to predict student enrollment in Germany for a variety of universities, each with its own model. They underline the use of time-series models most notably to include margins of errors on forecasts, which is said to be missing from official German predictions (id).

Simultaneous forecasts through VARs are employed by Ewing, Beckert and Ewing (2010). They simultaneously predict enrollment patterns, economic growth and inflation. The authors find some interdependence between enrollment and economic patterns that has a Keynesian flavour. For instance, a surge in inflation leads to an increase in enrollment, and an economic downturn is also shown to increase enrollment patterns. The theoretical foundations for a countercyclical connection between enrollment and economic activity is however a feat of classic economic theories as well and has a well-established foundation (e.g. Dellas \& Koubi, 2003; Dellas \& Sakellaris, 2003). The idea is rooted in the opportunity cost of time. When unemployment is high, the opportunity cost of going to school is much lower by the absence of a paying alternative (e.g. a job). The converse is true during booms. Such relationship between recessions on enrollment patterns has been fairly well documented through both historical accounts (Barr \& Turner, 2013) and empirical approaches (Witteveen, 2020; Smith, 2017). As argued in Allessandrini (2014), this can change the perspective on recessions, as they do allow for an accumulation of graduates that will turn productive once graduated. Following that logic, Sievertsen (2016) shows with individual level data that the unemployment rate increases graduation rates significantly and he further shows that part of this surge in enrollment comes from individuals who would not have enrolled otherwise. This effect is also shown to vary by ethnicity and social background (Smythe, 2019)

Based on this review, our contribution to the literature is twofold. First, we use a VAR framework to jointly estimate the mid-term forecasts on enrollment and public subsidies in a jurisdiction where public appropriations are tied to enrollment. We also use long-term estimates to perform a similar analysis. Second, we use the difference between long-term and mid-term forecasts to infer the impact of a pandemic on university's public subsidies. These additional findings help understanding how universities, individually or as a system, may be financially impacted by recessions. In parts based on the comparison between realized values and mid-term forecasts for the year 2021, our findings 
suggest that several universities received more subsidies than what the effect of the recession ought to suggest.

\section{Methodology}

The main challenge of estimating funding and enrollment patterns is one of simultaneous endogeneity. On the one hand, an unanticipated increase in enrollment may trigger an unanticipated increase in funding. As we shall see in the next section, the structure of the funding formula makes this pretty explicit. On the other hand, an unanticipated increase in funding may also translate into an unanticipated increase in enrollment. Accrued funding may push universities to increase their recruitment efforts, thereby increasing enrollment. As such, the separated estimation of funding and enrollment would neglect the interconnection.

This section thus presents how we have accounted for this endogeneity problem. First, we introduce the provincial funding formula, describing how it operates. We also display the constitution of our dataset. We then present the methodology of our mid-term forecasts using VARs. We finally present how IV regressions account for the endogeneity for long-run forecasts.

\subsection{The Quebec Funding Formula}

The set of rules and conditions through which public appropriations are transferred to universities is dubbed a funding formula (see Frølich, 2010 for a classification). The Quebec formula is input-based, where appropriations are tied to weighted and unweighted enrollment and mostly fixed transfers (Maroy, Doray \& Kabore, 2014; Bouchard St-Amant, Brabant \& Germain, 2020). Roughly $85 \%$ of appropriations is tied to enrollment and $14 \%$ of the formula is, or can be approximated as, fixed transfers.

The Quebec formula is made up of five conceptual channels through which funds are evaluated for the purpose of transfer to universities: teaching activities, auxiliary services, buildings, administration and missions, and miscellaneous programs (see Table 2). Each category relies on an underlying metric to proxy for expenses. Teaching activities are measured by weighting FTEs. Each weight changes with funding families that varies with tiers and programs (see Bouchard St-Amant, Brabant \& Germain, 2020, for details). Auxiliary services reflect expenses tied to campus usage and are proxied through unweighted FTEs. Combined, these two components account for more than $85 \%$ of the total funding. The buildings component reflects expenses tied to maintaining the physical infrastructure of the university. Such a category accounts for $10 \%$ of the funding and is tied to both the superficy of the university and the price of energy. The next category, although containing different channels in principle, rely on fixed transfers. Administration services are a fixed amount, identical for each university. The funding tied to specific missions, also in the form of fixed transfer, however, varies and aims to recognize important differences in universities: geographical coverage, specialized faculties, or small graduate schools. Combined, fixed transfers amount to $3.4 \%$ of the total appropriations. The remainder of the funding formula, tied to conditions, varies with governments and with the public policy goals of the day.

Table 2. Main components of the funding formula

\begin{tabular}{|c|c|c|c|c|}
\hline Category & Metric(s) & Funding (\%) & Funding (M\$) & Notation \\
\hline $\begin{array}{l}\text { Teaching } \\
\text { activities }\end{array}$ & Weighted FTEs & 70.04 & 2184 & $\begin{array}{r}F T E_{i j t} \\
w_{j}, p_{1}\end{array}$ \\
\hline $\begin{array}{l}\text { Auxiliary } \\
\text { services }\end{array}$ & FTEs & 15.29 & 477 & $\begin{array}{l}F T E_{i j t} \\
p_{2}\end{array}$ \\
\hline $\begin{array}{l}\text { Buildings and } \\
\text { Offices }\end{array}$ & $\begin{array}{l}\text { Squared meter, } \\
\text { price of energy. }\end{array}$ & 10.44 & 336 & $T_{i}$ \\
\hline $\begin{array}{l}\text { Administration } \\
\text { and mission }\end{array}$ & Constant & 3.43 & 107 & $T_{i}$ \\
\hline Other & Conditional & 0.45 & 14 & $\epsilon_{i t}$ \\
\hline
\end{tabular}

Source: author’s calculations and Ministère de l'Enseignement supérieur du Québec (2021). 
Three additional characteristics of the enrollment-based formula are important. First, the FTE metric determining funding is lagged: the funding for teaching activities in year $t$ depends at the latest on enrollment in $t$-2. Second, funding is smoothed. It is tied to the highest of either the FTEs in $t-2$ or the moving average of FTEs over years $t-2, t-3$ and $t-4$. Such a smoothing mechanism dampens the effect of sharp declines in enrollment. Third, the highest value of enrollment is multiplied by a baseline price that converts the FTE figure in a dollar amount. There are other transitionary smoothing mechanisms that are tied to some changes made to the funding weights in the year 2017. Those are explained in detail in (Bouchard St-Amant, Brabant \& Germain, 2020).

In what follows, we approximate the buildings category as a fixed component. We do so because the funding category is tied to infrastructures that do not change much from one year to another, echoing the idea that capital is fixed in the short run (Frank, Bernanke, Antonovics \& Heffetz, 2019). We thus denote $\mathrm{T}_{\mathrm{i}}$ the resulting sum of the three fixed transfers to university i. By further denoting $F T E_{i j t}$ enrollment at time $t$, university $\mathrm{i}$ and in funding family $\mathrm{j}, \mathrm{w}_{\mathrm{j}}$ the funding weights for each of the funding families and $\epsilon_{i t}$ the remaining funding for university $i$ at time $t$, then the total funding at time $\mathrm{t}\left(F_{i t}\right)$ can be expressed by:

$$
\begin{array}{r}
F_{i t}=T_{i}+p_{2} \max \left(\sum_{j} w_{j} F T E_{i j t-2}, \frac{1}{3}\left(\sum_{j} w_{j} F T E_{i j t-2}+\sum_{j} w_{j} F T E_{i j t-3}+\sum_{j} w_{j} F T E_{i j t-4}\right)\right)+\cdots \\
\ldots+\mathrm{p}_{1} \max \left(\sum_{\mathrm{j}} \mathrm{FTE}_{\mathrm{ijt}-2}, \frac{1}{3}\left(\sum_{\mathrm{j}} \mathrm{FTE}_{\mathrm{ijt}-2}+\sum_{\mathrm{j}} \mathrm{FTE}_{\mathrm{ijt}-3}+\sum_{\mathrm{j}} \mathrm{FTE}_{\mathrm{ijt}-4}\right)\right)+\epsilon_{\mathrm{it}}
\end{array}
$$

Equation (1) serves as a theoretical guide to develop a proper estimation model linking enrollment to funding.

\subsection{Dataset}

\subsubsection{Enrollment and Public Funding}

The dataset is a perfectly balanced panel of 18 universities over the years 1999 to 2021 (22 observations of funding and enrollment per university), for a total of 396 observations. The time range is implicitly tied to the year when enrollment-based funding was enacted in Quebec, which is year 2000 (Trahan and Carreau, 2010).

We have extracted the funding and FTEs data from the aggregated public financial statements (Ministère de l'Éducation et de l'Enseignement supérieur, 1999 to 2019) and the announced appropriations for the current year (Ministère de l'Enseignement supérieur, 2020). Because of the conditional component of the funding formula and slight changes in enrollment, the two sources differ slightly on both accounts. We kept the data from the financial statements when available and complemented with announced values for the year 2021.

These two sources are provided in portable document formats (PDFs). We developed a custom Python program to extract the data spanning over the period for each university, year and funding family, for a total of 7492 observations. This had to be complemented with human corrections. Most of the errors from the program were easily identifiable, as they related to changes in the page layout of the documents, or changes in the number of funding weights. Each author was then assigned a subset of universities to detect errors by comparing the original documents with the raw extracts. Two of the authors also re-examined the work produced by the other authors by performing the whole audit again. At this stage, the dataset has been aggregated by year, to generate its final shape and size. During the estimation, several preliminary graphics were produced, triggering automatic audits when suspicious breaks were found in enrollment patterns. The data was found to be $87 \%$ accurate after the first stage and $93 \%$ accurate at the second stage. The fact that no errors were found in the last stage, although some patterns did trigger audits, goes to suggest that the residual error in the dataset is fairly small.

\subsubsection{Unemployment}

Basic economic theory suggests that unemployment is a relevant proxy for the relative attractiveness of higher education. Individuals who recently lost their job may be tempted to pursue a degree in the aim of finding a new job, or simply acquire additional human capital in the interim (Dellas \& Koubi, 2003). Moreover, the exercise we conduct requires forecasts on unemployment. Because the unemployment rate is forecasted by banking institutions, it is also attractive on practical grounds: the plurality of available sources.

The realized unemployment rates were gathered from two different sources. The realized unemployment rates from 
1999 to 2021 were gathered from the national statistical agency (Statistics Canada, 2021). The forecasted unemployment rates stem from monthly outlooks of the main banks in Quebec (Desjardins, 2020; Arseneau \& Paquet, 2020; Caranci, Burleton, Sondhi \& Abdelrahman, 2020; Perrault, 2020). Two banks provide outlooks for the next four years (2021-2024), while two other banks only forecast for one year ahead (see table 3). We use the average value of those forecasts as our unemployment inputs for our mid-term models. The global outlook of unemployment in Quebec, including the forecasts, can be found in Figure 1.

Table 3. Québec Forecasting Model (Mid-Term)

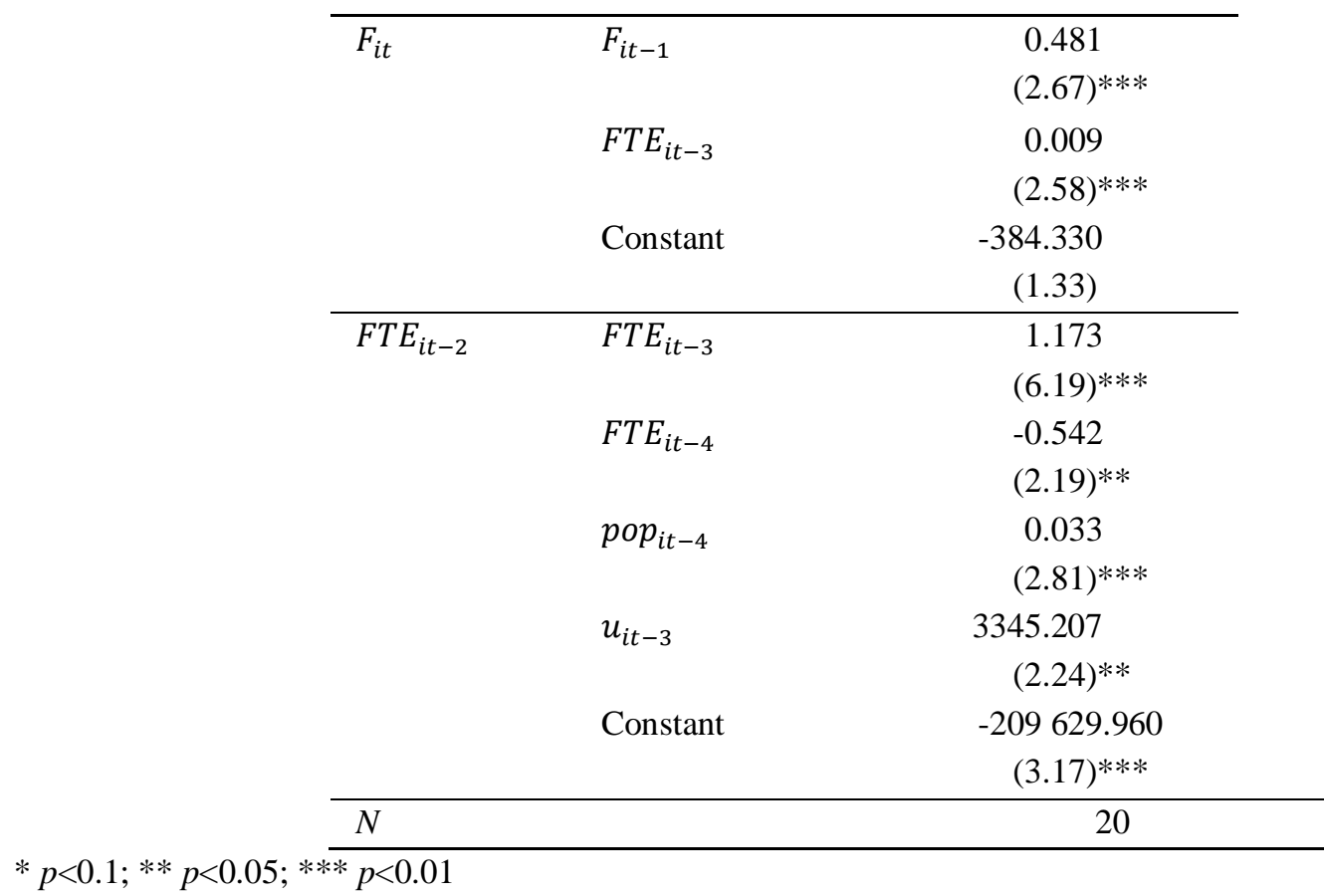

Source: Authors' classification and Québec Department of Higher Education.

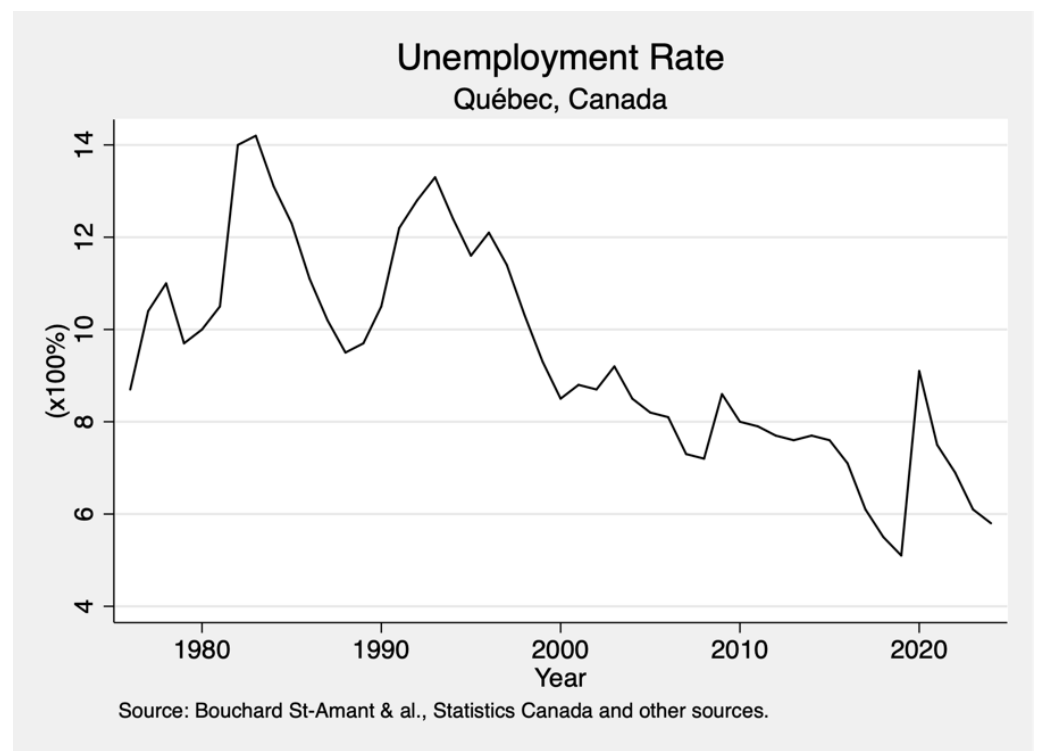

Figure 1. Quebec unemployment rate 


\subsubsection{Demography}

Long-term trends in enrollment are best represented by demographic patterns. They have the advantage of being reliably forecasted over long periods, allowing us to support our forecasting analysis. As such, we used the yearly total population size, the yearly 18 to 25 years old population size, as well as the number of yearly immigrants in Quebec. Each of these components capture segments of the population that may reflect a fundamental basin for enrollment.

Our demographic data comes from both the national and the provincial statistical agencies. In a similar fashion to unemployment, existing demographic values were extracted from Statistics Canada (2020). This source is combined with forecasted demographic trends over the next 20 years, providing us with support for our long-term forecasts (Institut de la statistique du Québec, 2019). The resulting population trends are presented in Figures 2-a to 2-c.

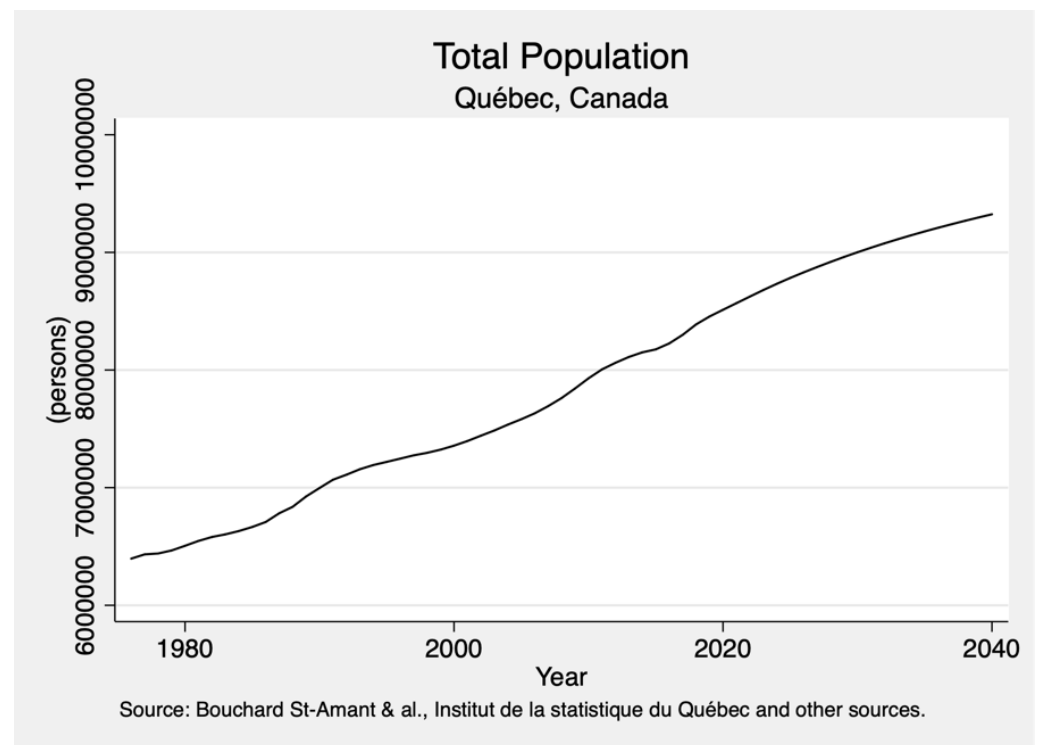

Figure 2a. Total population trend and projection

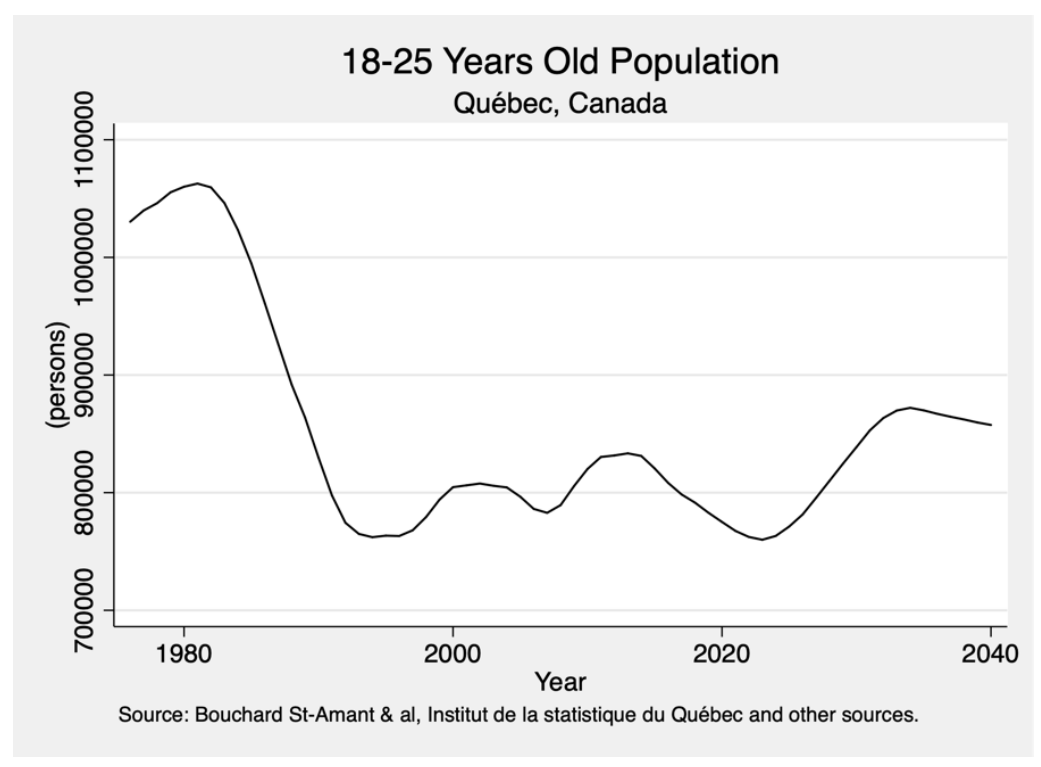

Figure 2b. 18-25 years old population trend and projection 


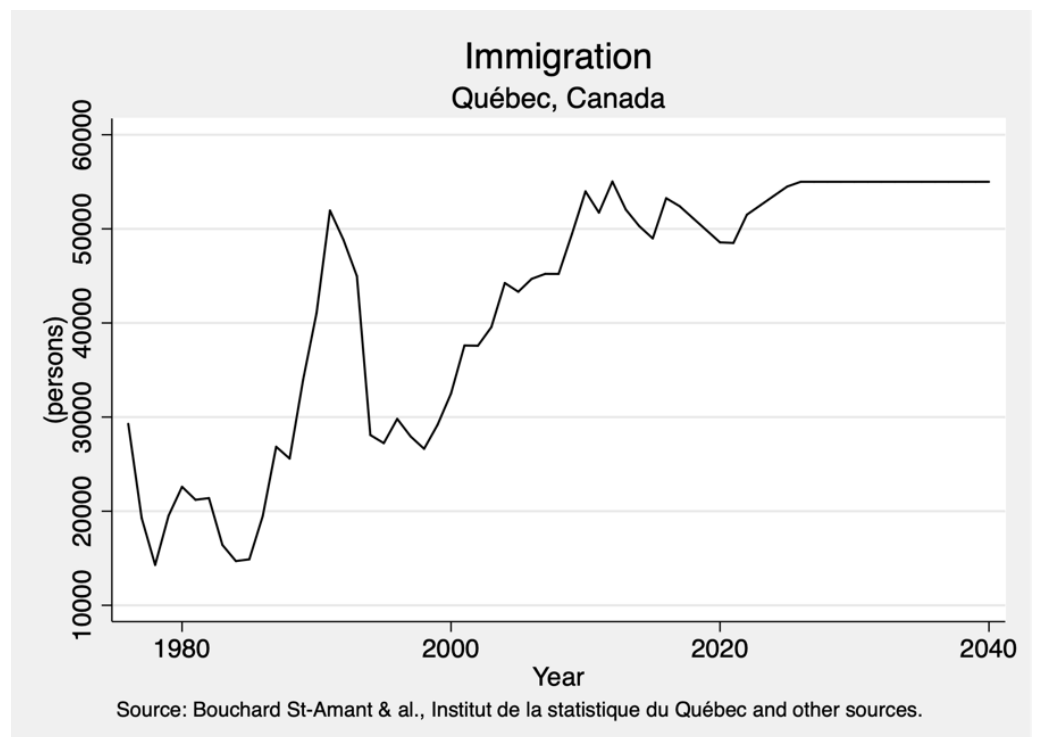

Figure 2c. Immigration trend and forecast

\subsection{Vector Autoregressive Models}

Following the notation used to develop equation (1), denote $F T E_{i t}$ (without the index $j$ ) the total unweighted enrollment in university $i$ at time t. We then show in Appendix B that a linear approximation of equation (1) around the values of $F T E_{i t-2}, F T E_{i t-3}$ and $F T E_{i t-4}$, yields the following reduced form:

$$
F_{i t}=\beta_{0}+\beta_{1} F T E_{i t-2}+\beta_{2} F T E_{i t-3}+\beta_{3} F T E_{i t-4} E_{i t-4}+\beta_{4} F_{i t-1}+\beta_{5} F_{i t-2}+\varepsilon_{i t},
$$

where the coefficients $\beta_{1}$ to $\beta_{3}$ capture the average effect of total enrollment at a given lag in time, $\beta_{0}$ denotes fixed transfers, and $\varepsilon_{i t}$ denotes the global estimation error induced by both the linear approximation and the conditional funding rules in the original formula. If it were not of lagged values in the funding variables, the error term $\varepsilon_{i t}$ would be correlated with past funding values, as a consequence of our linear approximation. The smoothing mechanism described in (1) is indeed aimed at mitigating changes in funding over time (and eliminated by linearization). And so, when statistically relevant, lagged trends on the funding variable are added as explanatory variables.

The estimation of enrollment is a straightforward connection between demographic patterns and short-term deviations proxied by unemployment. Denoting $\operatorname{pop}_{t}, \operatorname{pop}_{18_{t}}, i m_{t}$ and $u_{t}$ for respectively the general population count, the 18 to 25 years old population count, the immigration count and the unemployment rate, our generic reduced form is given by:

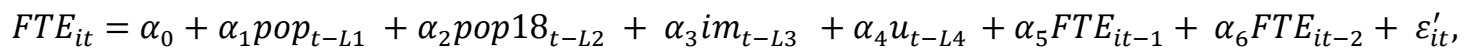

where the lag selection $(L 1 \ldots L 4)$ over variables is chosen so as to maximize the explanatory power of each variable. For population variables, the number of lags means that the current population, older by the specified number of lags, better captures the enrollment trends. The lags on unemployment, however, is an indication of the speed at which individuals adapt their behaviour on the labour market. For instance, an absence of lag would mean that the current unemployment drives the current enrollment, while one lag would mean that it takes (roughly) one year for individuals to move out of the labour market and in a university.

In a similar fashion to funding, we add a lagged variable on enrolment itself when justified by a rejection of the null hypothesis on the associated coefficient. The interpretation is rooted in the fact that it takes more than a year to complete most degrees. Accordingly, past enrollment can help predict current enrollment.

Equations (2) and (3) form a typical restricted VAR, an estimation technique that accounts for the interdependence in error terms. We first perform the statistical analysis with an unrestricted estimation, and then reduce the model only to variables where the null hypothesis is rejected on the associated coefficient. By doing so, we reduce the forecast 
margins by removing noisy variables with a weak explanatory power. We then use the resulting model to perform forecasts over the next four years, with bootstrapped margins of errors over 400 replications (Davison \& Hinkley, 1997).

\subsection{Instrumental Variables}

The estimation framework for long-term forecasts is much simpler. The unemployment variable is dropped, and there is no multiplicity in time-lags. We thus focus on the core relationship that exists between enrollment and funding:

$$
\begin{aligned}
& F_{i t}=\beta_{0}+\beta_{1} F T E_{i t-L}^{\max }+\varepsilon_{i t}, \\
& F T E_{i t-L}^{\max }=\alpha_{0}+\alpha_{1} \text { pop }_{t-L 1}+\alpha_{2} \text { pop } 18_{t-L 2}+\alpha_{3} i m_{t-L 3}+\varepsilon_{i t}^{\prime},
\end{aligned}
$$

where the lags $L, L 1, \ldots L 3$ are chosen empirically to best reproduce the long-term patterns and $F T E_{i t-L}^{\max }$ is a variable derived from the core component of the funding formula (1):

$$
F T E_{i t-L}^{\max } \equiv \max \left(\sum_{j} F T E_{i j t-2}, \frac{1}{3}\left(\sum_{j} F T E_{i j t-2}+\sum_{j} F T E_{i j t-3}+\sum_{j} F T E_{i j t-4}\right)\right) .
$$

Because none of the long-term drivers of enrollment can be reasonably explained by unexpected changes in the funding to universities, the endogeneity matters only when shocks in enrollment occur (and affect funding). Accordingly, a two-stage least square IV regression is used to estimate (4) from (5) (Greene, 2018). Similar in spirit to our VAR methodology, variables with a coefficient that fail to reject the null hypothesis are removed to reduce forecasting margins of error.

\section{Results}

We first present our forecast for the system as a whole. By the simple virtue of aggregation, random errors occurring at the university level are greatly reduced, therefore providing more accurate forecasts. We then present three additional forecasts for selected universities. Finally, we come back to the system analysis to evaluate differences between the short and the long run. Appendix A also presents summary results for the 14 other universities.

\subsection{Provincial Forecasts}

\subsubsection{Mid-term}

We present the mid-term forecasting model in Table 3 and the graphical presentation of the forecast in Figure 3. In both cases, panel $a$ presents the forecast on the public subsidy (in millions) while panel $b$ presents the evolution of full-time equivalent enrollment (in thousands). Table 4, panel a, reveals that the best predicting equation for the current period's funding includes $48 \%$ of past year's funding and 9,000\$ per FTEs (lagged by three years). Other variables have coefficients that are statistically indiscernible from zero. Panel $b$ shows coefficients of 1.17 for FTEs with a two-year lag and of -0.54 of enrollment for FTEs with a three-year lag. This reduction reflects the combination of graduation rates and drop-outs, and suggests a one-year surge in enrollment, followed by a reduction in enrollment two years later. The population coefficient suggests that roughly three percent of the population enters the university system yearly, although the pattern between enrollment and the population count is lagged by two years. Finally, unemployment has a positive effect with roughly 3,300 additional FTEs for a 100 basis points increase in unemployment.

The graphical representation of forecasts suggests a slight decrease in funding, assuming of course no significant changes to the funding formula. This decrease in funding is induced by decreases in enrollment, partly induced by the post-recession unemployment rate returning to normal values in the upcoming years. This forecasted decline in funding however has a margin of error large enough to allow for increases. Because enrollment patterns are forecasted to increase beyond year 2023, the funding is forecasted to increase again in 2025. 
Table 3. Québec forecasting model (Mid-term)

\begin{tabular}{llc}
\hline$F_{i t}$ & $F_{i t-1}$ & 0.481 \\
& & $(2.67)^{* * *}$ \\
& $F T E_{i t-3}$ & 0.009 \\
& & $(2.58)^{* * *}$ \\
& Constant & -384.330 \\
& & $(1.33)$ \\
\hline$F T E_{i t-2}$ & $F T E_{i t-3}$ & 1.173 \\
& & $(6.19)^{* * *}$ \\
& $F T E_{i t-4}$ & -0.542 \\
& & $(2.19)^{* *}$ \\
& & 0.033 \\
& & $(2.81)^{* * *}$ \\
& & 3345.207 \\
& & $(2.24)^{* *}$ \\
& & -209629.960 \\
& & $(3.17)^{* * *}$ \\
\hline$N p<0.1 ; * * p<0.05 ; * * * p<0.01$ & & 20 \\
\hline
\end{tabular}

Source: Authors' calculations and Québec Department of Higher Education.

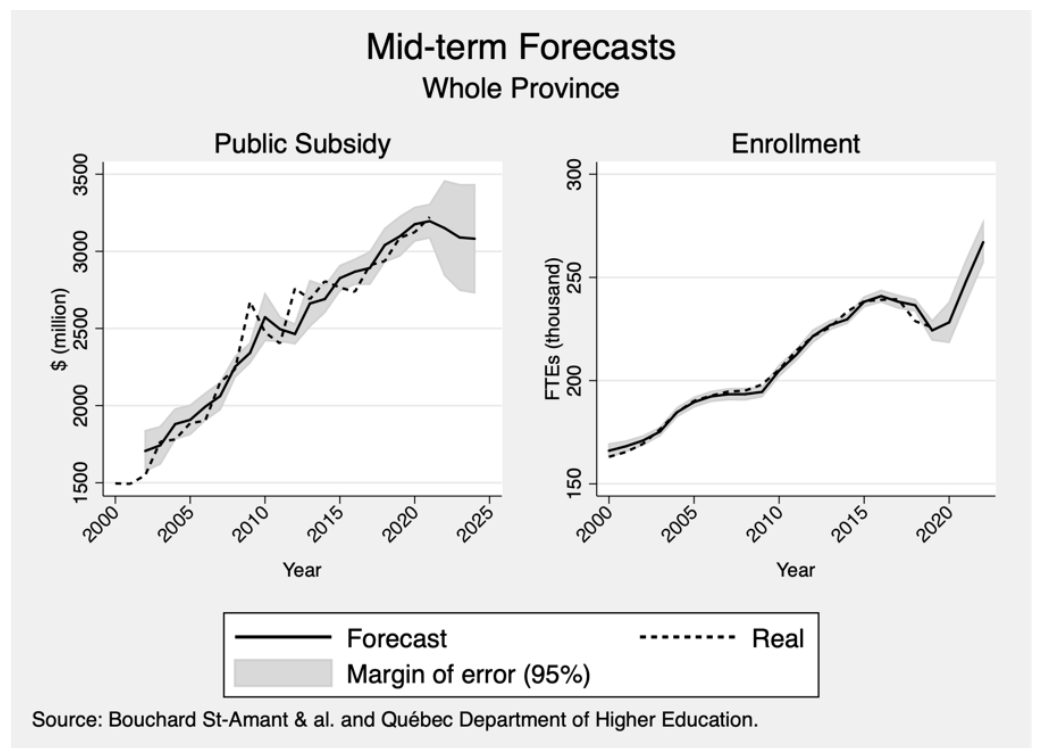

Figure 3. Québec Forecast (Mid-term) 


\subsubsection{Long-term}

Long-term provincial forecasts are presented in Table 4 and Figure 4. Because mid-term dynamics are not modeled, deviations from the forecasts are more frequent (and thus margins of error larger). In particular, mid-term forecasts for funding predict a milder decline than what long-term forecasts present because changes in enrollment patterns do not account for unemployment, nor the autocorrelation with past funding. However, forecasts go as far as 2040 and suggest a steady increase both in terms of funding and enrollment.

Table 4. Québec Forecasting Model (Long-Term)

\begin{tabular}{cc}
\cline { 2 - 2 } & $F_{i t}$ \\
\cline { 2 - 2 } Constant & 19.091 \\
& $(18.60)^{* * *}$ \\
& -1603.150 \\
& $(7.94)^{* * *}$ \\
\hline$R^{2}$ & 0.92 \\
$N$ & 22 \\
\hline
\end{tabular}

$* p<0.1 ; * * p<0.05 ; * * * p<0.01$

Source: Authors' calculations and Québec Department of Higher Education.

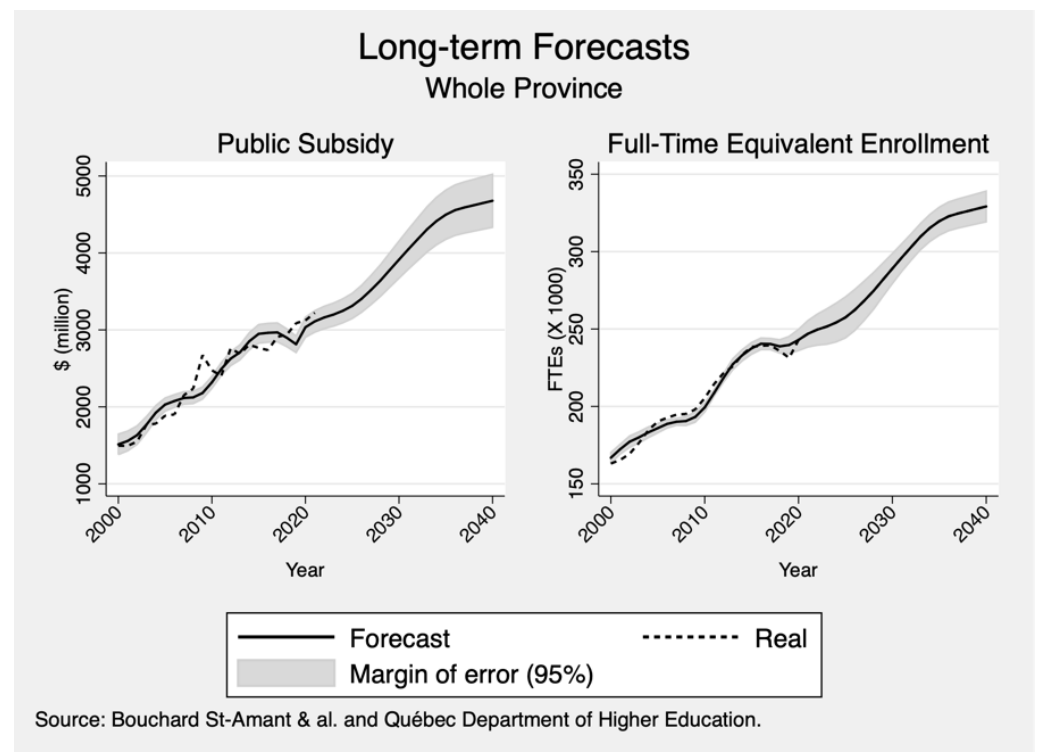

Figures 4. Québec Forecast (Long-term)

\subsection{Three Selected Universities}

Not all universities are similar in terms of mid-term trends. Some seem unaffected by shocks to unemployment, while others seem to rely more on past enrollment values than provincial demographics. Globally, 8 universities respond to unemployment, as well as the Université du Québec system as a whole, and the whole provincial system as well. In broad terms, large universities respond to unemployment as well as a few regional universities. To outline these differences, we present the mid-term forecasts for three separate universities: one large university (Université de Sherbrooke), one small regional university (Université du Québec en Abitibi Témiscamingue), and one English speaking university (Concordia University).

The peculiarity of Université de Sherbrooke's forecast is the regularity of its enrollment pattern. This is reflected by the 
fact that unemployment has no impact on enrollment. Because of that regularity, the simplest model for this university turns out to be that past enrollment predicts future enrollment. This university has a distinctive trait from other universities that may very well explain why unemployment is not a significant driver: it relies on an alternance between internship semesters and classes semesters, where students are registered all year long and alternate between mandatory internships and more traditional courses (Université de Sherbrooke, 2020). This tighter, year-round curriculum may make it less appealing for recently unemployed individuals, thereby shielding Université de Sherbrooke from short-term fluctuations.

Université du Québec en Abitibi-Témiscamingue is also unaffected by unemployment but is driven by the size of the total population. As such, it shows a fairly straightforward increase in enrollment and in funding over time.

Table 5. Université de Sherbrooke's Forecasting Model (Mid-Term)

\begin{tabular}{|c|c|c|}
\hline \multirow[t]{6}{*}{$F_{i t}$} & \multirow[t]{2}{*}{$F T E_{i t-3}$} & 39.103 \\
\hline & & $(4.64) * * *$ \\
\hline & \multirow[t]{2}{*}{$F T E_{i t-4}$} & -20.005 \\
\hline & & $(2.34)^{*}$ \\
\hline & \multirow[t]{2}{*}{ Constant } & $-95,713$ \\
\hline & & $(5.61)^{* * *}$ \\
\hline \multirow[t]{6}{*}{$F T E_{i t-2}$} & \multirow[t]{2}{*}{ pop $_{i t-4}$} & 0.008 \\
\hline & & $(15.34)^{* * *}$ \\
\hline & \multirow[t]{2}{*}{$p_{o p} p_{i t-3}$} & 229.405 \\
\hline & & (1.13) \\
\hline & \multirow[t]{2}{*}{ Constant } & $-52,309$ \\
\hline & & $(9.04)$ \\
\hline \multicolumn{2}{|l|}{$N$} & 20 \\
\hline
\end{tabular}

Source: Authors' calculations and Québec Department of Higher Education.

Table 6. Université du Québec en Abitibi-Temiscamingue Forecasting Model (Mid-Term)

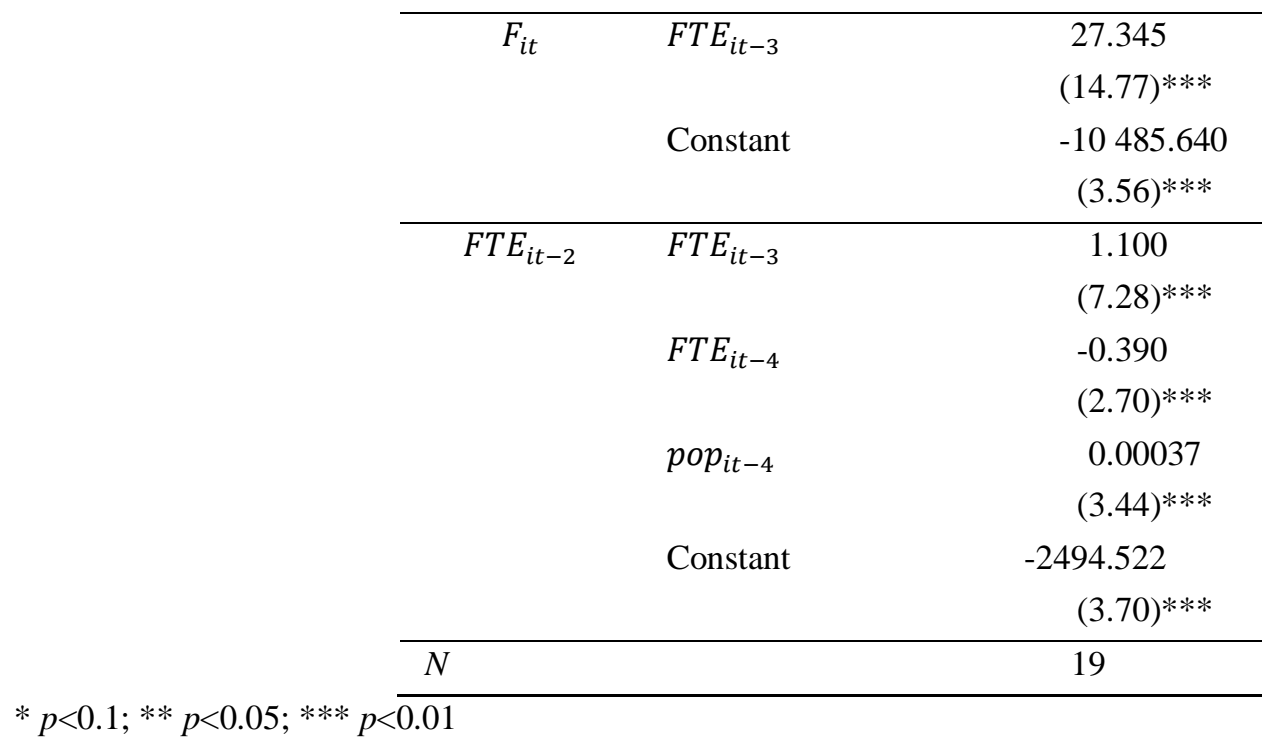

Source: Authors' calculations and Québec Department of Higher Education. 
Table 7. Concordia University Forecasting Model (Mid-Term)

\begin{tabular}{ccc}
\hline$F_{i t}$ & $F T E_{i t-4}$ & 7.835 \\
& & $(3.22)^{* * *}$ \\
& Constant & 2005.135 \\
& & $(0.07)$ \\
\hline$F T E_{i t-2}$ & $F T E_{i t-3}$ & 0.605 \\
& & $(3.16)^{* * *}$ \\
& $F T E_{i t-4}$ & 0.400 \\
& & $(2.01)^{* *}$ \\
& $u_{i t}$ & 916.768 \\
& & $(4.10)^{* * *}$ \\
& Constant & -6731.945 \\
& & $(2.55)^{* *}$ \\
\hline$N$ & & 20 \\
\hline
\end{tabular}

$* p<0.1 ; * * p<0.05 ; * * * p<0.0 \overline{1}$

Source: Authors' calculations and Québec Department of Higher Education.

Concordia university, on the other hand, is sensitive to changes in unemployment, but is not statistically tied to the demographics of the province. The university's pool of students is $30 \%$ from outside the province (Concordia University, 2020). Moreover, 32\% of the student body has another language than English or French as their mother tongue (id.). Concordia thus has a larger pool for recruitment than what the provincial demographics can model. Combined with the limited 22 observations available per university, this translates into past enrollment trends giving better forecasts than provincial demographics.

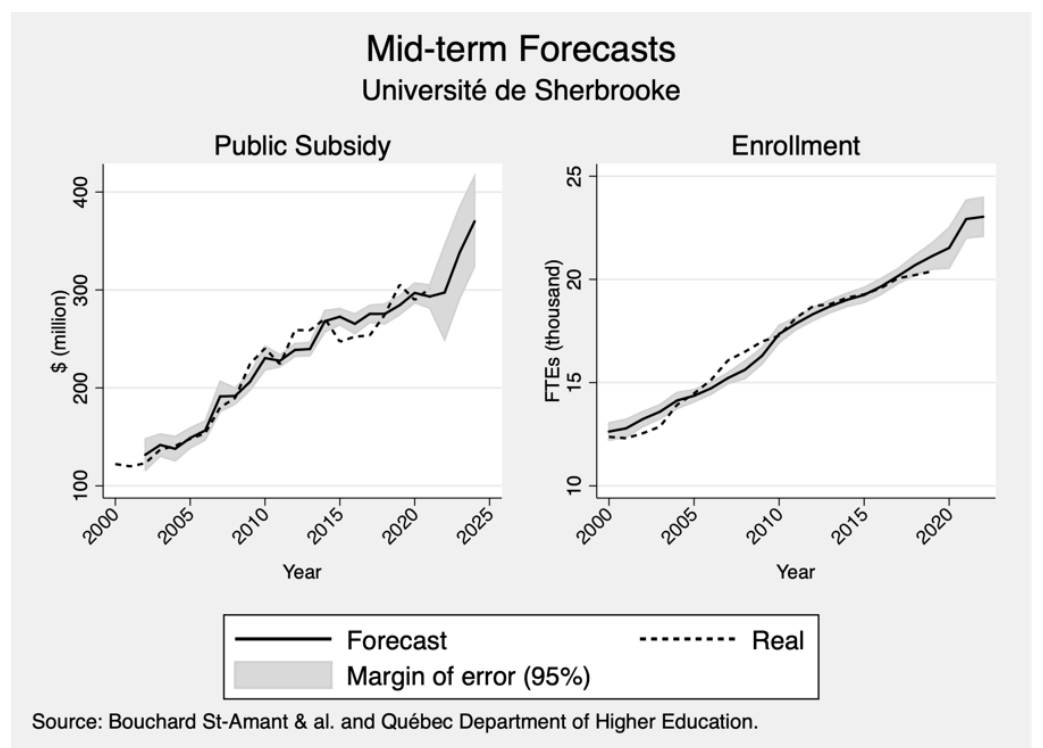

Figure 5. Université de Sherbrooke Forecast (Mid-term) 


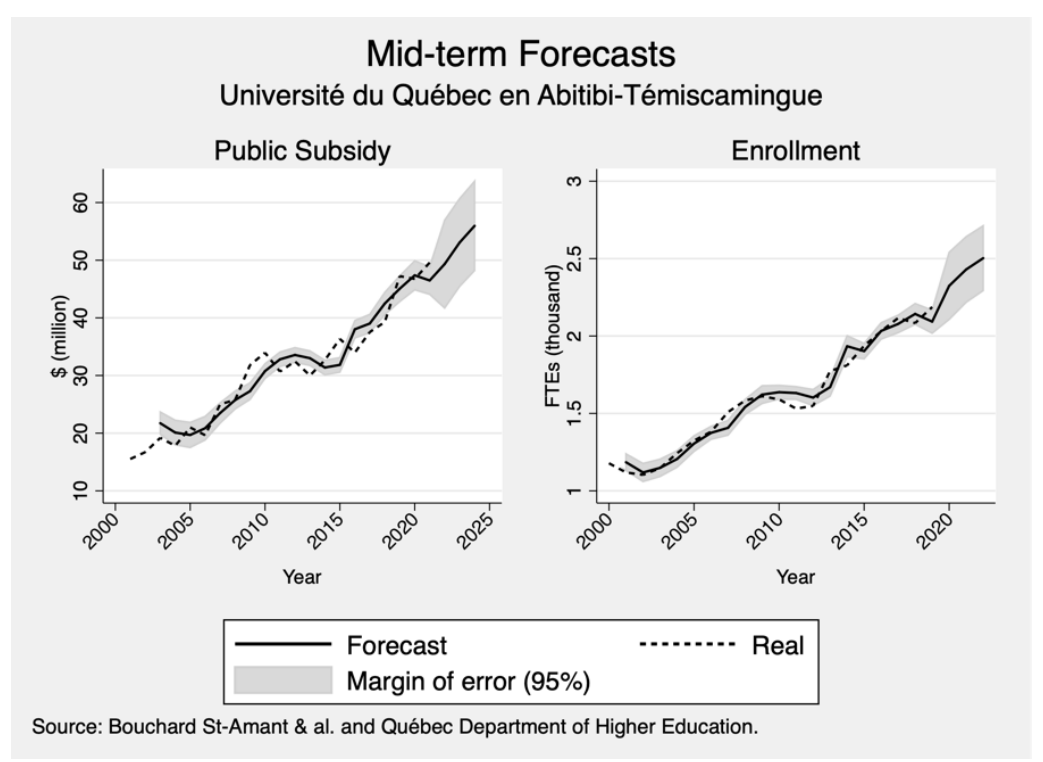

Figure 6. Université du Québec en Abitibi-Temiscamingue Forecast (Mid-term)

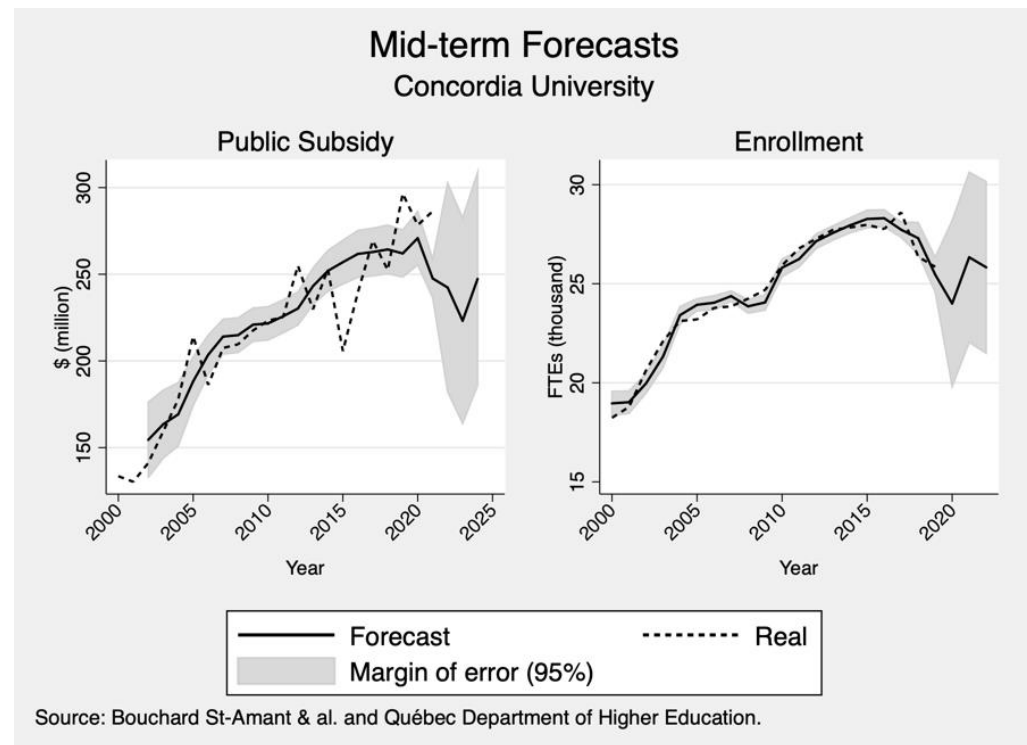

Figure 7. Concordia University Forecast (Mid-term)

In terms of forecasting models, two broad results stem from our analyses. First, smaller universities have proportionally larger variations in enrollment patterns, thus yielding proportionally larger predictive margins of error. We interpret this as an organizational incarnation of the law of large numbers: because smaller universities have fewer programs through which they can compensate for local enrollment shocks, aggregate variations turn out to be larger in proportion. Second, English speaking universities have patterns of their own, less tied to the provincial population patterns. We interpret this last fact as an indication that English speaking universities have a greater proportion of enrollment coming from an international pool, and that incidentally, the demographics of the province have a weaker predictive value. 


\subsection{Impact of COVID on Universities' Finances}

Our modelling approach allows us to distinguish long-term trends from mid-term trends. In this section, we thus use them as a counterfactual experiment to isolate their respective impacts on funding. Prior to year 2022, we can further decompose the trends by analyzing the difference between the realized values for funding and the mid-term trend. If one denotes $F L_{i t}, F M_{i t}$ and $F_{i t}$, as respectively the long-term forecast (eq. 4), the mid-term forecast (eq. 2) and the realized value, the following identity is a useful decomposition to interpret the source of the realized funding values:

$$
F_{i t}=F L_{i t}+\left(F M_{i t}-F L_{i t}\right)+\left(F_{i t}-F M_{i t}\right)
$$

In (6), the first term of the right-hand side represents the long-term funding (eq. 4), the second term represents the known impacts of the mid-term deviations (eq. 4 - eq. 2) and the last term represents the unanticipated changes in funding ( $\varepsilon_{i t}$ in eq. 2 ). In what comes below, we interpret the last term as the additional funding awarded to universities during the pandemic.

The first and last terms of (6) can be computed with a margin of error, as both values stem directly from an estimated equation. If the middle term is conceptually easier to understand as the difference between the two forecasting methods, it does not have a margin of error, as it comes from the difference of two equations estimated separately. Another way to estimate the middle term is to compute the impact of unemployment on funding through the combination of equations (2) and (3), with the associated margin of error:

$$
\Delta F_{i t}=\beta_{1} \alpha_{4} \mathrm{u}_{\mathrm{t}-\mathrm{L} 4}+\beta_{2} \alpha_{4} \mathrm{u}_{\mathrm{t}-1-\mathrm{L} 4}+\beta_{3} \alpha_{4} \mathrm{u}_{\mathrm{t}-2-\mathrm{L} 4}
$$

This second approach (7) yields an estimate different than the first approach, with the benefits of having margins of errors. Since both approaches are instructive, we report them in Table 8, as well as the rest of the decomposition, for year 2021 .

Table 8. Short to Mid Term Decomposition for Year 2021

\begin{tabular}{lccc} 
& $F L-F M$ & $\Delta F$ & $\varepsilon$ \\
\hline Qc & 84.45 & $159.67 *$ & 26.56 \\
Bishop & & $(-31.33,350.67)$ & $(-107.79,107.79)$ \\
& & -4.4214 & $2.7333^{*}$ \\
Concordia & 1.4357 & $53.724^{* *}$ & $38.748^{* * *}$ \\
& & $(25.549,81.899)$ & $(-11.122,11.122)$ \\
HEC & -6.930 & -6.9752 & -0.3960 \\
& & $(-43.914,29.964)$ & $(-3.8121,3.8121)$ \\
McGill & -14.875 & 21.546 & $30.183 * *$ \\
& & $(-17.935,61.026)$ & $(-27.788,27.788)$ \\
Poly & -3.317 & 3.0334 & 3.8491 \\
& & $(-2.2145,8.2815)$ & $(-4.5548,4.5548)$ \\
Montréal & -4.6523 & $28.204 *$ & $18.999 * *$ \\
& & $(-3.3093,59.716)$ & $(18.504,18.504)$ \\
Sherbrooke & 5.2230 & 49.337 & 8.2397 \\
& & $(-38.675,137.35)$ & $(-11.830,11.830)$ \\
Laval & -2.9501 & 10.971 & 8.3394 \\
& & $(-4.8713,26.814)$ & $(-15.701,15.701)$ \\
UQ System & 13.671 & $76.490^{* * *}$ & $30.095^{* *}$ \\
& & $(2.1633,150.82)$ & $(-20.121,20.121)$ \\
ENAP & $\mathrm{n} / \mathrm{a}$ & $\mathrm{n} / \mathrm{a}$ & 6.8056 \\
& & & $(-1.7444,1.7444)$
\end{tabular}


Table 8 continued from previous page

$\begin{array}{lccc}\text { ETS } & 4.2089 & 0.00 & -7.8247 \\ & & \mathrm{n} / \mathrm{a} & (-9.1636,9.1636) \\ \text { INRS } & -7.232 & -1.597 & 1.2333 \\ & & (-5.1774,1.9844) & (-2.357,2.357) \\ \text { UQAC } & 0.2931 & 8.4478^{* *} & 0.8413 \\ & & (0.3211,16.574) & (-3.8149,3.8149) \\ \text { UQAM } & -13.934 & 28.113 & 32.197 * * * \\ & & (-13.173,63.398) & (-10.294,10.294) \\ \text { UQAR } & 1.3422 & 7.9022^{* *} & 10.326^{* * *} \\ & & (0.3809,15.424) & (-3.068,3.068) \\ \text { UQAT } & -1.578 & 2.503 & 3.1094 * * \\ & & (-2.223,7.2281) & (-2.4041,2.4041) \\ \text { UQO } & 0.1995 & 4.9727 & 2.7835 \\ & & (-6.7581,16.704) & (-3.6514,3.6514) \\ \text { UQTR } & 4.8770 & 25.617 * * * & 3.0454 \\ & & (8.1030,43.131) & (-5.1796,5.1796) \\ \text { TELUQ } & 2.5882 & -4.6512 & -5.6147 * * \\ & & (-15.051,5.7491) & (-5.3349,5.3349)\end{array}$

Source: Authors' calculations. Legend: $* p<0.1 ; * * p<0.05$; *** $p<0.01$. The $95 \%$ confidence interval is in parentheses below the forecast. The not applicable mention (n/a) means that the data is not available. Because equations are estimated separately, the sum of funding (or funding variations) does not equal the total funding (or total variations).

Table 8 shows that 7 universities, or systems of universities, see their finances increase because of the unemployment rate (column $\Delta F$ ). For instance, the unemployment rate increased the total funding by $\$ 159.67$ millions for the provincial system as a whole. The Université du Québec system got an estimated additional $\$ 76.49$ millions for the same reason. This goes to show the concrete effect of unemployment on enrollment which, in turn, increases the public subsidy through the funding formula. Two metropolitan universities, Université de Montreal and Concordia University, seem to have benefited from additional subsidies through the effect of unemployment. The two other universities that see statistically significant increases in funding are regional universities of the Université du Québec system.

All of the remaining universities do not have a statistically significant variation in funding induced by unemployment. This can be so for several reasons. First, some of those universities' enrollment patterns are unaffected by unemployment. Second, for 3 estimated models, the non-linear combination of the unemployment effect on funding (eq. 7) is not statistically different from zero, although unemployment has a statistically significant effect on enrollment. This can be the case if the smoothing mechanisms on funding -- in our estimates, the lagged variables on funding -- has a greater effect on funding than unemployment itself. Third, there may simply not be enough statistical power, with 22 observations, to distinguish the result from the null effect. This last case is a plausible explanation for smaller universities.

In terms of outliers during year 2021, eight universities seem to have benefited from the pandemic beyond what the unemployment rate can explain: Bishop's University, École nationale d'administration publique, McGill University, Université de Montréal, Université du Québec à Montréal, Université du Québec à Rimouski and Université du Québec en Abitibi-Témiscamingue. Since four of those universities are in the Université du Québec system, including the largest one (UQAM), the statistically significant effect of additional funding unexplained by unemployment also shows up in the aggregate, with an extra $\$ 30.10$ millions for the system. On the other end of the spectrum, one university stands out as having current subsidies below its predicted value during the pandemic, which is Université TÉLUQ. This is so because enrollment went much higher two years ago than what its normal trend predicts, pushing 
funding upwards. Thus, predicted funding is higher than what is actually being given.

\section{Conclusion}

Our paper presents several insights that help understanding how university systems respond to economic conditions which can be helpful for practitioners and researchers alike. First, we develop a methodology to estimate simultaneously enrollment and public subsidies. In jurisdictions where appropriations depend on enrollment, this is a particularly apt framework to model the evolution of public finances and its interdependence with enrollment. Second, it is shown that unemployment drives enrollment upwards in some universities or university systems, including the whole system of universities. This means that during (or around) recessions, public subsidies are forecasted to increase if the funding policies are left as is. Moreover, we further find that during the current pandemic, inducing a recession, the increase in funding went beyond what changes in unemployment could explain. Thus, some factors left out of our analysis increase funding by more than what it ought to. One interpretation is one of overshooting, where public authorities gave more funding than what would be the typical value during a recession. In all cases, forecasting models such as the ones developed in this paper can help strengthen our understanding of how university systems respond during recessions, and thus, facilitate planning.

On top of these findings, we also find qualitative forecasting results of interest. First, the margin of error of the forecast is generally larger for smaller universities, suggesting that they are more prone to enrollment shifts from one program to another, a phenomenon that vanishes for large universities. This goes to suggest that the lack of effect of the unemployment variable for some of these universities is simply a consequence of a lack of statistical power. Second, English speaking universities are better explained by autocorrelation patterns than by the French speaking driven demographics of the province. In broader terms, universities that depend more on out-of-jurisdiction enrollment, rather than within-jurisdiction enrollment, are better explained by autocorrelation patterns, or additional variables not found in this paper.

\section{Acknowledgements}

The authors would like to thank Matis Alali, Étienne Charbonneau, Charles-Henri Lavoie and one anonymous referee for their feedback and comments. All errors remain our own.

\section{References}

Alessandrini, D. (2014). Human Capital, Business Cycles and Labor Supply Volatility [Doctoral dissertation, University of Guelph. Retrieved from https://atrium.lib.uoguelph.ca/xmlui/bitstream/handle/10214/8024/Alessandrini_Diana_201404_PhD.pdf?seque nce $=1$ \&isAllowed $=\mathrm{y}$

Andersen, T. G., Davis, R. A., KreiB, J.-P., \& Mikosch, T. (Eds.) (2009). Handbook of Financial Time Series. Springer-Verlag.

Arseneau, M., \& Paquet, J. (2020, September). Mensuel économique. Banque nationale du Canada. Retrieved from https://www.bnc.ca/content/dam/bnc/fr/taux-et-analyses/analyse-economique/mensuel-economique.pdf

Barr, A., \& Turner, S. E. (2013). Expanding Enrollments and Contracting State Budgets: The Effect of the Great Recession on Higher Education. The Annals of the American Academy of Political and Social Science, 650(1), 168-193. https://doi.org/10.1177/0002716213500035

Boes, S., \& Pflaumer, P. (2006). University Student Enrollment forecasts by analysis structural ratios using ARIMA-methods. Allgemeines Statistisches Arch, 90, 253-271. https://doi.org/10.1007/s10182-006-0233-1

Bouchard St-Amant, P.-A., Brabant, A.-N., \& Germain, E. (2020). University Funding Formulas: Incentives and Reforms. Canadian Journal of Higher Education, 50(1).

Box, G. E. P., Jenkins, G. M., Reinsel, G. M., \& Ljung, G. M. (2015). Time Series Analysis: Forecasting and Control (5th ed.). John Wiley \& Sons.

Caranci, B., Burleton, D., Sondhi, R., \& Abdelrahman, O. (2020, September 17). Provincial Economic Forescast: Not Out of the Woods Yet. TD. Retrieved from https://economics.td.com/provincial-economic-forecast

Chen, C.-K. (2008). An Integrated Forecast Model. IR Applications. Association for Institutional Research, 8(15), $1-18$.

Chen, Y., Li, R., \& Hagedorn, L. S. (2019). Undergraduate International Student Enrollment Forecasting Model: An Application of Time Series Analysis. Journal of International Students, 9(1), 242-261. 
https://doi.org/10.32674/jis.v9i1.266

Concordia University. (2020, Septembre 30). Fast facts, Concordia in numbers. Retrieved from https://www.concordia.ca/about/fast-facts.html

Davison, A. C., \& Hinkley, D. V. (1997). Bootstrap Methods and their Application. Cambridge University Press. https://doi.org/10.1017/CBO9780511802843

Dellas, H., \& Koubi, V. (2003). Business cycles and schooling. European Journal of Political Economy, 19(4), 843-859. https://doi.org/10.1016/S0176-2680(03)00039-9

Dellas, H., \& Sakellaris, P. (2003). On the Cyclicality of Schooling: Theory and Evidence. Oxford Economic Papers, 55(1), 148-172. https://doi.org/10.1093/oep/55.1.148

Dennen, V. (2020, March 13). Colleges across the US are moving online amid the coronavirus pandemic. Here's what that means for students and instructors, according to an expert. Business insider. Retrieved from https://www.businessinsider.com/us-colleges-shutting-down-coronavirus-impact-when-classes-move-online-2020-3

Desjardins. (2020, Septembre 18). Prévisions économiques et financières: la reprise de l'économie est bien entamée, mais des inquiétudes demeurent... https://www.desjardins.com/ressources/pdf/peft2009-f.pdf?resVer=1600438443000

Éditeur officiel du Québec. (2020a, June 1). Loi sur les établissements d'enseignement de niveau universitaire. Retrieved from http://legisquebec.gouv.qc.ca/fr/showdoc/cs/e-14.1

Éditeur officiel du Québec. (2020b, June 1). Loi sur l'Université du Québec. Retrieved from http://legisquebec.gouv.qc.ca/fr/showdoc/cs/U-1

Ewing, K. M., Beckert, K. A., \& Ewing, B. T. (2010). The response of US college enrollment to unexpected changes in macroeconomic activity. Education Economics, 18(4), 423-434. https://doi.org/10.1080/0964529090346573

Frank, R., Bernanke, B., Antonovics, K., \& Heffetz, O. (2019). Principles of Macroeonomics (7th ed.). McGraw Hill.

Frølich, N., Kalpazidou Schmidt, E., \& Rosa, M. J. (2010). Funding systems for Higher Education and their impacts on institutional strategies and academia: a comparative perspective. International Journal of Educational Management, 24(1), 7-21. https://doi.org/10.1108/09513541011013015

Greene, W. H. (2018). Econometric Analysis (8th ed.). Pearson.

Guérin, G. (1972). Elaboration d'un modèle de prévision des effectifs étudiants au niveau universitaire [Doctoral dissertation, Université de Montréal]. $\quad$ Retrieved from https://papyrus.bib.umontreal.ca/xmlui/bitstream/handle/1866/1678/a1.6g1.pdf?sequence=1\&isAllowed=y

Hamilton, J. D. (1994). Time Series Analysis. Princeton University Press.

Hawkins, D. M. (2004). The Problem of Overfitting. American Chemical Society, 44(1), 1-12. https://doi.org/10.1021/ci0342472

Institut de la statistique du Québec. (2019). Annuaire québécois des statistiques du travail: Portrait des principaux indicateurs du marché et des conditions de travail 2008-2018. Gouvernement du Québec. Retrieved from https://www.stat.gouv.qc.ca/statistiques/travail-remuneration/annuaire-v15.pdf

Kwak, N. K., Brown, R., \& Schiederjans, M. J. (1986). A Markov analysis of estimating student enrollment transition in a trimester institution. Socio-Economic Planning Sciences, 20(5), 311-318. https://doi.org/10.1016/0038-0121(86)90040-6

Maroy, C., Doray, P., \& Kabore, M. (2014). La politique de financement des universités au Québec à l'épreuve du «Printemps érable». Montréal, Centre interuniversitaire de recherche sur la science et la technologie.

Marshall, K. T., \& Oliver, R. M. (1979). Estimating errors in student enrollment forecasting. Research in Higher Education, 11, 195-205. https://doi.org/10.1007/BF00975124

Ministère de l'Éducation et de l'Enseignement supérieur. (1999). Calculs définitifs des subventions de fonctionnement aux universités du Québec: année universitaire 1998-1999. Gouvernement du Québec. Retrieved from http://www.education.gouv.qc.ca/references/tx-solrtyperecherchepublicationtx-solrpublicationnouveaute/resulta ts-de-la-recherche/detail/article/subventions-de-fonctionnement-aux-universites-du-quebec/

Ministère de l'Éducation et de l'Enseignement supérieur. (2000). Calculs définitifs des subventions de fonctionnement aux universités du Québec: année universitaire 1999-2000. Gouvernement du Québec. Retrieved from 
http://www.education.gouv.qc.ca/references/tx-solrtyperecherchepublicationtx-solrpublicationnouveaute/resulta ts-de-la-recherche/detail/article/subventions-de-fonctionnement-aux-universites-du-quebec/

Ministère de l'Éducation et de l'Enseignement supérieur. (2001). Calculs définitifs des subventions de fonctionnement aux universités du Québec: année universitaire 2000-2001. Gouvernement du Québec. Retrieved from http://www.education.gouv.qc.ca/references/tx-solrtyperecherchepublicationtx-solrpublicationnouveaute/resulta ts-de-la-recherche/detail/article/subventions-de-fonctionnement-aux-universites-du-quebec/

Ministère de l'Éducation et de l'Enseignement supérieur. (2002). Calculs définitifs des subventions de fonctionnement aux universités du Québec: année universitaire 2001-2002. Gouvernement du Québec. Retrieved from http://www.education.gouv.qc.ca/references/tx-solrtyperecherchepublicationtx-solrpublicationnouveaute/resulta ts-de-la-recherche/detail/article/subventions-de-fonctionnement-aux-universites-du-quebec/

Ministère de l'Éducation et de l'Enseignement supérieur. (2003). Calculs définitifs des subventions de fonctionnement aux universités du Québec: année universitaire 2002-2003. Gouvernement du Québec. Retrieved from http://www.education.gouv.qc.ca/references/tx-solrtyperecherchepublicationtx-solrpublicationnouveaute/resulta ts-de-la-recherche/detail/article/subventions-de-fonctionnement-aux-universites-du-quebec/

Ministère de l'Éducation et de l'Enseignement supérieur. (2004). Calculs définitifs des subventions de fonctionnement aux universités du Québec: année universitaire 2003-2004. Gouvernement du Québec. Retrieved from http://www.education.gouv.qc.ca/references/tx-solrtyperecherchepublicationtx-solrpublicationnouveaute/resulta ts-de-la-recherche/detail/article/subventions-de-fonctionnement-aux-universites-du-quebec/

Ministère de l'Éducation et de l'Enseignement supérieur. (2005). Calculs définitifs des subventions de fonctionnement aux universités du Québec: année universitaire 2004-2005. Gouvernement du Québec. Retrieved from http://www.education.gouv.qc.ca/references/tx-solrtyperecherchepublicationtx-solrpublicationnouveaute/resulta ts-de-la-recherche/detail/article/subventions-de-fonctionnement-aux-universites-du-quebec/

Ministère de l'Éducation et de l'Enseignement supérieur. (2006). Calculs définitifs des subventions de fonctionnement aux universités du Québec: année universitaire 2005-2006. Gouvernement du Québec. Retrieved from http://www.education.gouv.qc.ca/references/tx-solrtyperecherchepublicationtx-solrpublicationnouveaute/resulta ts-de-la-recherche/detail/article/subventions-de-fonctionnement-aux-universites-du-quebec/

Ministère de l'Éducation et de l'Enseignement supérieur. (2007). Calculs définitifs des subventions de fonctionnement aux universités du Québec: année universitaire 2006-2007. Gouvernement du Québec. Retrieved from http://www.education.gouv.qc.ca/references/tx-solrtyperecherchepublicationtx-solrpublicationnouveaute/resulta ts-de-la-recherche/detail/article/subventions-de-fonctionnement-aux-universites-du-quebec/

Ministère de l'Éducation et de l'Enseignement supérieur. (2008). Calculs définitifs des subventions de fonctionnement aux universités du Québec: année universitaire 2007-2008. Gouvernement du Québec. Retrieved from http://www.education.gouv.qc.ca/references/tx-solrtyperecherchepublicationtx-solrpublicationnouveaute/resulta ts-de-la-recherche/detail/article/subventions-de-fonctionnement-aux-universites-du-quebec/

Ministère de l'Éducation et de l'Enseignement supérieur. (2009). Calculs définitifs des subventions de fonctionnement aux universités du Québec: année universitaire 2008-2009. Gouvernement du Québec. Retrieved from http://www.education.gouv.qc.ca/references/tx-solrtyperecherchepublicationtx-solrpublicationnouveaute/resulta ts-de-la-recherche/detail/article/subventions-de-fonctionnement-aux-universites-du-quebec/

Ministère de l'Éducation et de l'Enseignement supérieur. (2010). Calculs définitifs des subventions de fonctionnement aux universités du Québec: année universitaire 2009-2010. Gouvernement du Québec. Retrieved from http://www.education.gouv.qc.ca/references/tx-solrtyperecherchepublicationtx-solrpublicationnouveaute/resulta ts-de-la-recherche/detail/article/subventions-de-fonctionnement-aux-universites-du-quebec/

Ministère de l'Éducation et de l'Enseignement supérieur. (2011). Calculs définitifs des subventions de fonctionnement aux universités du Québec: année universitaire 2010-2011. Gouvernement du Québec. Retrieved from http://www.education.gouv.qc.ca/references/tx-solrtyperecherchepublicationtx-solrpublicationnouveaute/resulta ts-de-la-recherche/detail/article/subventions-de-fonctionnement-aux-universites-du-quebec/

Ministère de l'Éducation et de l'Enseignement supérieur. (2012). Calculs définitifs des subventions de fonctionnement aux universités du Québec: année universitaire 2011-2012. Gouvernement du Québec. Retrieved from http://www.education.gouv.qc.ca/references/tx-solrtyperecherchepublicationtx-solrpublicationnouveaute/resulta ts-de-la-recherche/detail/article/subventions-de-fonctionnement-aux-universites-du-quebec/

Ministère de l'Éducation et de l'Enseignement supérieur. (2013). Calculs définitifs des subventions de fonctionnement 
aux universités du Québec: année universitaire 2012-2013. Gouvernement du Québec. Retrieved from http://www.education.gouv.qc.ca/references/tx-solrtyperecherchepublicationtx-solrpublicationnouveaute/resulta ts-de-la-recherche/detail/article/subventions-de-fonctionnement-aux-universites-du-quebec/

Ministère de l'Éducation et de l'Enseignement supérieur. (2014). Calculs définitifs des subventions de fonctionnement aux universités du Québec: année universitaire 2013-2014. Gouvernement du Québec. Retrieved from http://www.education.gouv.qc.ca/references/tx-solrtyperecherchepublicationtx-solrpublicationnouveaute/resulta ts-de-la-recherche/detail/article/subventions-de-fonctionnement-aux-universites-du-quebec/

Ministère de l'Éducation et de l'Enseignement supérieur. (2015). Calculs définitifs des subventions de fonctionnement aux universités du Québec: année universitaire 2014-2015. Gouvernement du Québec. Retrieved from http://www.education.gouv.qc.ca/references/tx-solrtyperecherchepublicationtx-solrpublicationnouveaute/resulta ts-de-la-recherche/detail/article/subventions-de-fonctionnement-aux-universites-du-quebec/

Ministère de l'Éducation et de l'Enseignement supérieur. (2016). Calculs définitifs des subventions de fonctionnement aux universités du Québec: année universitaire 2015-2016. Gouvernement du Québec. Retrieved from http://www.education.gouv.qc.ca/references/tx-solrtyperecherchepublicationtx-solrpublicationnouveaute/resulta ts-de-la-recherche/detail/article/subventions-de-fonctionnement-aux-universites-du-quebec/

Ministère de l'Éducation et de l'Enseignement supérieur. (2017). Calculs définitifs des subventions de fonctionnement aux universités du Québec: année universitaire 2016-2017. Gouvernement du Québec. Retrieved from http://www.education.gouv.qc.ca/references/tx-solrtyperecherchepublicationtx-solrpublicationnouveaute/resulta ts-de-la-recherche/detail/article/subventions-de-fonctionnement-aux-universites-du-quebec/

Ministère de l'Éducation et de l'Enseignement supérieur. (2018). Calculs définitifs des subventions de fonctionnement aux universités du Québec: année universitaire 2017-2018. Gouvernement du Québec. Retrieved from http:/www.education.gouv.qc.ca/references/tx-solrtyperecherchepublicationtx-solrpublicationnouveaute/resulta ts-de-la-recherche/detail/article/subventions-de-fonctionnement-aux-universites-du-quebec/

Ministère de l'Éducation et de l'Enseignement supérieur. (2019). Calculs définitifs des subventions de fonctionnement aux universités du Québec: année universitaire 2018-2019. Gouvernement du Québec. Retrieved from http://www.education.gouv.qc.ca/references/tx-solrtyperecherchepublicationtx-solrpublicationnouveaute/resulta ts-de-la-recherche/detail/article/subventions-de-fonctionnement-aux-universites-du-quebec/

Ministère de l'Éducation et de l'Enseignement supérieur. (2020). Règles budgétaires et calcul des subventions des fonctionnement aux universités du Québec: année universitaire 2020-2021. Gouvernement du Québec. Retrieved from http://www.education.gouv.qc.ca/references/tx-solrtyperecherchepublicationtx-solrpublicationnouveaute/resultats-de-1 a-recherche/detail/article/subventions-de-fonctionnement-aux-universites-du-quebec/

O’Bryant, S. D. (1991). Enrollment Forecasting as Sinclair Community College. Wright Stata University. Retrieved from https://corescholar.libraries.wright.edu/econ_student/64/

Perrault, J.-F. (2020, Septembre 3). Solid Progress, but Still Not Out of the Woods: Soctiabank's Forecast Tables. Scotia Bank. Retrieved from https://www.scotiabank.com/ca/en/about/economics/economics-publications/post.other-publications.global-outl ook-and-forecast-tables.scotiabank's-forecast-tables.2020.september-3--2020.html

Qin, L., Shanks, K., Phillips, G. A., \& Bernard, D. (2019). The Impacts of Lengths of Time Series on the Accuracy of the ARIMA Forecasting. International Research in Higher Education, 4(3), 58-68. https://doi.org/10.5430/irhe.v4n3p58

Shaw, R. C. (1984). Enrollment forecasting: what methods work best?. NASSP Bulletin, 68(468), 52-58. https://doi.org/10.1177/019263658406846810

Sievertsen, H. H. (2016). Local unemployment and the timing of post-secondary schooling. Economics of Education Review, 50, 17-28. https://doi.org/10.1016/j.econedurev.2015.11.002

Smith, T. (2017). Can Macroeconomic Conditions Affect Enrollments in Higher Education? A Study of U.S. College Enrollment Rates From 2002-2014. University of California. Retrieved from http://giovanniperi.ucdavis.edu/uploads/5/6/8/2/56826033/thomas_smith_final_draft.pdf

Smythe, A. (2019). Labor Market Conditions and Racial/Ethnic Differences in College Enrollment. Journal of Economics, Race and Policy, 2, 173-183. https://doi.org/10.1007/s41996-019-00030-4

Statistics Canada. (2020). Table 17-10-0005-01 Population estimates on July 1st, by age and sex. 
https://doi.org/10.25318/1710000501-eng

Statistics Canada. (2021). Table 14-10-0287-03 Labour force characteristics by province, monthly, seasonally adjusted. https://doi.org/10.25318/1410028701-eng

Trahan, M., \& Carreau, G. (2010). La formule de financement de la fonction enseignement des universités (Report No. 2010RP-07). Centre interuniversitaire de recherche en analyse des organisations. Retrieved from http://cirano.qc.ca/files/publications/2010RP-07.pdf

Université de Sherbrooke. (2020, Septembre 30). Les programmes avec stages coopératifs. Retrieved from https://www.usherbrooke.ca/admission/1er-cycle/trouver-un-programme-de-1er-cycle/programmes-avec-stagescooperatifs/

Witteveen, D. (2020). Encouraged or Discouraged? The Effect of Adverse Macroeconomic Conditions on School Leaving and Reentry. American Sociological Association. https://doi.org/10.1177/0038040720960718

\section{Appendix A}

\section{Remaining Universities' Forecasts}

All universities have both a long-term and a mid-term model, with the exception of École nationale d'administration publique (ENAP), whose enrollment pattern cannot be characterized in the long run. All universities have their estimated mid-term model presented below, as well as tables for both short-term and long-term forecasts for selected numerical values. Each university has also two graphical representations of forecasts. Only a subset of the forecasts are shown. Mid-term forecasts are available from 2018-2019 to 2023-2024 and long-term forecasts are available from 2020-2021 to 2039-2040. However, because some universities use lagged variables of population or immigration, the last forecasted year can be 2037-2038 or 2038-2039. All FTE figures are in thousands and all Subsidies figures are in millions of dollars. Consequently, all estimated coefficients in all equations reflect those units.

\section{A.1 Bishop's University}

Table A1. Bishop's University Forecasting Results (Mid-Term)

\begin{tabular}{llrrrr} 
& & $2018-2019$ & $2019-2020$ & $2020-2021$ & $2021-2022$ \\
\hline \multirow{2}{*}{ FTEs } & 95\% Upper Bound & 2.0682 & 1.9406 & 1.8292 & 1.7416 \\
& Forecast & 2.2011 & 2.1390 & 2.0355 & 1.9463 \\
& 95\% Lower Bound & 2.3340 & 2.3375 & 2.2417 & 2.1511 \\
Subsidy & 95\% Upper Bound & 28.829 & 30.811 & 30.615 & 36.518 \\
& Forecast & 26.766 & 28.332 & 27.748 & 28.967 \\
& 95\% Lower Bound & 24.703 & 25.852 & 24.881 & 21.416 \\
\hline
\end{tabular}

Source: Authors' calculations and Québec Department of Higher Education.

Table A2. Bishop's University Forecasting Results (Long-Term)

\begin{tabular}{llrrr} 
& & $2018-2019$ & $2028-2029$ & $2038-2039$ \\
\hline \multirow{2}{*}{ FTEs } & 95\% Upper Bound & 2.2377 & 2.5180 & 2.8605 \\
& Forecast & 2.1433 & 2.4268 & 2.6639 \\
& 95\% Lower Bound & 2.0491 & 2.3357 & 2.4673 \\
\hline Subsidy & 95\% Upper Bound & 36.693 & 38.644 & 39.691 \\
& Forecast & 32.200 & 35.405 & 36.815 \\
& 95\% Lower Bound & 27.706 & 32.166 & 33.938 \\
\hline
\end{tabular}

Source: Authors' calculations and Québec Department of Higher Education. 


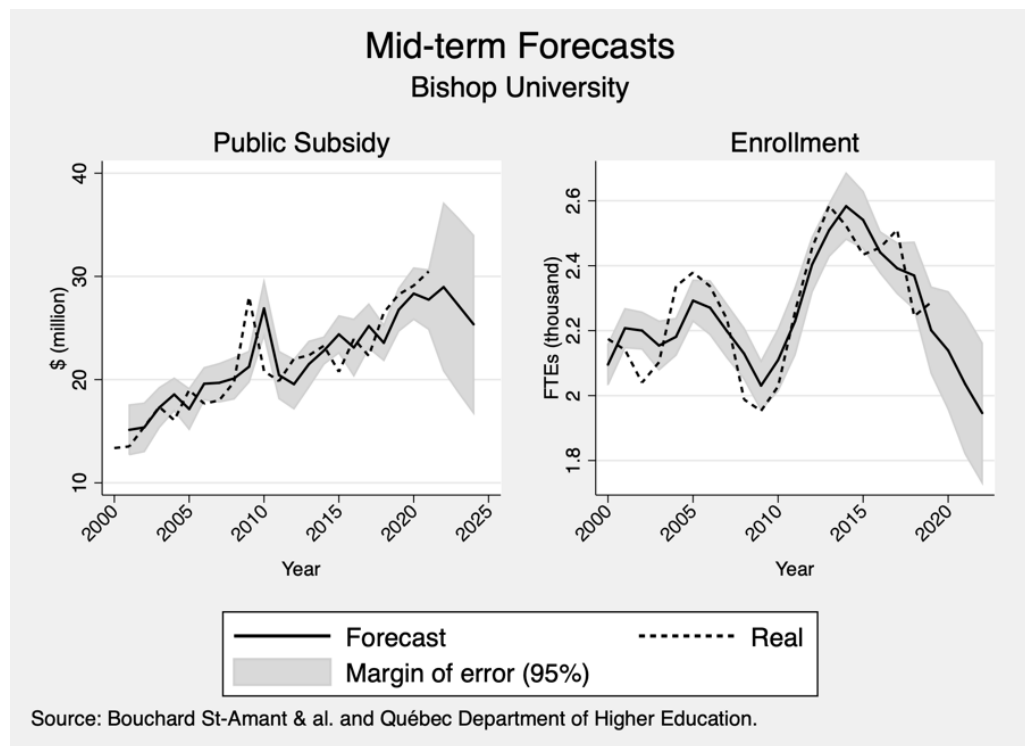

Figure A1. Bishop's University Forecast (Mid-term)

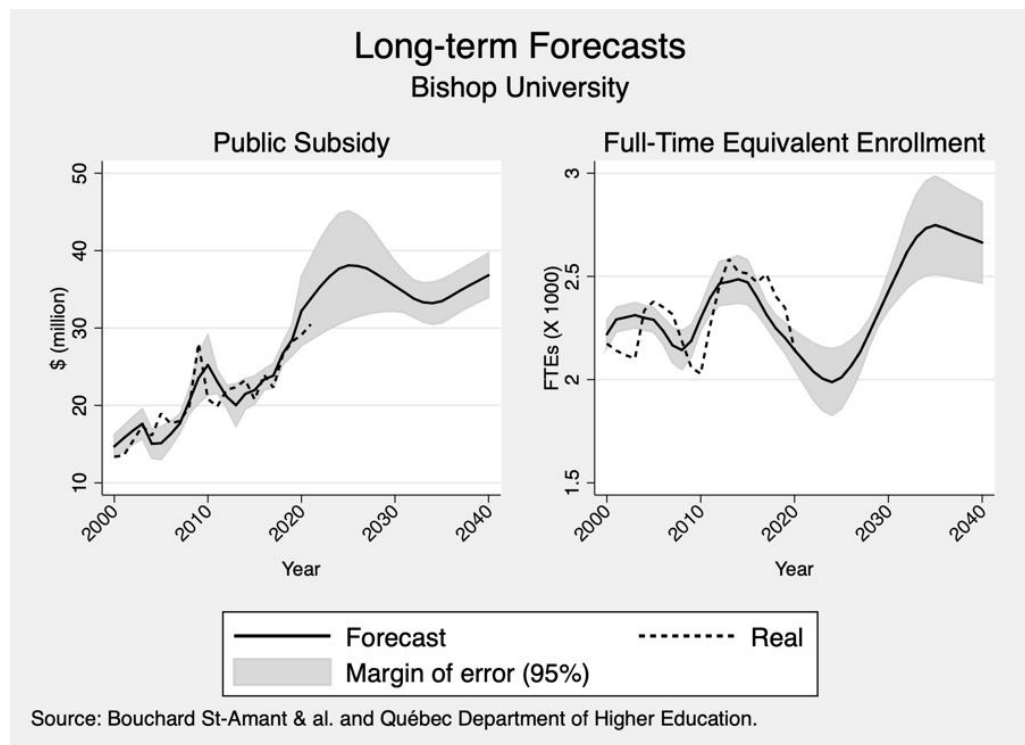

Figure A2. Bishop's University Forecast (Long-term)

$$
\begin{gathered}
F_{t}=-4.0771+0.7417 F_{t-1}+0.0047 F T E_{t-3}+\varepsilon_{t} \\
F T E_{t-2}=-3315.26+0.4991 F T E_{t-3}+0.0056 \text { pop } 18_{t-5}+\varepsilon_{t} .
\end{gathered}
$$




\section{A.2 Concordia University}

See the main text for the short-term forecasting model and projections.

Table A3. Concordia University Forecasting Results (Long-Term)

\begin{tabular}{llrrr} 
& & $2018-2019$ & $2028-2029$ & $2038-2039$ \\
\hline FTEs & 95\% Upper Bound & 27.689 & 30.927 & 31.916 \\
& Forecast & 28.537 & 32.483 & 34.090 \\
& 95\% Lower Bound & 26.840 & 29.371 & 29.742 \\
\hline Subsidy & 95\% Upper Bound & 263.29 & 311.04 & 325.69 \\
& Forecast & 248.36 & 289.32 & 301.83 \\
& 95\% Lower Bound & 233.43 & 267.60 & 277.96 \\
\hline
\end{tabular}

Source: Authors' calculations and Québec Department of Higher Education.

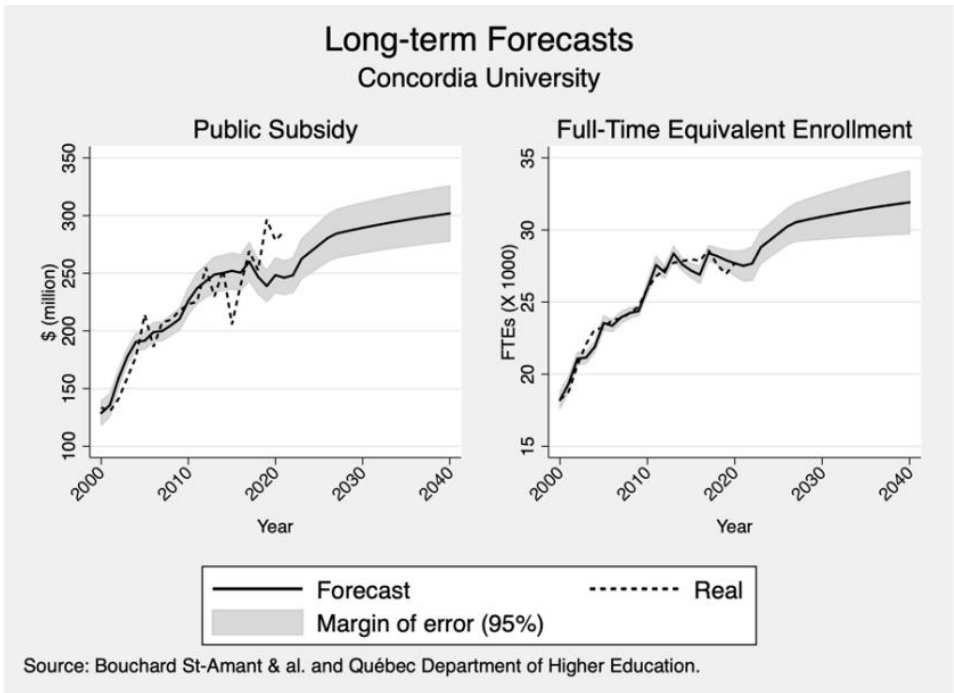

Figure A3. Concordia University Forecast (Long-term)

$$
\begin{gathered}
F_{t}=-25.021+0.1034 F T E_{t-3}+\varepsilon_{t} \\
F T E_{t-2}=-7235.19+0.6889 F T E_{t-3}+0.3264 F T E_{t-4}+944.57 u_{t-3}+\varepsilon_{t} .
\end{gathered}
$$

\section{A.3 École nationale d'administration publique}

Table A4. École nationale d'administration publique Forecasting Results (Mid-Term)

\begin{tabular}{llrrrr} 
& & $2018-2019$ & $2019-2020$ & $2020-2021$ & $2021-2022$ \\
\hline \multirow{2}{*}{ FTEs } & 95\% Upper Bound & 0.6770 & 0.7154 & 0.7843 & 0.9069 \\
& Forecast & 0.6260 & 0.6156 & 0.6046 & 0.5977 \\
& 95\% Lower Bound & 0.5751 & 0.5157 & 0.4249 & 0.2884 \\
Subsidy & $95 \%$ Upper Bound & 14.349 & 13.748 & 13.366 & 13.075 \\
& Forecast & 12.755 & 11.621 & 11.621 & 11.278 \\
& 95\% Lower Bound & 11.161 & 10.385 & 9.8768 & 9.4812 \\
\hline
\end{tabular}

Source: Authors' calculations and Québec Department of Higher Education. 


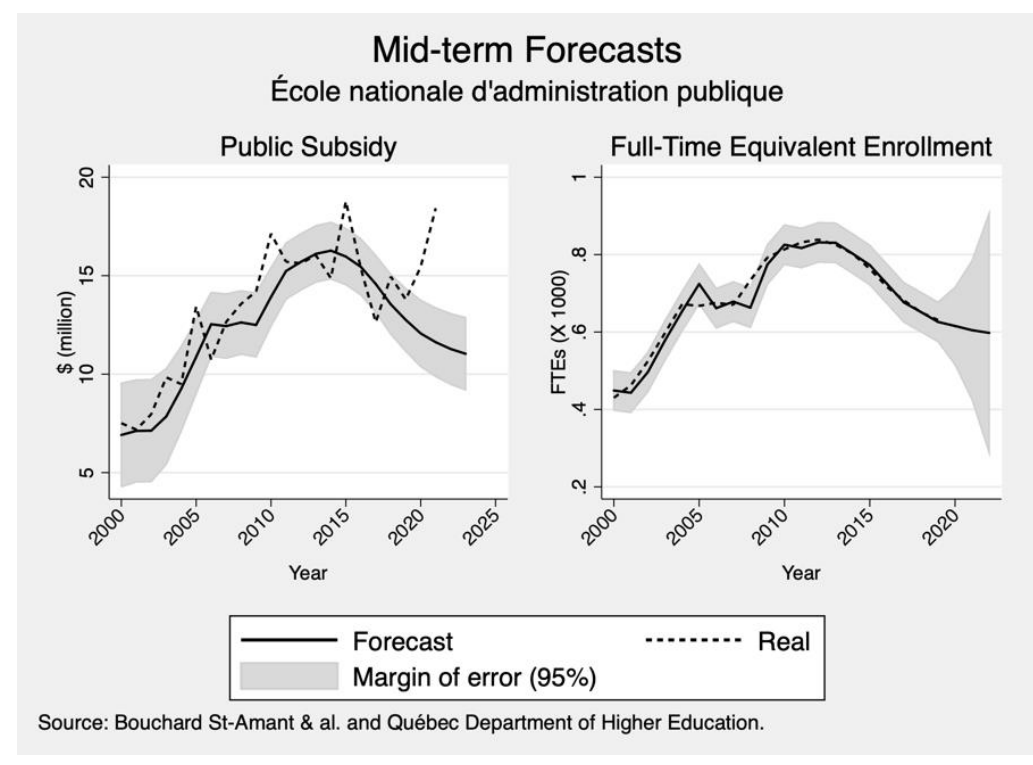

Figure A4.École nationale d'administration publique Forecast (Mid-term)

$$
F T E_{t}^{\max }=0.6239+1.6836 F T E_{t-1}^{\max }-0.7483 F T E_{t-2}^{\max }+\varepsilon_{t} .
$$

\section{A.4 École de technologie supérieure}

Table A5. École de technologie supérieure Forecasting Results (Mid-Term)

\begin{tabular}{llrrrr} 
& & $2018-2019$ & $2019-2020$ & $2020-2021$ & $2021-2022$ \\
\hline \multirow{2}{*}{ FTEs } & 95\% Upper Bound & 8.5104 & 9.0613 & 9.3822 & 9.7814 \\
& Forecast & 8.1150 & 8.1874 & 8.4451 & 8.8282 \\
& 95\% Lower Bound & 8.0638 & 7.3135 & 7.5081 & 7.8749 \\
Subsidy & $95 \%$ Upper Bound & 132.21 & 131.14 & 133.44 & 145.42 \\
& Forecast & 123.20 & 122.27 & 116.46 & 122.92 \\
& 95\% Lower Bound & 114.19 & 113.39 & 115.12 & 100.41 \\
\hline
\end{tabular}

Source: Authors' calculations and Québec Department of Higher Education.

Table A6. École de technologie supérieure Forecasting Results (Long-Term)

\begin{tabular}{llrrr} 
& & $2018-2019$ & $2028-2029$ & $2038-2039$ \\
\hline \multirow{2}{*}{ FTEs } & 95\% Upper Bound & 8.9192 & 13.107 & 15.981 \\
& Forecast & 8.4578 & 12.529 & 15.227 \\
& 95\% Lower Bound & 7.9963 & 11.951 & 14.473 \\
\hline Subsidy & 95\% Upper Bound & 128.03 & 186.72 & 239.73 \\
& Forecast & 121.25 & 174.88 & 223.15 \\
& 95\% Lower Bound & 114.46 & 163.04 & 206.57 \\
\hline
\end{tabular}

Source: Authors' calculations and Québec Department of Higher Education. 


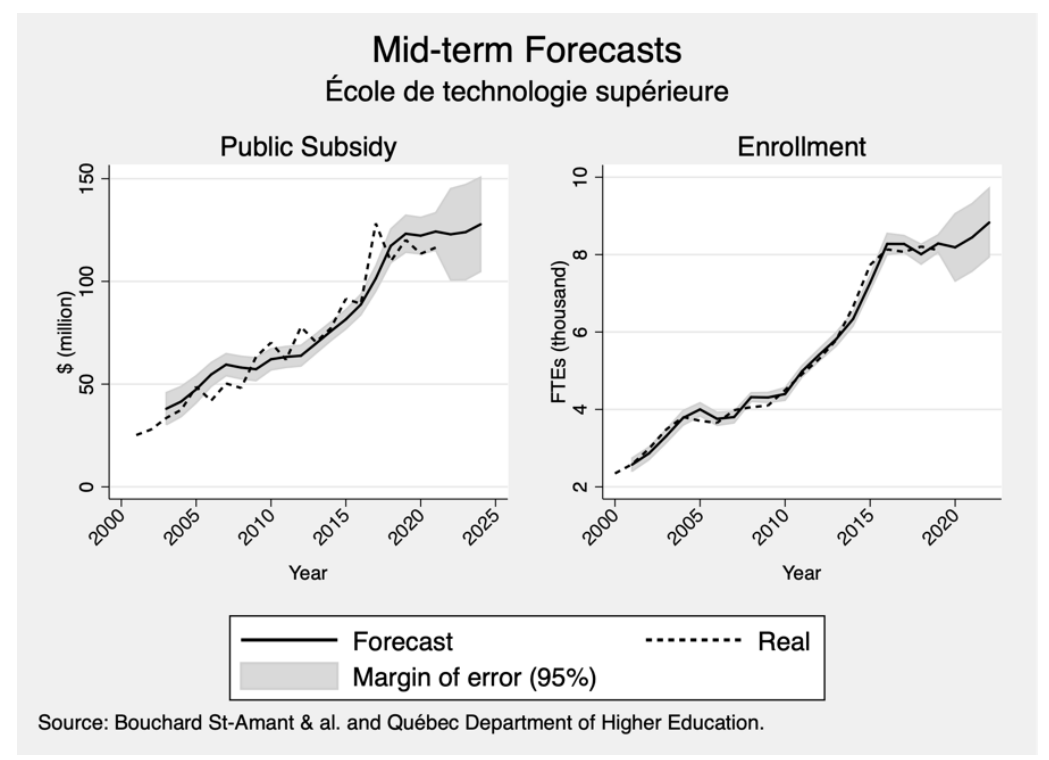

Figure A5. École de technologie supérieure Forecast (Mid-term)

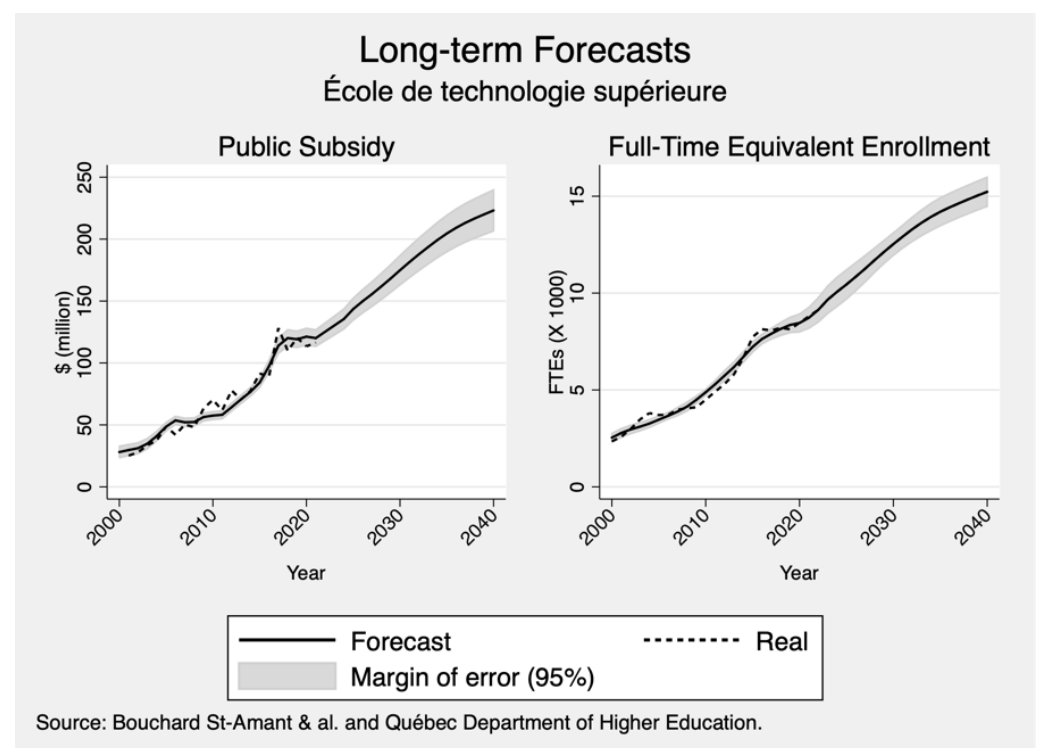

Figure A6. École de technologie supérieure Forecast (Long-term)

$$
\begin{gathered}
F_{t}=3517.31+14.716 F T E_{t-3}+\varepsilon_{t}, \\
F T E_{t-2}=-8663.60+1.2992 F T E_{t-3}-0.5320 F T E_{t-4}+0.0013 p o p_{t-7}+\varepsilon_{t} .
\end{gathered}
$$




\section{A.5 Haute Études Commerciales}

Table A7. Haute Études Commerciales Forecasting Results (Mid-Term)

\begin{tabular}{|c|c|c|c|c|c|}
\hline & & & & \\
\hline & & 2018-2019 & 2019-2020 & 2020-2021 & 2021-2022 \\
\hline \multirow[t]{3}{*}{ FTEs } & 95\% Upper Bound & 9.2078 & 9.3523 & 9.1493 & 9.2180 \\
\hline & Forecast & 8.8807 & 8.7758 & 8.5753 & 8.6229 \\
\hline & 95\% Lower Bound & 8.3887 & 8.1992 & 8.0014 & 8.0278 \\
\hline \multirow[t]{3}{*}{ Subsidy } & $95 \%$ Upper Bound & 84.423 & 88.723 & 86.911 & 92.943 \\
\hline & Forecast & 80.230 & 84.552 & 82.702 & 77.923 \\
\hline & 95\% Lower Bound & 76.037 & 80.381 & 79.286 & 62.903 \\
\hline
\end{tabular}

Source: Authors' calculations and Québec Department of Higher Education.

Table A8. Haute Études Commerciales Forecasting Results (Long-Term)

\begin{tabular}{llrrr} 
& & $2018-2019$ & $2028-2029$ & $2037-2038$ \\
\hline \multirow{2}{*}{ FTEs } & 95\% Upper Bound & 9.0824 & 8.1260 & 8.2082 \\
& Forecast & 8.8444 & 7.8051 & 7.9137 \\
& 95\% Lower Bound & 8.6064 & 7.4842 & 7.6192 \\
\hline \multirow{2}{*}{ Subsidy } & 95\% Upper Bound & 87.096 & 70.528 & 72.235 \\
& Forecast & 83.670 & 68.073 & 69.703 \\
& 95\% Lower Bound & 80.244 & 65.618 & 67.173 \\
\hline
\end{tabular}

Source: Authors' calculations and Québec Department of Higher Education. The year 2038 is used as it is the last available forecast.

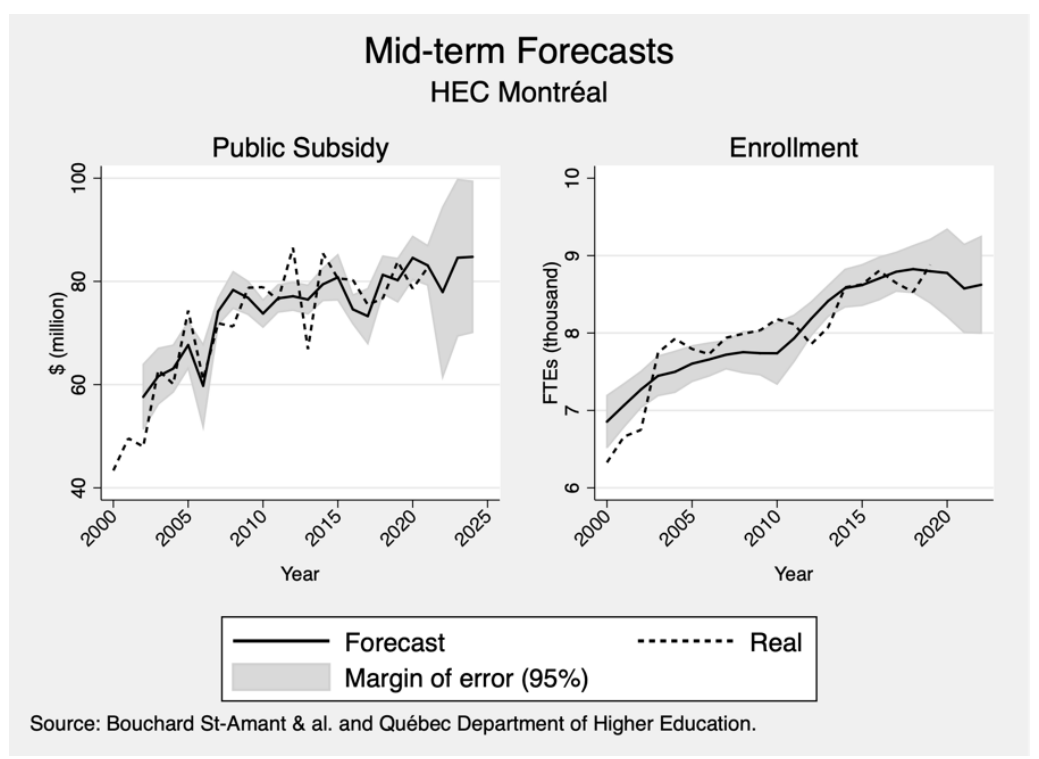

Figure A7. Haute Études Commerciales Forecast (Mid-term) 


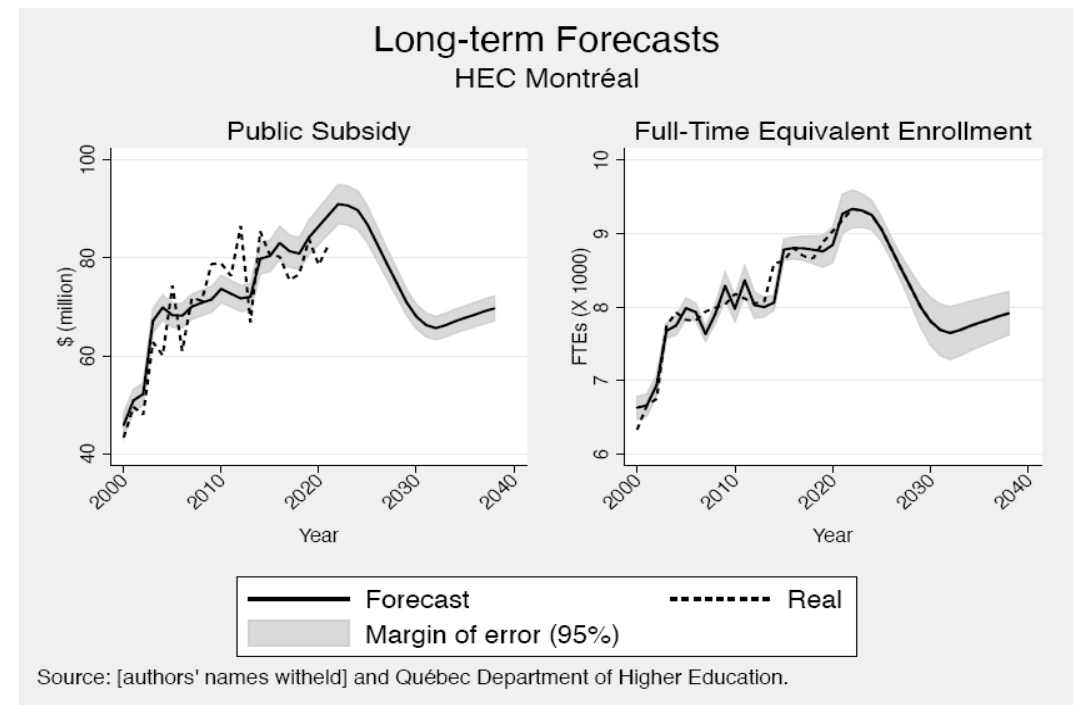

Figure A8. Haute Études Commerciales Forecast (Long-term)

$$
\begin{gathered}
F_{t}=23.110-0.0093 F_{T E E_{t-3}}+0.0161 F T E_{t-4}+\varepsilon_{t}, \\
F T E_{t-2}=-10069.75-47.455 u_{t-3}+0.0111 \text { pop } 18_{t-3}+0.00120 \text { pop }_{t-2}+\varepsilon_{t} .
\end{gathered}
$$

The coefficient associated with $F T E_{t-3}$ is not statistically different from zero.

\section{A.6 Institut National de Recherche Scientifique}

Table A9. Institut National de Recherche Scientifique Forecasting Results (Mid-Term)

\begin{tabular}{llrrrr} 
& & $2018-2019$ & $2019-2020$ & $2020-2021$ & $2021-2022$ \\
\hline FTEs & 95\% Upper Bound & 0.4808 & 0.5049 & 0.4888 & 0.4947 \\
& Forecast & 0.4582 & 0.4696 & 0.4522 & 0.4613 \\
& 95\% Lower Bound & 0.4354 & 0.4343 & 0.4156 & 0.4278 \\
\hline Subsidy & 95\% Upper Bound & 53.828 & 59.795 & 60.068 & 65.036 \\
& Forecast & 52.105 & 57.308 & 58.955 & 58.899 \\
& 95\% Lower Bound & 50.383 & 54.822 & 55.353 & 52.762 \\
\hline
\end{tabular}

Source: Authors' calculations and Québec Department of Higher Education.

Table A10. Institut National de Recherche Scientifique Forecasting Results (Long-Term)

\begin{tabular}{llrrr} 
& & $2018-2019$ & $2028-2029$ & $2037-2038$ \\
\hline \multirow{2}{*}{ FTEs } & 95\% Upper Bound & 471.60 & 490.66 & 635.35 \\
& Forecast & 450.85 & 525.82 & 607.23 \\
& 95\% Lower Bound & 430.09 & 560.97 & 579.10 \\
\hline Subsidy & 95\% Upper Bound & 29240.93 & 36898.37 & 40440.84 \\
& Forecast & 27528.73 & 34064.98 & 36007.07 \\
& 95\% Lower Bound & 25816.52 & 31231.59 & 31573.31 \\
\hline
\end{tabular}

Source: Authors' calculations and Québec Department of Higher Education. Year 2038 is used as the last forecast since the variable choice prevents 2039 to be forecasted. 


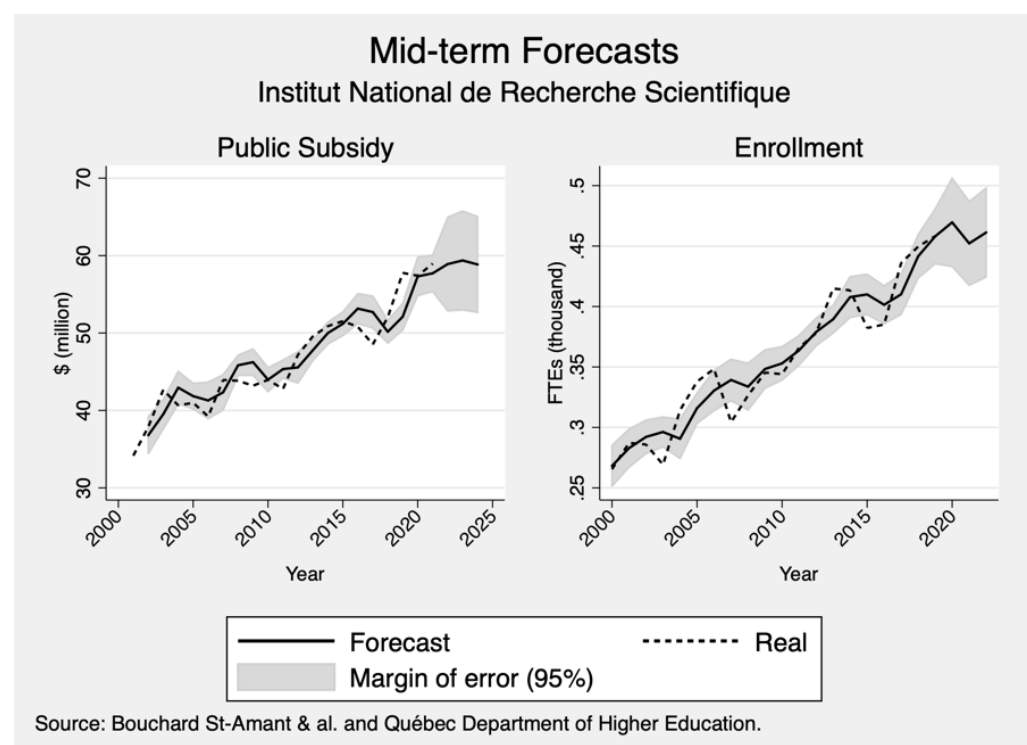

Figure A9. Institut National de Recherche Scientifique Forecast (Mid-term)

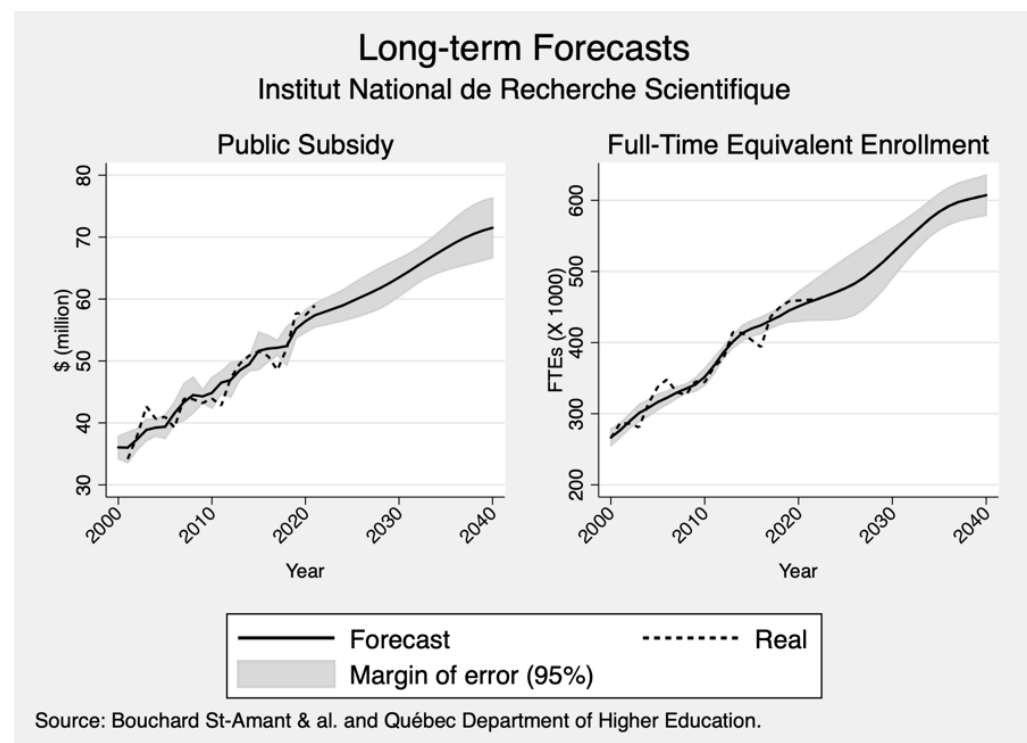

Figure A10. Institut National de Recherche Scientifique Forecast (Long-term)

$$
\begin{gathered}
F_{t}=8217.29+0.5185 F_{t-1}+\varepsilon_{t}, \\
F T E_{t-2}=-387.85+0.0001 \text { Pop }_{t-5}+\varepsilon_{t} .
\end{gathered}
$$




\section{A.7 McGill University}

Table A11. McGill University Forecasting Results (Mid-Term)

\begin{tabular}{llrrrr} 
& & $2018-2019$ & $2019-2020$ & $2020-2021$ & $2021-2022$ \\
\hline \multirow{2}{*}{ FTEs } & 95\% Upper Bound & 27.260 & 34.537 & 36.551 & 37.265 \\
& Forecast & 26.405 & 30.816 & 32.848 & 33.698 \\
& 95\% Lower Bound & 22.926 & 27.094 & 29.146 & 30.131 \\
\hline Subsidy & 95\% Upper Bound & 372.03 & 384.87 & 373.31 & 435.74 \\
& Forecast & 354.96 & 367.68 & 375.70 & 357.42 \\
& 95\% Lower Bound & 337.94 & 350.47 & 317.73 & 279.09 \\
\hline
\end{tabular}

Source: Authors' calculations and Québec Department of Higher Education.

Table A12. McGill University Forecasting Results (Long-Term)

\begin{tabular}{llrrr} 
& & $2018-2019$ & $2028-2029$ & $2037-2038$ \\
\hline \multirow{2}{*}{ FTEs } & 95\% Upper Bound & 32.477 & 43.060 & 46.820 \\
& Forecast & 30.852 & 40.552 & 43.823 \\
& 95\% Lower Bound & 29.228 & 30.06 & 40.83 \\
\hline \multirow{2}{*}{ Subsidy } & 95\% Upper Bound & 373.13 & 585.07 & 656.83 \\
& Forecast & 350.64 & 526.72 & 506.11 \\
& 95\% Lower Bound & 328.14 & 468.37 & 515.38 \\
\hline
\end{tabular}

Source: Authors' calculations and Québec Department of Higher Education. Year 2038 is used as the last forecast since the variable choice prevents 2039 to be forecasted.

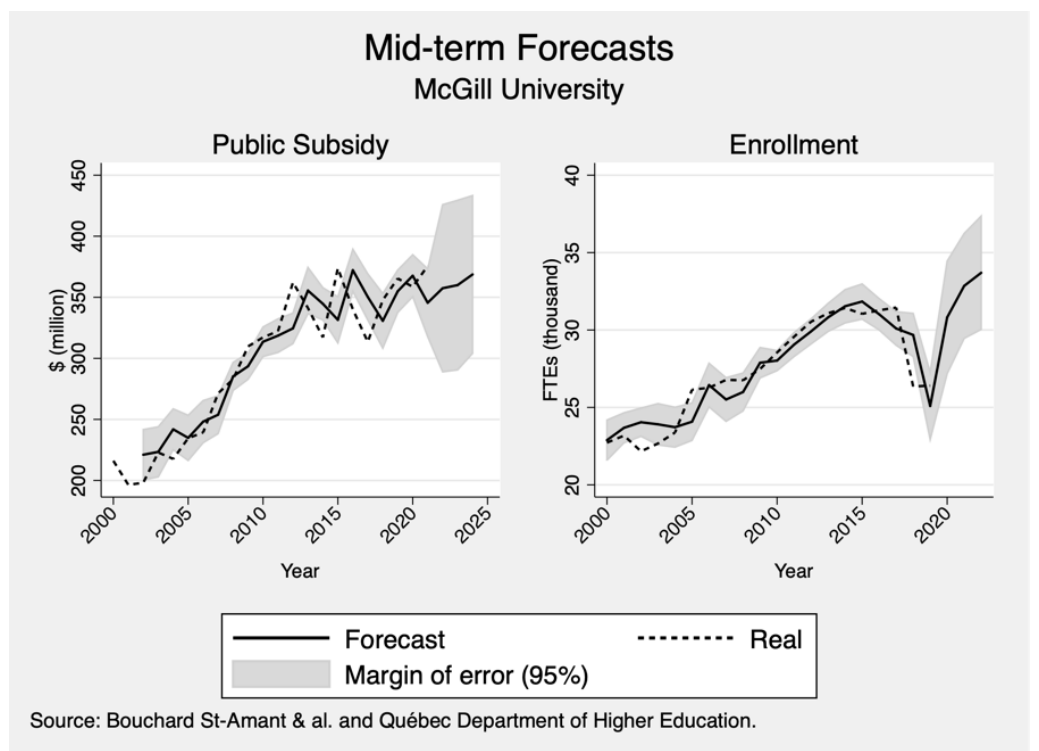

Figure A11. McGill University Forecast (Mid-term) 


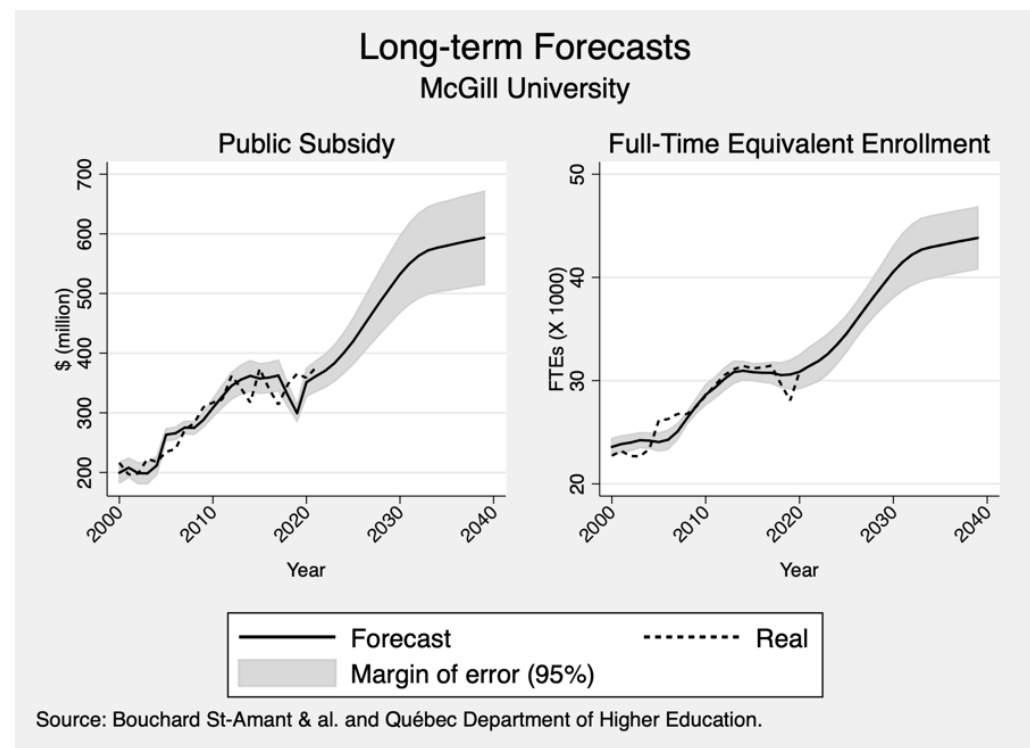

Figure A12. McGill University Forecast (Long-term)

$$
\begin{gathered}
F_{t}=10.194+0.6838 F_{t-1}+0.0034 F T E_{t-3}+\varepsilon_{t} \\
F T E_{t-2}=-31891.64+0.8532 F T E_{t-3}+0.001 \text { Pop }_{t-6}+1235.16 u_{t}+\varepsilon_{t} .
\end{gathered}
$$

\section{A.8 Polytechnique Montréal}

Table A13. Polytechnique Montréal Forecasting Results (Mid-Term)

\begin{tabular}{llrrrr} 
& & $2018-2019$ & $2019-2020$ & $2020-2021$ & $2021-2022$ \\
\hline \multirow{2}{*}{ FTEs } & 95\% Upper Bound & 7.7232 & 8.0969 & 8.3245 & 8.5074 \\
& Forecast & 7.1978 & 7.5390 & 7.7979 & 7.9538 \\
& 95\% Lower Bound & 6.6724 & 6.9810 & 7.2712 & 7.4003 \\
\hline Subsidy & 95\% Upper Bound & 111.12 & 105.54 & 125.57 & 129.33 \\
& Forecast & 106.00 & 104.84 & 106.49 & 110.26 \\
& 95\% Lower Bound & 100.88 & 96.433 & 87.409 & 91.199 \\
\hline
\end{tabular}

Source: Authors' calculations and Québec Department of Higher Education.

Table A14. Polytechnique Montréal Forecasting Results (Long-Term)

\begin{tabular}{llrrr} 
& & $2018-2019$ & $2028-2029$ & $2038-2039$ \\
\cline { 3 - 5 } FTEs & 95\% Upper Bound & 7.3449 & 10.167 & 12.048 \\
& Forecast & 7.0897 & 9.4814 & 11.044 \\
& 95\% Lower Bound & 6.8345 & 8.7962 & 10.040 \\
\hline Subsidy & 95\% Upper Bound & 104.50 & 156.79 & 188.77 \\
& Forecast & 101.68 & 149.65 & 178.61 \\
& 95\% Lower Bound & 98.868 & 142.50 & 168.46 \\
\hline
\end{tabular}

Source: Authors' calculations and Québec Department of Higher Education. 


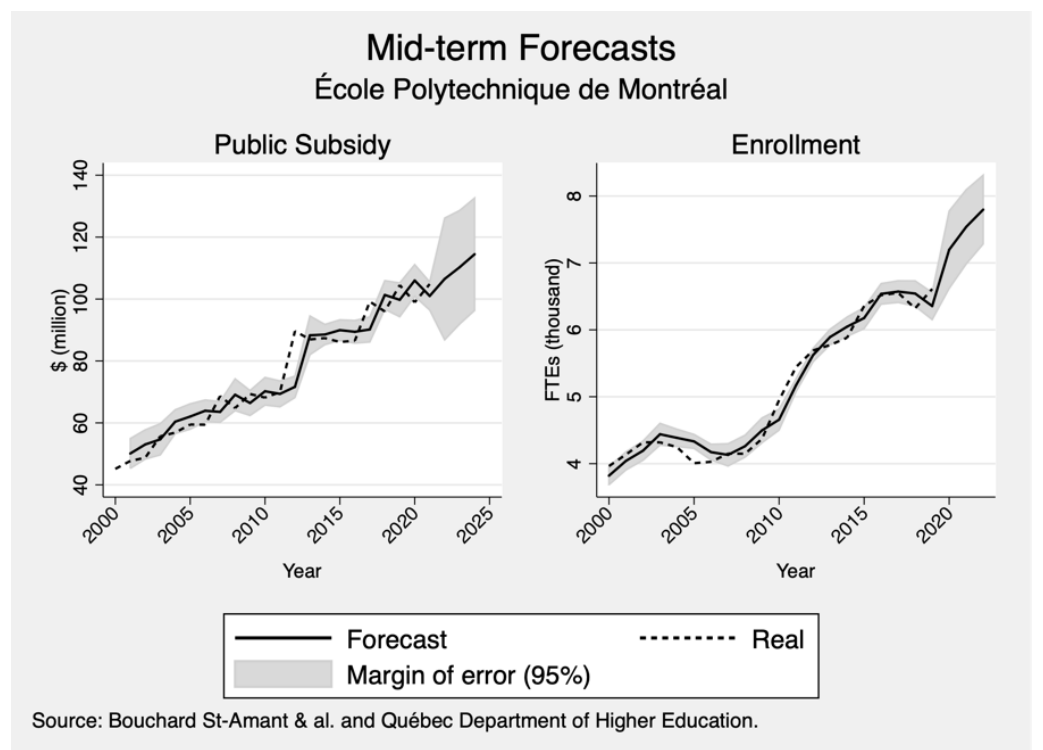

Figure A13. Polytechnique Montréal Forecast (Mid-term)

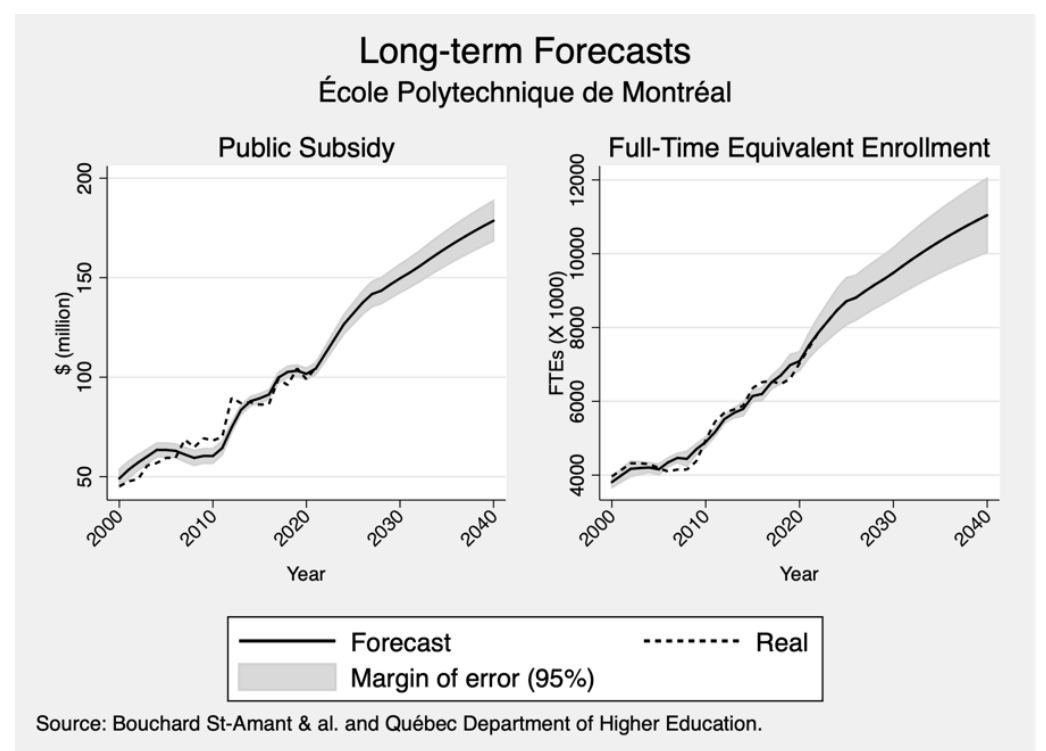

Figure A14. Polytechnique Montréal Forecast (Long-term)

$$
\begin{gathered}
F_{t}=2.2841+0.7149 F_{t-1}+0.0044 F T E_{t-1}+\varepsilon_{t}, \\
F T E_{t-2}=-7604.566+0.7975 F T E_{t-3}+0.001 \text { pop }_{t-7}+134.43 u_{t-3}+\varepsilon_{t} .
\end{gathered}
$$




\section{A.9 Université de Montréal}

Table A15. Université de Montréal Forecasting Results (Mid-Term)

\begin{tabular}{llrrrr} 
& & $2018-2019$ & $2019-2020$ & $2020-2021$ & $2021-2022$ \\
\hline \multirow{2}{*}{ FTEs } & 95\% Upper Bound & 38.300 & 43.340 & 45.084 & 46.193 \\
& Forecast & 38.115 & 42.055 & 43.846 & 44.909 \\
& 95\% Lower Bound & 36.995 & 40.770 & 42.609 & 43.625 \\
\hline Subsidy & $95 \%$ Upper Bound & 578.05 & 586.64 & 582.13 & 637.67 \\
& Forecast & 558.68 & 570.07 & 582.63 & 575.82 \\
& 95\% Lower Bound & 539.30 & 553.49 & 545.13 & 513.96 \\
\hline
\end{tabular}

Source: Authors' calculations and Québec Department of Higher Education.

Table A16. Université de Montréal Forecasting Results (Long-Term)

\begin{tabular}{llrrr} 
& & $2018-2019$ & $2028-2029$ & $2038-2039$ \\
\hline \multirow{2nyyy}{*}{ FTEs } & 95\% Upper Bound & 41.880 & 49.674 & 54.039 \\
& Forecast & 40.709 & 47.524 & 51.036 \\
& 95\% Lower Bound & 39.537 & 45.376 & 48.034 \\
\hline Subsidy & 95\% Upper Bound & 586.42 & 748.51 & 832.42 \\
& Forecast & 560.77 & 706.10 & 780.97 \\
& 95\% Lower Bound & 535.12 & 663.70 & 729.52 \\
\hline
\end{tabular}

Source: Authors' calculations and Québec Department of Higher Education.

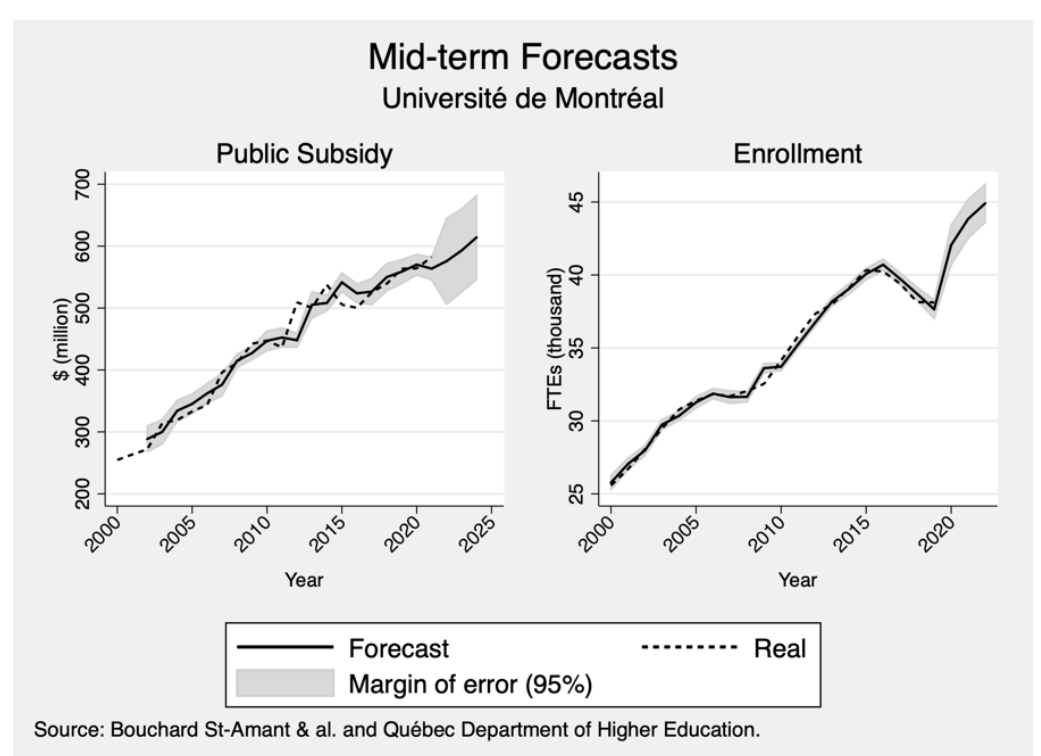

Figure A15. Université de Montréal Forecast (Mid-term) 


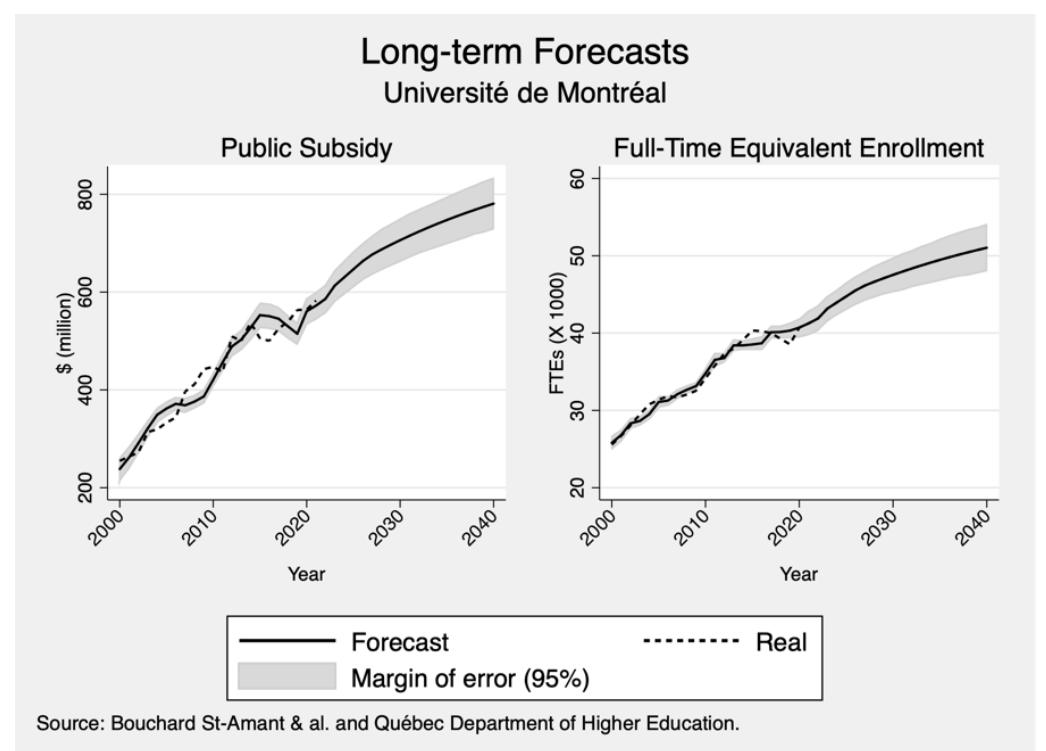

Figure A16. Université de Montréal Forecast (Long-term)

$$
\begin{gathered}
F_{t}=-21479.04+0.6658 F_{t-1}+\varepsilon_{t}, \\
F T E_{t-2}=-35321.80+0.7855 F T E_{t-1}+0.0046 \text { Pop }_{t-6}+1006.78 u_{t}+\varepsilon_{t} .
\end{gathered}
$$

\section{A.10 Université de Sherbrooke}

See the main text for the short-term forecasting model and projections.

Table A17. Université de Sherbrooke Forecasting Results (Long-Term)

\begin{tabular}{llrrr} 
& & $2018-2019$ & $2028-2029$ & $2038-2039$ \\
\hline \multirow{7}{*}{ FTEs } & 95\% Upper Bound & 21.729 & 25.061 & 27.209 \\
& Forecast & 21.290 & 24.046 & 25.737 \\
& 95\% Lower Bound & 20.851 & 23.032 & 24.265 \\
\hline Subsidy & 95\% Upper Bound & 300.63 & 377.17 & 418.49 \\
& Forecast & 290.03 & 360.75 & 398.81 \\
& 95\% Lower Bound & 279.43 & 344.34 & 379.14 \\
\hline
\end{tabular}

Source: Authors' calculations and Québec Department of Higher Education. 


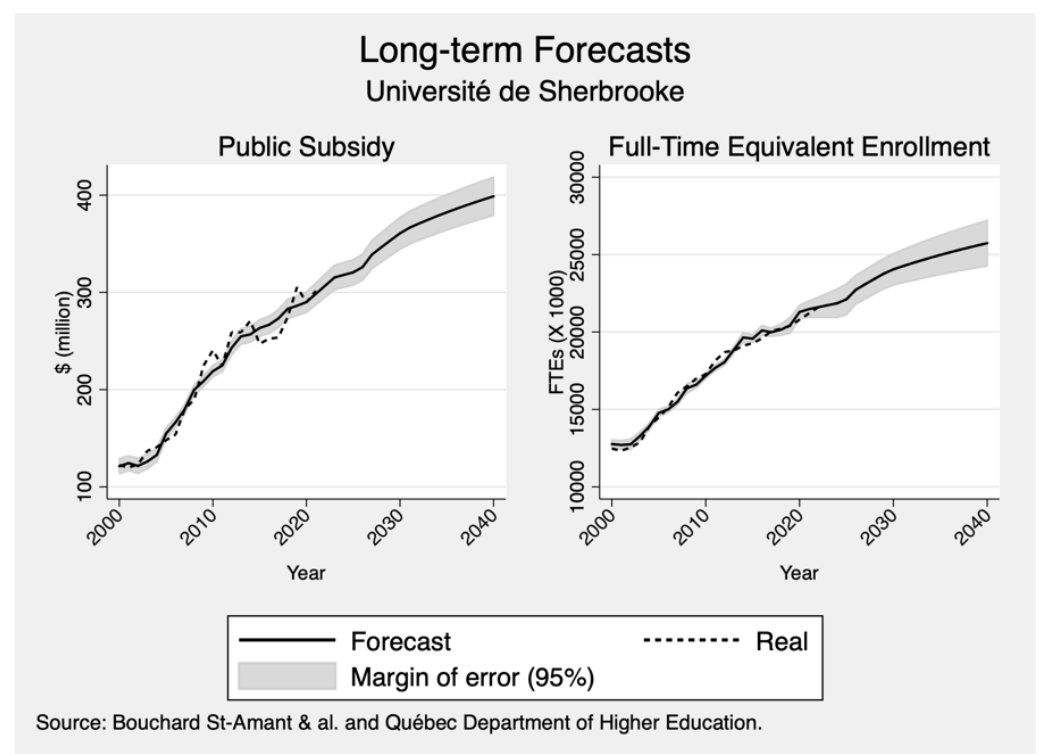

Figure A17. Université de Sherbrooke Forecast (Long-term)

$$
\begin{gathered}
F_{t}=-97.0369+0.0325 F T E_{t-1}-0.0132 F T E_{t-2}+\varepsilon_{t}, \\
F T E_{t-2}=-3188.33+0.9723 F T E_{t-3}+0.0004 F T E_{t-4}+125.8219 u_{t-3}+\varepsilon_{t} .
\end{gathered}
$$

\section{A.11 Université Laval}

Table A18. Université Laval Forecasting Results (Mid-Term)

\begin{tabular}{llrrrr} 
& & $2018-2019$ & $2019-2020$ & $2020-2021$ & $2021-2022$ \\
\hline FTEs & 95\% Upper Bound & 33.044 & 34.029 & 36.593 & 38.983 \\
& Forecast & 32.951 & 32.273 & 35.855 & 38.218 \\
& 95\% Lower Bound & 32.367 & 35.117 & 37.452 & 37.452 \\
\hline Subsidy & $95 \%$ Upper Bound & 468.35 & 489.05 & 472.48 & 517.34 \\
& Forecast & 447.54 & 471.42 & 465.11 & 462.84 \\
& 95\% Lower Bound & 426.73 & 453.77 & 441.06 & 408.33 \\
\hline
\end{tabular}

Source: Authors' calculations and Québec Department of Higher Education.

Table A19. Université Laval Forecasting Results (Long-Term)

\begin{tabular}{llrrr} 
& & $2018-2019$ & $2028-2029$ & $2038-2039$ \\
\hline \multirow{2}{*}{ FTEs } & 95\% Upper Bound & 35.080 & 40.330 & 44.653 \\
& Forecast & 34.336 & 39.278 & 43.579 \\
& 95\% Lower Bound & 33.593 & 38.226 & 42.505 \\
\hline Subsidy & 95\% Upper Bound & 465.74 & 591.68 & 702.38 \\
& Forecast & 444.40 & 551.57 & 645.05 \\
& 95\% Lower Bound & 423.06 & 511.68 & 587.61 \\
\hline
\end{tabular}

Source: Authors' calculations and Québec Department of Higher Education. 


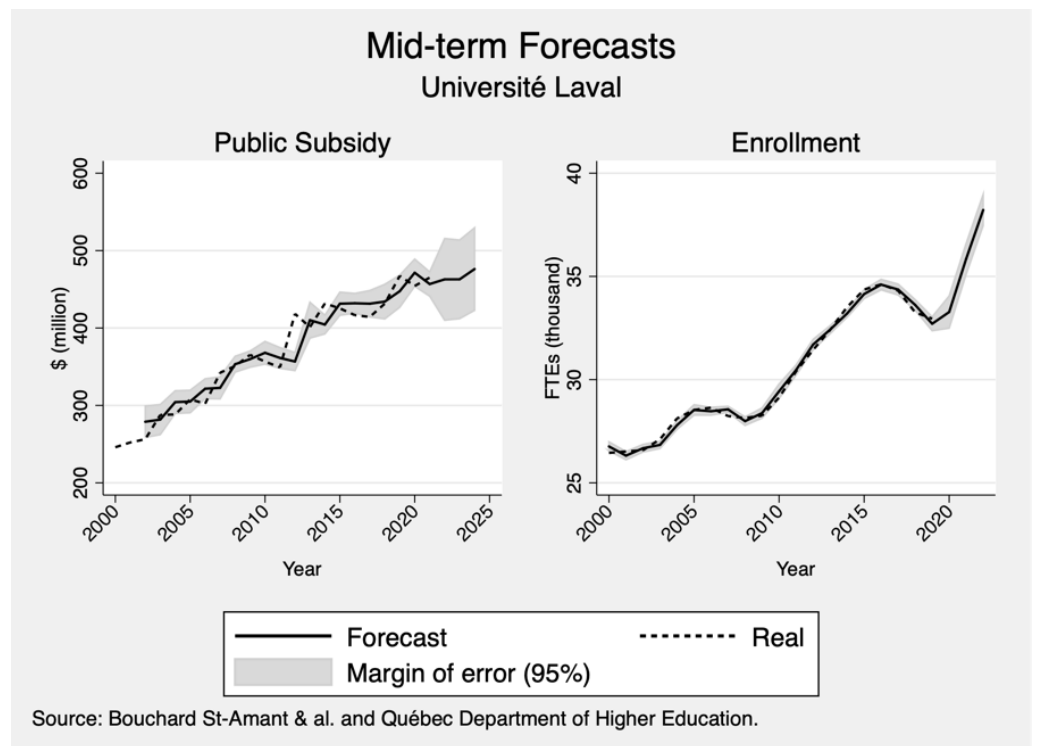

Figure A18. Université Laval Forecast (Mid-term)

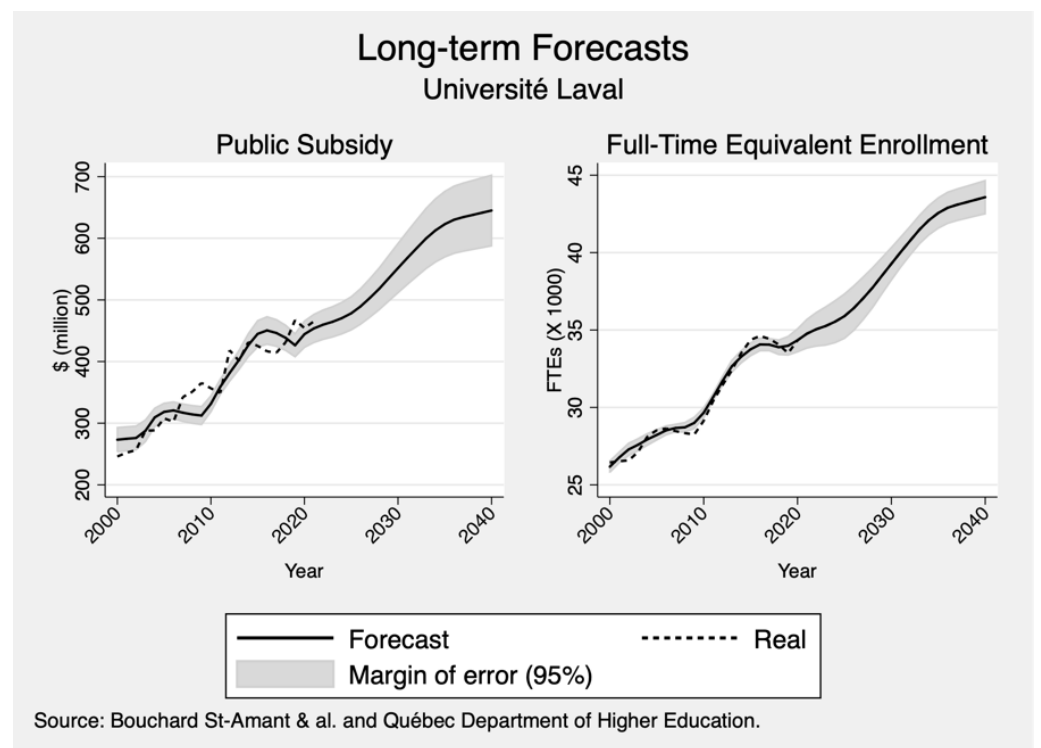

Figure A19. Université Laval Forecast (Long-term)

$$
\begin{gathered}
F_{t}=-35.576+0.0051 F_{T T E_{t-3}}+0.7078 * F_{t-1}+\varepsilon_{t} \\
F T E_{t-2}=-28841.98+388.41 u_{t-3}+0.00543 \text { pop }_{t-5}+1.0926 F T E_{t-3}-0.6304 F T E_{t-4}+\varepsilon_{t}
\end{gathered}
$$




\section{A.12 Université du Québec System}

Table A20. Université du Québec System Forecasting Results (Mid-Term)

\begin{tabular}{llrrrr} 
& & $2018-2019$ & $2019-2020$ & $2020-2021$ & $2021-2022$ \\
\hline \multirow{2}{*}{ FTEs } & $95 \%$ Upper Bound & 70.309 & 70.884 & 70.669 & 69.538 \\
& Forecast & 67.314 & 67.965 & 67.792 & 66.775 \\
& 95\% Lower Bound & 64.319 & 65.046 & 64.915 & 64.011 \\
Subsidy & $95 \%$ Upper Bound & 993.04 & 991.84 & 1010.23 & 1040.84 \\
& Forecast & 963.81 & 992.81 & 920.59 & 951.38 \\
& 95\% Lower Bound & 934.59 & 933.59 & 830.95 & 861.93 \\
\hline
\end{tabular}

Source: Authors' calculations and Québec Department of Higher Education.

Table A21. Université du Québec System Forecasting Results (Long-Term)

\begin{tabular}{llrrr} 
& & $2018-2019$ & $2028-2029$ & $2038-2039$ \\
\cline { 3 - 5 } FTEs & 95\% Upper Bound & 71.600 & 84.959 & 95.787 \\
& Forecast & 69.693 & 82.413 & 93.206 \\
& 95\% Lower Bound & 67.786 & 79.866 & 90.624 \\
Subsidy & $95 \%$ Upper Bound & 977.02 & 1270.23 & 1519.66 \\
& Forecast & 926.73 & 1186.25 & 1406.45 \\
& 95\% Lower Bound & 876.44 & 1102.29 & 1293.25 \\
\hline
\end{tabular}

Source: Authors' calculations and Québec Department of Higher Education.

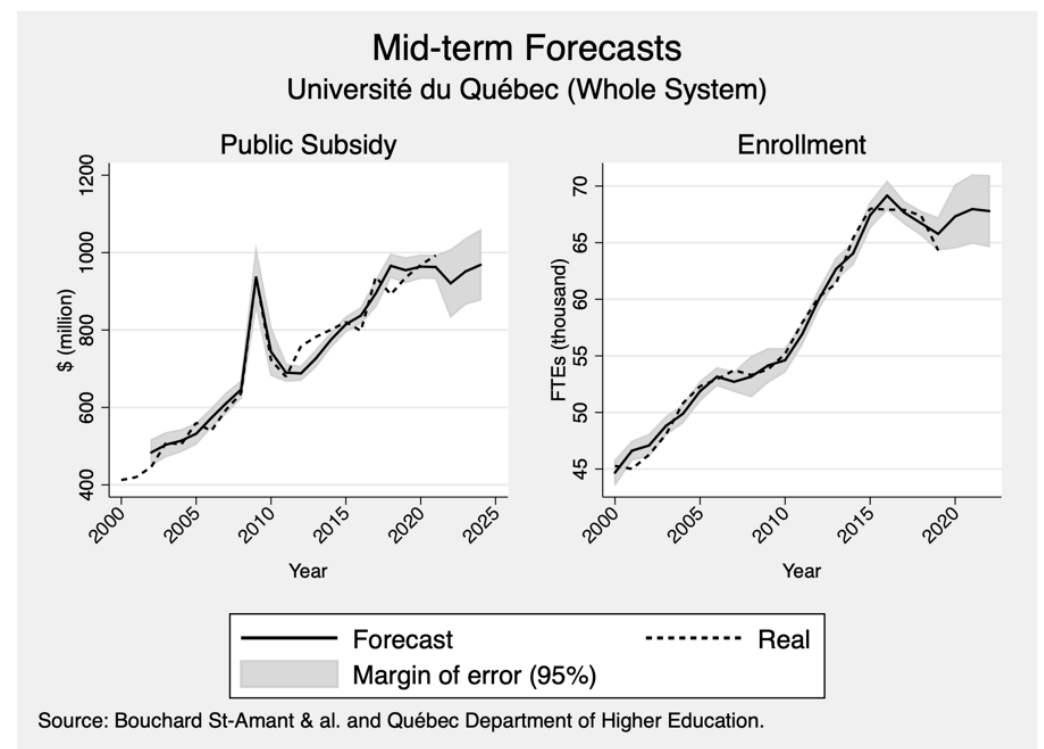

Figure A20. Université du Québec System Forecast (Mid-term) 


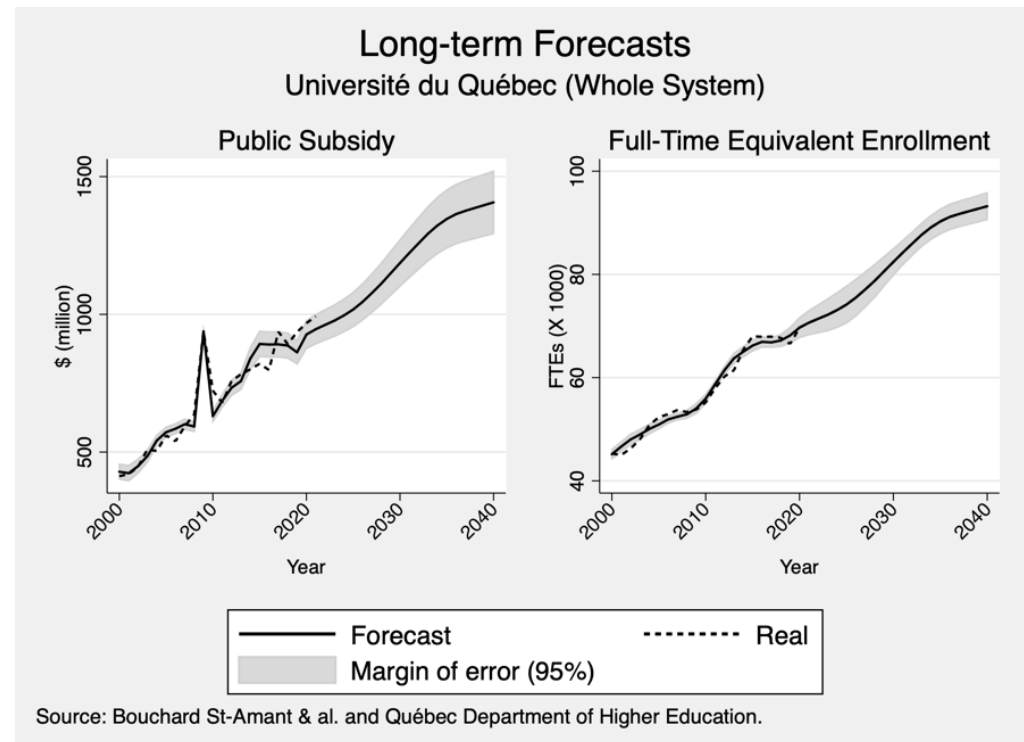

Figure A21. Université du Québec System Forecast (Long-term)

$$
\begin{gathered}
F_{t}=-299023+0.2204 F_{t-1}+15.562 F T E_{t-3}+271096 \mathrm{~F}_{2009=0}+\varepsilon_{t} \\
F T E_{t-2}=-75114+0.0007 F_{t-3}+0.78536 F T E_{t-3}+0.0049 \text { Pop }_{t-6}+0.5219 \text { Pop } 18_{t-6}+\cdots \\
\ldots+963.76 u_{t-2}+\varepsilon_{t}
\end{gathered}
$$

\section{A.13 Université du Québec à Chicoutimi}

Table A22. Université du Québec à Chicoutimi Forecasting Results (Mid-Term)

\begin{tabular}{llrrrr} 
& & $2018-2019$ & $2019-2020$ & $2020-2021$ & $2021-2022$ \\
\hline \multirow{2}{*}{ FTEs } & 95\% Upper Bound & 5.0763 & 5.0965 & 5.6110 & 5.6843 \\
& Forecast & 4.9828 & 5.0111 & 5.5200 & 5.5987 \\
& 95\% Lower Bound & 4.8894 & 4.9257 & 5.4289 & 5.5131 \\
\hline \multirow{3}{*}{ Subsidy } & $95 \%$ Upper Bound & 92.534 & 88.291 & 95.611 & 95.215 \\
& Forecast & 87.878 & 85.317 & 84.864 & 84.825 \\
& 95\% Lower Bound & 83.224 & 80.661 & 74.117 & 74.436 \\
\hline
\end{tabular}

Source: Authors' calculations and Québec Department of Higher Education.

Table A23. Université du Québec à Chicoutimi Forecasting Results (Long-Term)

\begin{tabular}{llrrr} 
& & $2018-2019$ & $2028-2029$ & $2038-2039$ \\
\hline FTEs & 95\% Upper Bound & 5.3873 & 6.2055 & 6.7944 \\
& Forecast & 5.2813 & 6.0045 & 6.5101 \\
& 95\% Lower Bound & 5.1752 & 5.8034 & 6.2258 \\
\hline Subsidy & 95\% Upper Bound & 89.135 & 117.91 & 139.87 \\
& Forecast & 84.425 & 109.54 & 128.60 \\
& 95\% Lower Bound & 79.716 & 101.17 & 117.33 \\
\hline
\end{tabular}

Source: Authors' calculations and Québec Department of Higher Education. 


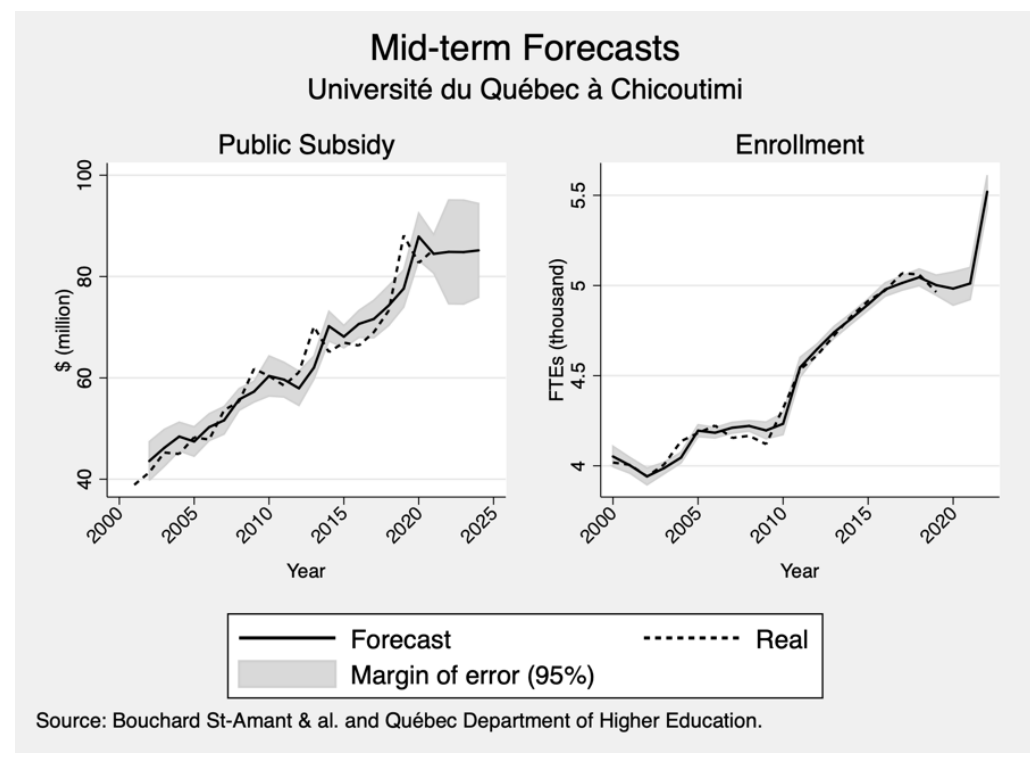

Figure A22. Université du Québec à Chicoutimi Forecast (Mid-term)

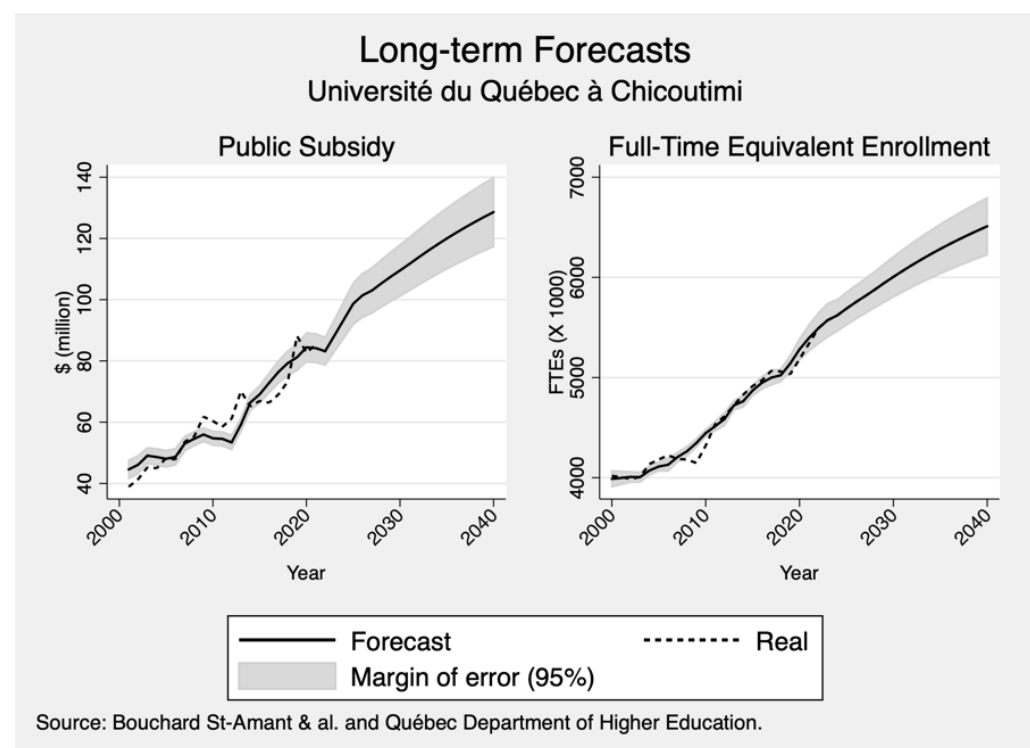

Figure A23. Université du Québec à Chicoutimi Forecast (Long-term)

$$
\begin{gathered}
F_{t}=-29.231+0.6105 F_{t-1}+0.1251 F T E_{t-1}+\varepsilon_{t} \\
F T E_{t-2}=-5681.291+0.3964 \text { FTE }_{t-1}+0.001 \text { Pop }_{t-4}+110.6882 u_{t-2}+\varepsilon_{t}
\end{gathered}
$$




\section{A.14 Université du Québec à Montréal}

Table A24. Université du Québec à Montréal Forecasting Results (Mid-Term)

\begin{tabular}{llrrrr} 
& & $2018-2019$ & $2019-2020$ & $2020-2021$ & $2021-2022$ \\
\hline FTEs & 95\% Upper Bound & 27.618 & 27.042 & 26.173 & 25.168 \\
& Forecast & 25.840 & 25.197 & 24.313 & 23.193 \\
& 95\% Lower Bound & 24.061 & 23.352 & 22.453 & 21.218 \\
\hline \multirow{5}{*}{ Subsidy } & 95\% Upper Bound & 325.86 & 299.14 & 326.12 & 322.70 \\
& Forecast & 313.35 & 321.04 & 272.67 & 268.93 \\
& 95\% Lower Bound & 300.85 & 278.55 & 219.23 & 215.15 \\
\hline
\end{tabular}

Source: Authors' calculations and Québec Department of Higher Education.

Table A25. Université du Québec à Montréal Forecasting Results (Long-Term)

\begin{tabular}{llrrr} 
& & $2018-2019$ & $2028-2029$ & $2038-2039$ \\
\hline FTEs & 95\% Upper Bound & 28.667 & 31.891 & 35.391 \\
& Forecast & 27.704 & 30.604 & 34.086 \\
& 95\% Lower Bound & 26.740 & 29.317 & 32.781 \\
\hline \multirow{2}{*}{ Subsidy } & 95\% Upper Bound & 316.72 & 415.48 & 535.43 \\
& Forecast & 293.93 & 373.05 & 468.04 \\
& 95\% Lower Bound & 271.14 & 330.62 & 400.66 \\
\hline
\end{tabular}

Source: Authors' calculations and Québec Department of Higher Education.

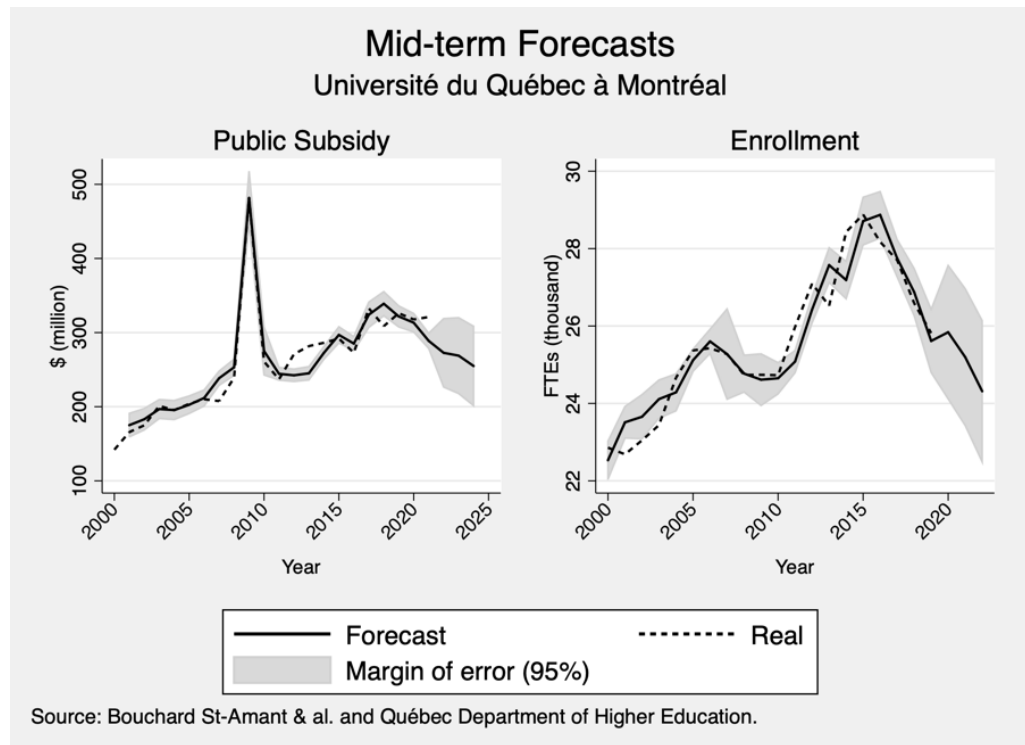

Figure A24. Université du Québec à Montréal Forecast (Mid-term) 


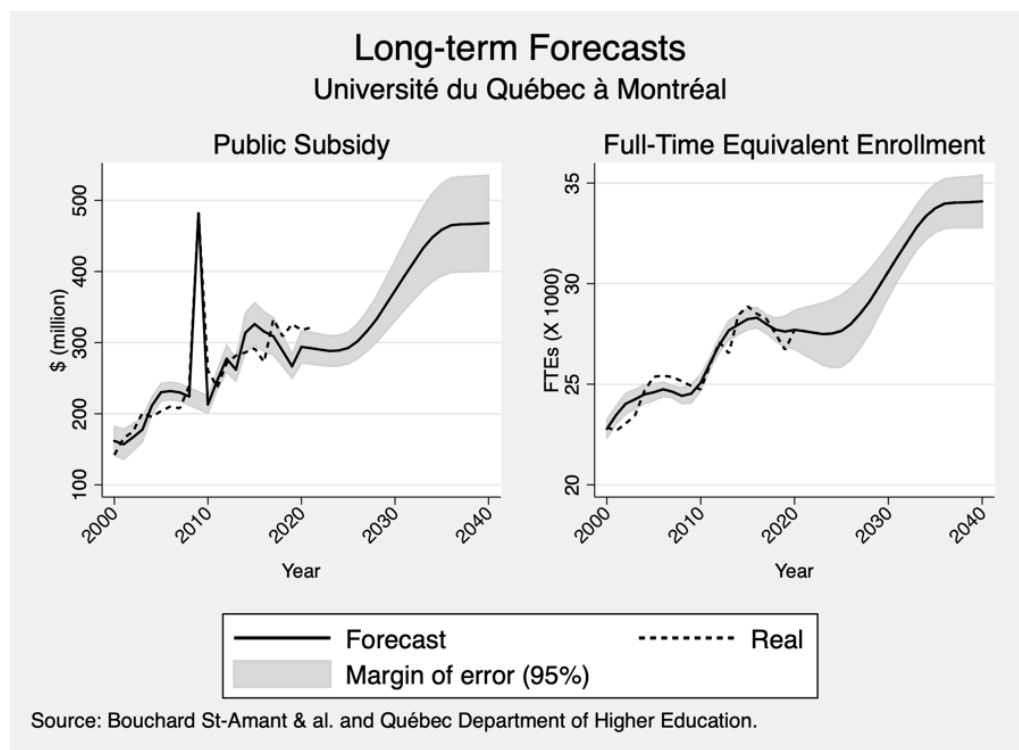

Figure A25. Université du Québec à Montréal Forecast (Long-term)

$$
\begin{gathered}
F_{t}=-305.5902+0.0873 F_{t-1}+0.0213 F T E_{t-1}+224.5116 F_{2009=0}+\varepsilon_{t} \\
F T E_{t-2}=-19553.13+0.7859 F T E_{t-1}+0.02874 P o p 18_{t-4}+110.6882 u_{t}+258.6426 F_{2009}+\varepsilon_{t}
\end{gathered}
$$

\section{A.15 Université du Québec à Rimouski}

Table A26. Université du Québec à Rimouski Forecasting Results (Mid-Term)

\begin{tabular}{llrrrr} 
& & $2018-2019$ & $2019-2020$ & $2020-2021$ & $2021-2022$ \\
\hline \multirow{2}{*}{ FTEs } & 95\% Upper Bound & 4.1275 & 4.5695 & 4.9806 & 5.2666 \\
& Forecast & 3.9199 & 4.2666 & 4.6534 & 4.9439 \\
& 95\% Lower Bound & 3.8211 & 3.9638 & 4.3261 & 4.6212 \\
Subsidy & $95 \%$ Upper Bound & 72.743 & 69.349 & 65.985 & 71.005 \\
& Forecast & 68.705 & 65.825 & 73.242 & 60.045 \\
& 95\% Lower Bound & 64.666 & 62.300 & 59.847 & 49.086 \\
\hline
\end{tabular}

Source: Authors' calculations and Québec Department of Higher Education.

Table A27. Université du Québec à Rimouski Forecasting Results (Long-Term)

\begin{tabular}{llrrr} 
& & $2018-2019$ & $2028-2029$ & $2038-2039$ \\
\hline \multirow{2}{*}{ FTEs } & 95\% Upper Bound & 4.8198 & 6.1169 & 7.0888 \\
& Forecast & 4.5607 & 5.8358 & 6.7342 \\
& 95\% Lower Bound & 4.3016 & 5.5547 & 6.3795 \\
\hline Subsidy & 95\% Upper Bound & 69.893 & 96.341 & 123.95 \\
& Forecast & 64.791 & 86.184 & 108.41 \\
& 95\% Lower Bound & 59.689 & 76.026 & 92.876 \\
\hline
\end{tabular}

Source: Authors' calculations and Québec Department of Higher Education. 


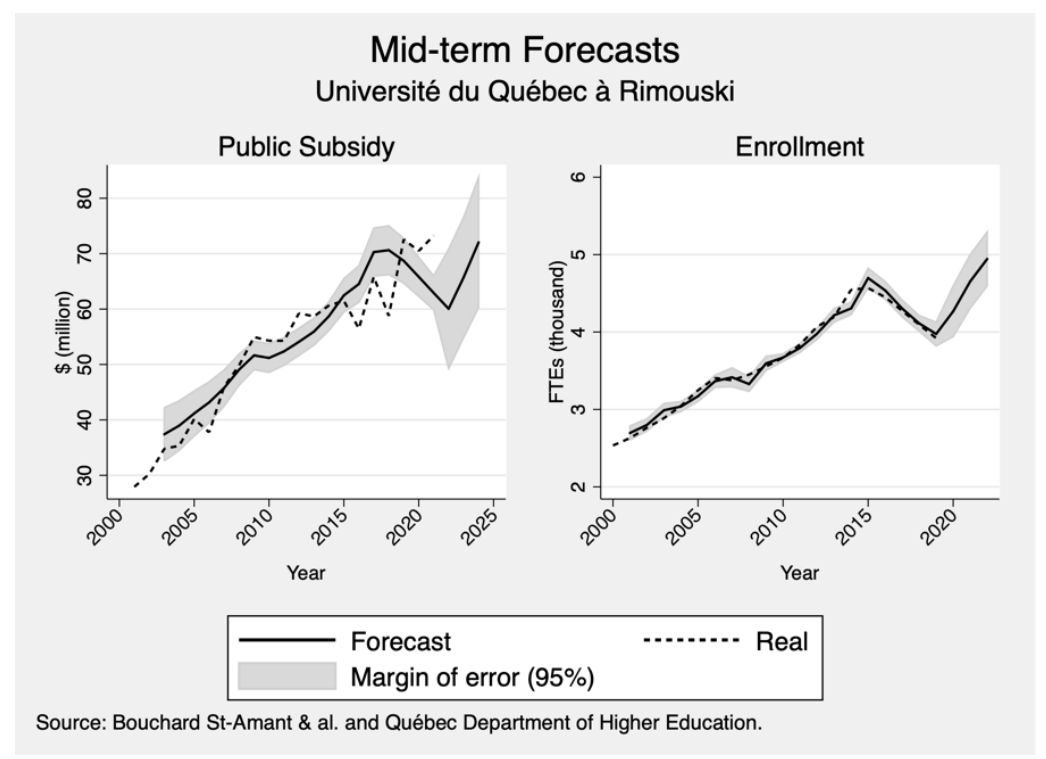

Figure A26. Université du Québec à Rimouski Forecast (Mid-term)

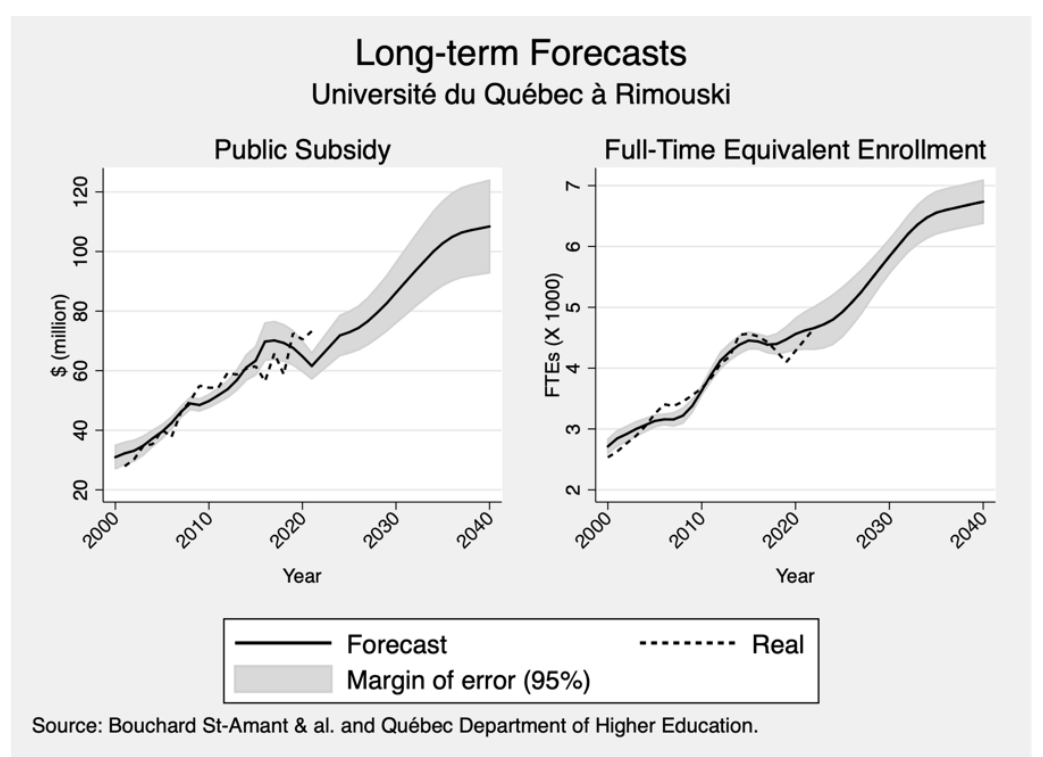

Figure A27. Université du Québec à Rimouski Forecast (Long-term)

$$
\begin{gathered}
F_{t}=-4010.347+16.3409 F T E_{t-3}+\varepsilon_{t} \\
F T E_{t-2}=-4053.388+1.2214 F T E_{t-3}-0.4488 F T E_{t-4}+0.0005 p o p_{t-6}+94.821 u_{t-2}+\varepsilon_{t}
\end{gathered}
$$

Coefficients associated with $u_{t-2}$ and $F T E_{t-3}$ are not statistically different from zero. 


\section{A.16 Université du Québec en Abitibi-Temiscamingue}

See the main text for the short-term forecasting model and projections.

Table A28. Université du Québec en Abitibi-Temiscamingue Forecasting Results (Long-Term)

\begin{tabular}{llrrr} 
& & $2018-2019$ & $2028-2029$ & $2038-2039$ \\
\hline \multirow{2}{*}{ FTEs } & $95 \%$ Upper Bound & 2.4565 & 2.9074 & 3.1995 \\
& Forecast & 2.3631 & 2.8060 & 3.0716 \\
& 95\% Lower Bound & 2.2696 & 2.7046 & 2.9437 \\
\hline \multirow{2}{*}{ Subsidy } & $95 \%$ Upper Bound & 47.015 & 69.587 & 75.243 \\
& Forecast & 45.103 & 65.760 & 70.916 \\
& 95\% Lower Bound & 43.191 & 61.933 & 66.589 \\
\hline
\end{tabular}

Source: Authors' calculations and Québec Department of Higher Education.

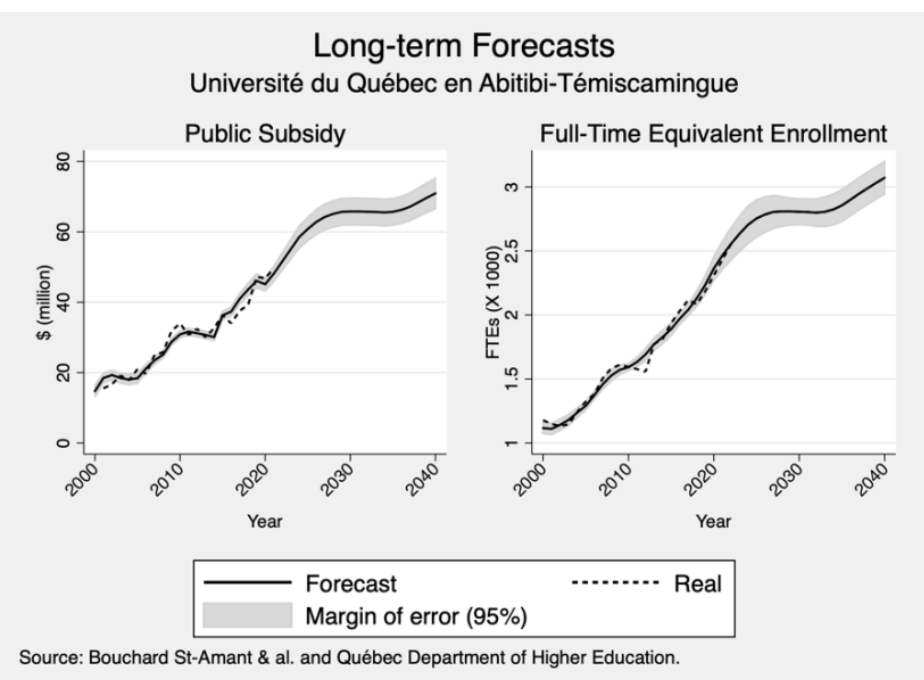

Figure A28. Université du Québec en Abitibi-Temiscamingue Forecast (Long-term)

$$
\begin{gathered}
F_{t}=-10.4856+0.0273 F T E_{t-1}+\varepsilon_{t} \\
F T E_{t-2}=-2494.522+1.1001 F T E_{t-1}+0.0004 \text { Pop }_{t-4}+17.9446 u_{t}+\varepsilon_{t}
\end{gathered}
$$

\section{A.17 Université du Québec en Outaouais}

Table A29. Université du Québec en Outaouais Forecasting Results (Mid-Term)

\begin{tabular}{llrrrr} 
& & $2018-2019$ & $2019-2020$ & $2020-2021$ & $2021-2022$ \\
\hline \multirow{2}{*}{ FTEs } & 95\% Upper Bound & 5.8302 & 5.6976 & 5.4484 & 5.1086 \\
& Forecast & 4.8599 & 4.7004 & 4.4536 & 4.1279 \\
& 95\% Lower Bound & 3.8896 & 3.7033 & 3.4587 & 3.1472 \\
\hline \multirow{2}{*}{ Subsidy } & $95 \%$ Upper Bound & 80.350 & 74.261 & 88.624 & 88.292 \\
& Forecast & 76.021 & 73.394 & 69.371 & 69.136 \\
& 95\% Lower Bound & 71.692 & 66.959 & 50.118 & 49.981 \\
\hline
\end{tabular}

Source: Authors' calculations and Québec Department of Higher Education. 
Table A30. Université du Québec en Outaouais Forecasting Results (Long-Term)

\begin{tabular}{llrrr} 
& & $2018-2019$ & $2028-2029$ & $2038-2039$ \\
\hline FTEs & $95 \%$ Upper Bound & 5.5399 & 6.9233 & 8.0077 \\
& Forecast & 5.2449 & 6.5293 & 7.6083 \\
& 95\% Lower Bound & 4.9499 & 6.1353 & 7.2088 \\
\hline \multirow{2}{*}{ Subsidy } & $95 \%$ Upper Bound & 75.787 & 96.500 & 123.72 \\
& Forecast & 72.529 & 91.475 & 116.18 \\
& 95\% Lower Bound & 69.270 & 86.450 & 108.64 \\
\hline
\end{tabular}

Source: Authors' calculations and Québec Department of Higher Education.

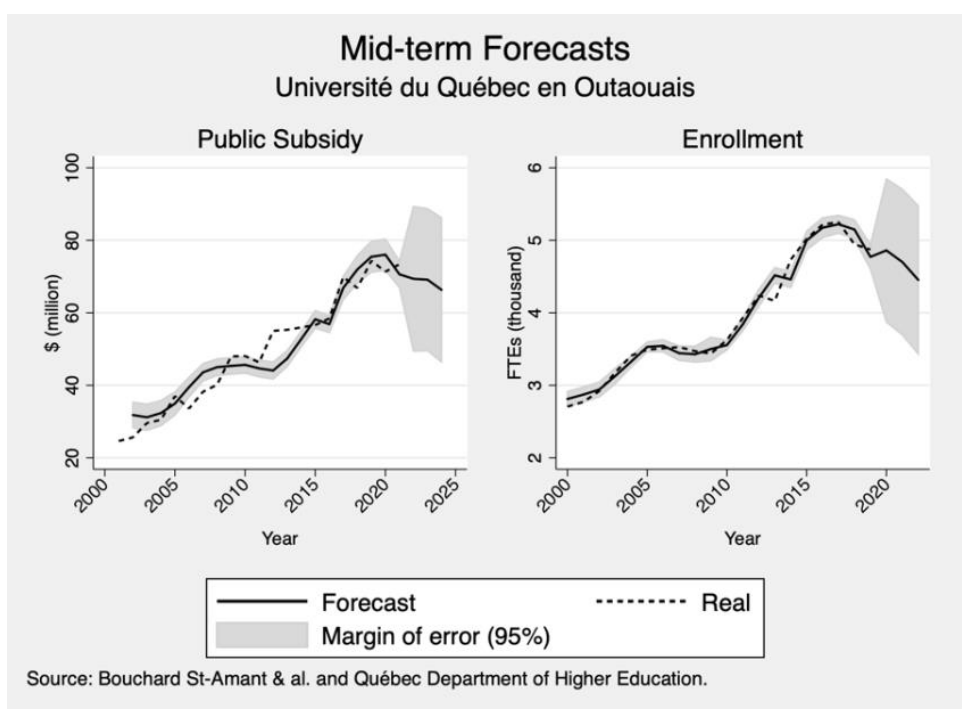

Figure A29. Université du Québec en Outaouais Forecast (Mid-term)

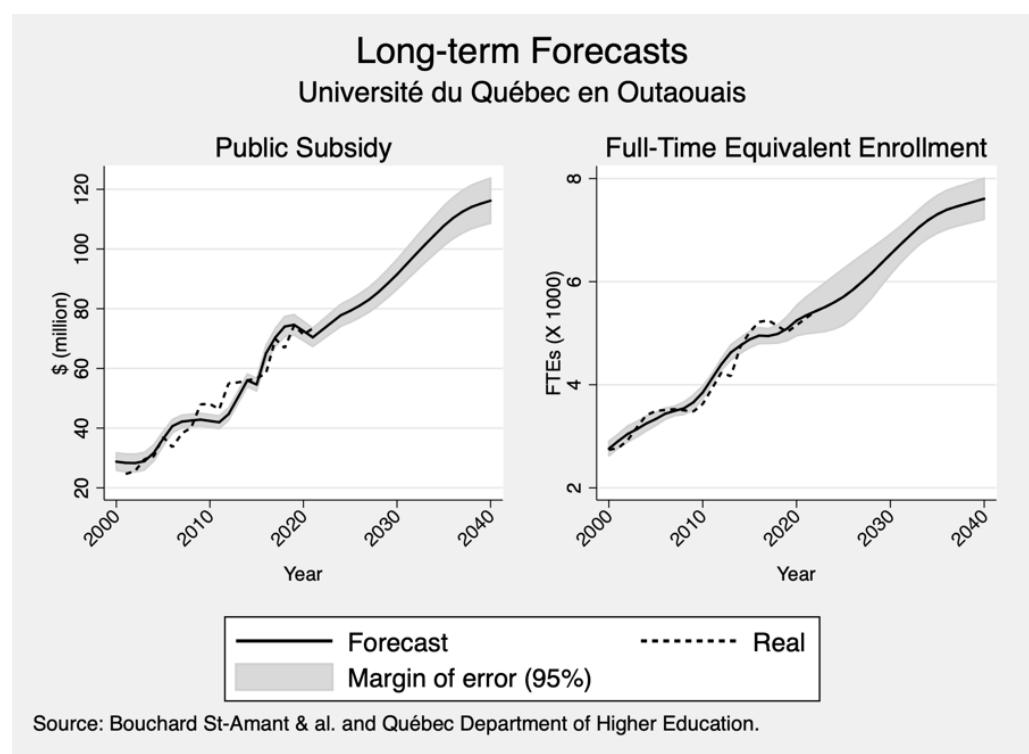

Figure A30. Université du Québec en Outaouais Forecast (Long-term) 


$$
\begin{gathered}
F_{t}=-16.5344+0.0176 F T E_{t-1}+\varepsilon_{t} \\
F T E_{t-2}=-6264.817+0.9847 F T E_{t-1}+0.0074 \operatorname{Pop}_{18} 8_{t-3}+55.3118 u_{t}+\varepsilon_{t}
\end{gathered}
$$

\section{A.18 Université du Québec à Trois-Rivières}

Table A31. Université du Québec à Trois-Rivières Forecasting Results (Mid-Term)

\begin{tabular}{llrrrr} 
& & $2018-2019$ & $2019-2020$ & $2020-2021$ & $2021-2022$ \\
\hline \multirow{2}{*}{ FTEs } & 95\% Upper Bound & 10.137 & 10.004 & 11.504 & 12.106 \\
& Forecast & 9.7008 & 9.5218 & 10.986 & 11.593 \\
& 95\% Lower Bound & 9.6801 & 9.0389 & 10.468 & 11.081 \\
\hline \multirow{2}{*}{ Subsidy } & $95 \%$ Upper Bound & 136.67 & 144.62 & 139.98 & 144.55 \\
& Forecast & 131.11 & 138.35 & 137.84 & 137.84 \\
& 95\% Lower Bound & 125.54 & 132.08 & 129.62 & 117.68 \\
\hline
\end{tabular}

Source: Authors' calculations and Québec Department of Higher Education.

Table A32. Université du Québec à Trois-Rivières Forecasting Results (Long-Term)

\begin{tabular}{llrrr} 
& & $2018-2019$ & $2028-2029$ & $2038-2039$ \\
\hline \multirow{2}{*}{ FTEs } & 95\% Upper Bound & 11.052 & 13.087 & 14.435 \\
& Forecast & 10.689 & 12.513 & 13.716 \\
& 95\% Lower Bound & 10.327 & 11.327 & 12.997 \\
\hline Subsidy & $95 \%$ Upper Bound & 138.85 & 182.60 & 210.60 \\
& Forecast & 132.50 & 171.83 & 196.88 \\
& 95\% Lower Bound & 126.15 & 161.06 & 183.17 \\
\hline
\end{tabular}

Source: Authors' calculations and Québec Department of Higher Education.

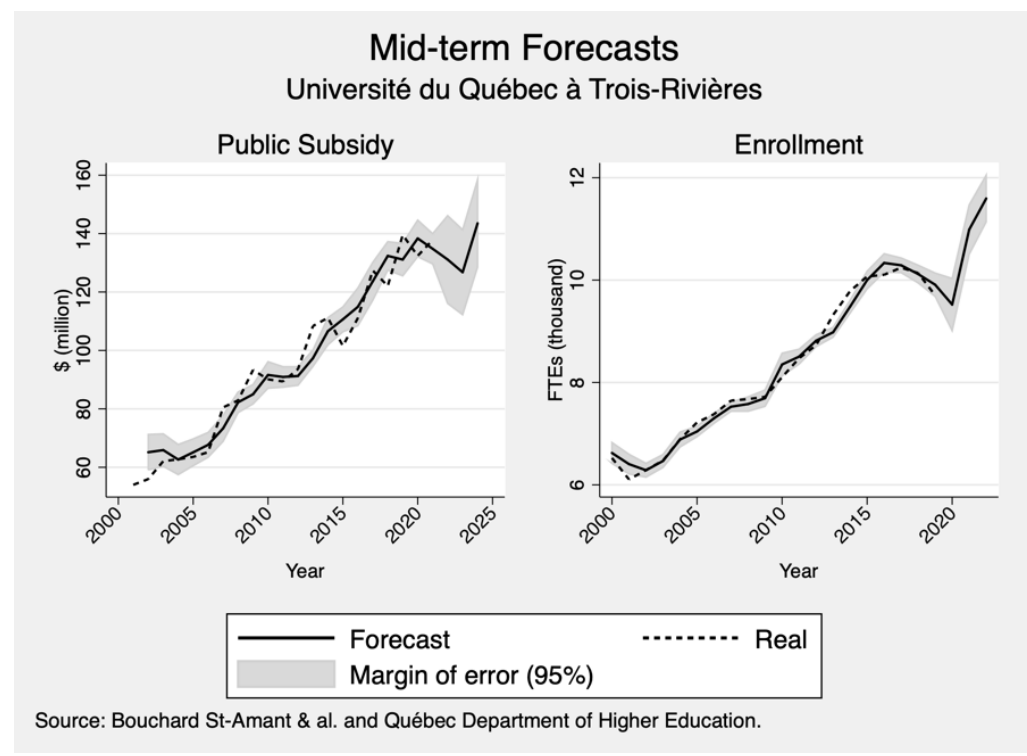

Figure A31. Université du Québec à Trois-Rivières Forecast (Mid-term) 


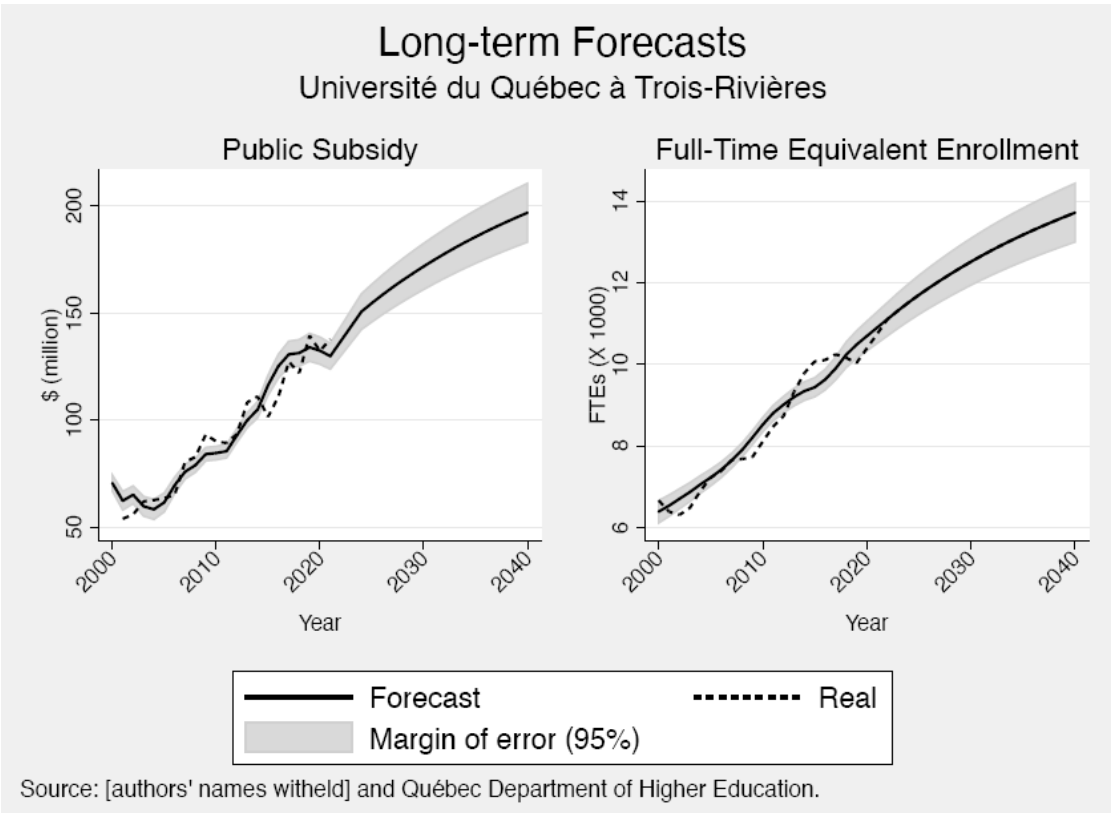

Figure A32. Université du Québec à Trois-Rivières Forecast (Long-term)

$$
\begin{gathered}
F_{t}=-32.591-0.0124 F_{T T E_{t-3}}+0.0161 F T E_{t-4}+\varepsilon_{t} \\
F T E_{t-2}=-14733.58+376.21 u_{t-3}+0.0017 \text { pop }_{t-2}+0.7634 F T E_{t-3}+\varepsilon_{t}
\end{gathered}
$$

\section{A.19 Télé-université}

Table A33. Télé-université Forecasting Results (Mid-Term)

\begin{tabular}{llrrrr} 
& & & & \\
\cline { 3 - 6 } FTEs & 95\% Upper Bound & 4.4423 & 4.8014 & 5.0131 & 5.0042 \\
& Forecast & 3.6691 & 4.2269 & 4.4678 & 4.4846 \\
& 95\% Lower Bound & 3.5616 & 3.6523 & 3.9225 & 3.9650 \\
\hline \multirow{2}{*}{ Subsidy } & $95 \%$ Upper Bound & 37.357 & 40.959 & 54.539 & 42.803 \\
& Forecast & 35.123 & 38.173 & 43.589 & 34.010 \\
& 95\% Lower Bound & 32.889 & 35.387 & 43.869 & 25.216 \\
\hline
\end{tabular}

Source: Authors' calculations and Québec Department of Higher Education.

Table A34. Télé-université Forecasting Results (Long-Term)

\begin{tabular}{llrrr} 
& & & \\
\cline { 3 - 5 } FTEs & 95\% Upper Bound & 5.1342 & 5.6919 & 6.3128 \\
& Forecast & 4.8229 & 5.3512 & 5.8630 \\
& 95\% Lower Bound & 4.5117 & 5.0104 & 5.4130 \\
\hline Subsidy & 95\% Upper Bound & 54.180 & 63.973 & 73.450 \\
& Forecast & 44.473 & 51.304 & 57.923 \\
& 95\% Lower Bound & 34.767 & 38.685 & 42.350 \\
\hline
\end{tabular}

Source: Authors' calculations and Québec Department of Higher Education. 


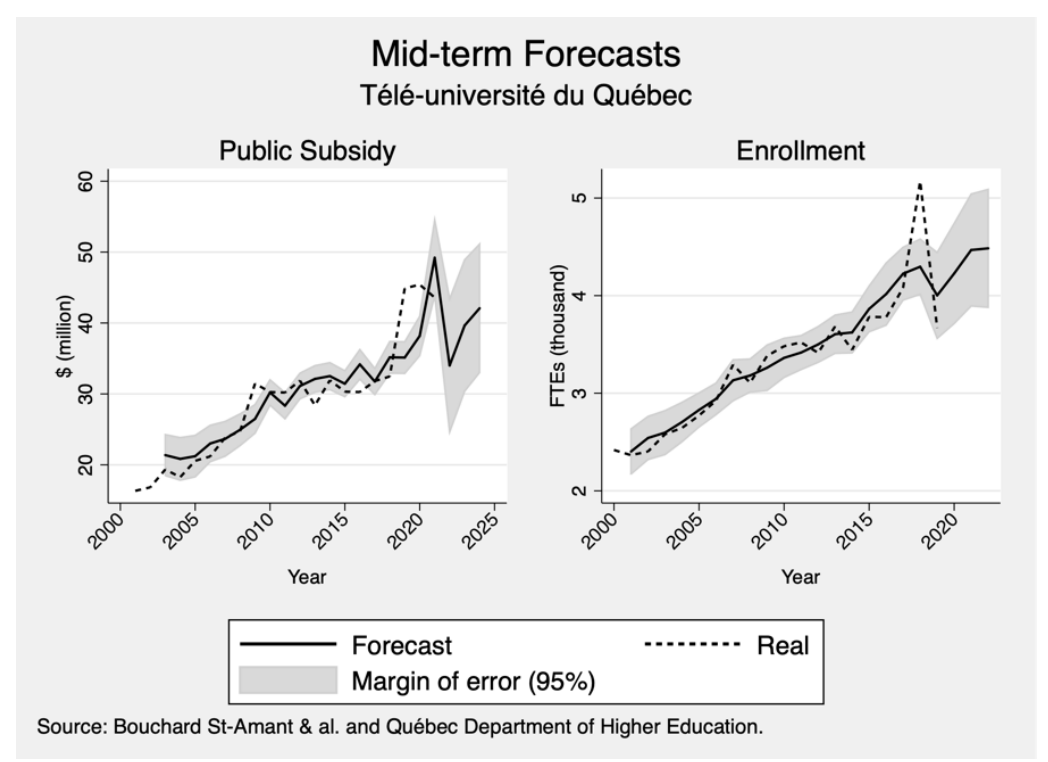

Figure A33. Télé-université Forecast (Mid-term)

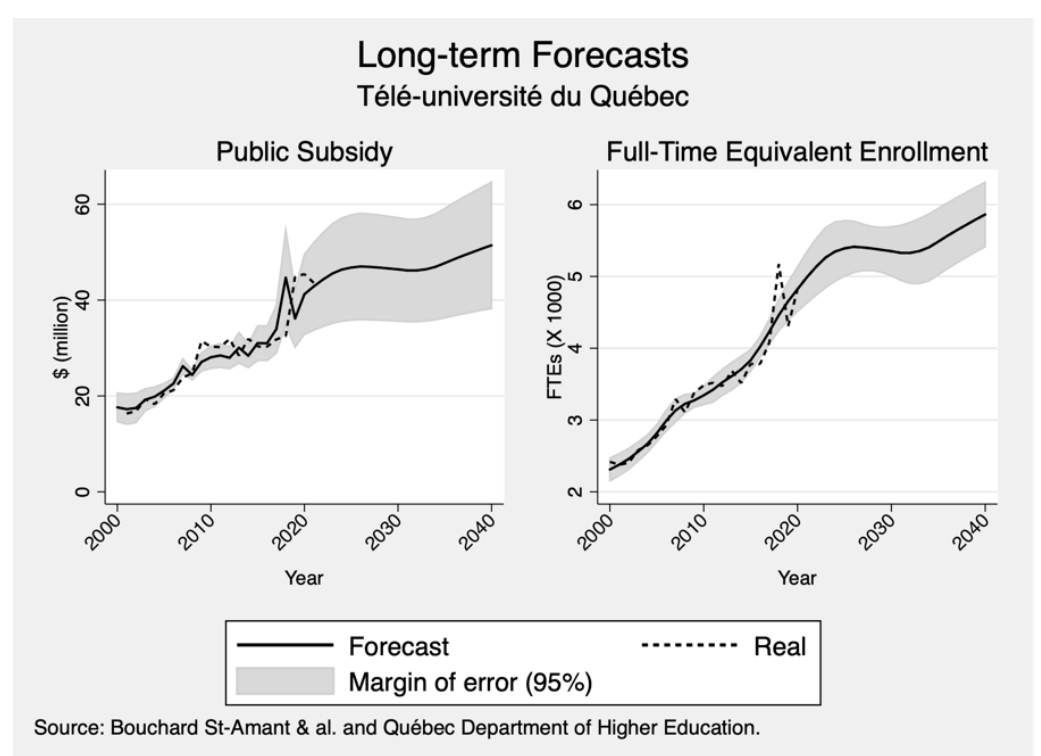

Figure A34. Télé-université Forecast (Long-term)

$$
\begin{gathered}
F_{t}=23.110-0.0093 F_{T E E_{t-3}}+0.0161 F T E_{t-4}+\varepsilon_{t} \\
F T E_{t-2}=-13219.02-90.2535 u_{t-2}+0.0023 \text { pop }_{t-2}-0.3901 F T E_{t-3}-0.1220 F T E_{t-4}+\varepsilon_{t}
\end{gathered}
$$




\section{Appendix B}

\section{Linear Approximation of the Formula}

Equation (1) can be approximated by (2) if each component is linearized. We focus on:

$$
p_{1} \max \left(\sum_{j} w_{j} F T E_{i j t-2}, \frac{1}{3}\left(\sum_{j} w_{j} F T E_{i j t-2}+\sum_{j} w_{j} F T E_{i j t-3}+\sum_{j} w_{j} F T E_{i j t-4}\right)\right)
$$

The other parts of (1) are linearized in a similar fashion. Suppose first that:

$$
\sum_{j} w_{j} F T E_{i j t-2} \geq \frac{1}{3}\left(\sum_{j} w_{j} F T E_{i j t-2}+\sum_{j} w_{j} F T E_{i j t-3}+\sum_{j} w_{j} F T E_{i j t-4}\right)
$$

This then means that the component in (B1) amounts to:

$$
p_{1} \sum_{j} w_{j} F T E_{i j t-2}=p_{1} \bar{w} F T E_{i t-2}+p_{1} \sum_{j}\left(w_{j}-\bar{w}\right) F T E_{i j t-2},
$$

with $\bar{w}=\sum_{j} w_{j} F T E_{i j t-2} / \sum_{j} F T E_{i j t-2}$ being the average weight on FTEs. Then, with $\beta_{1}=p_{1} \bar{w}$ and $p_{1} \sum_{j}\left(w_{j}-\right.$ $\bar{W}) F T E_{i j t-2}$, considered as an approximation error, the expression can be written as:

$$
p_{1} \sum_{j} w_{j} F T E_{i j t-2}=\beta_{1} F T E_{i t-2}+\epsilon_{t}
$$

Now consider second that the inequality in (B2) is reversed. In such case, similar definitions for

$\overline{w_{2}}=\sum_{j} w_{j} F T E_{i j t-3} / \sum_{j} F T E_{i j t-3}, \overline{w_{3}}=\sum_{j} w_{j} F T E_{i j t-4} / \sum_{j} F T E_{i j t-4}$ and $\beta_{i}=\frac{1}{3} \bar{w}_{i} p_{1}$, and similar definitions for the approximation errors, we have:

$$
\begin{aligned}
& \frac{1}{3}\left(\sum_{j} w_{j} F T E_{i j t-2}+\sum_{j} w_{j} F T E_{i j t-3}+\sum_{j} w_{j} F T E_{i j t-4}\right) \ldots \\
& \ldots=\beta_{1} F T E_{i t-2}+\beta_{2} F T E_{i j t-3}+\beta_{3} F T E_{i j t-4}+\epsilon_{t}^{\prime}+\epsilon_{t}^{\prime \prime}+\epsilon_{t}^{\prime \prime}
\end{aligned}
$$

Combining the approximation errors into a single term yields the appropriate structure. Whichever direction is the inequality in (B3), both (B4) and (B5) are satisfied with (2). The other terms in (1) are linearized in a similar fashion.

\section{Copyrights}

Copyright for this article is retained by the author(s), with first publication rights granted to the journal.

This is an open-access article distributed under the terms and conditions of the Creative Commons Attribution license (http://creativecommons.org/licenses/by/4.0/). 